\title{
BRUNO RODRIGUES ALVES RUSSO
}

\section{ANÁLISE IN SILICO DOS HOMÓLOGOS DO RECEPTOR DE TNF- ALFA EM HELMINTOS}

Dissertação apresentada ao Programa de Pós-graduação Interunidades em Biotecnologia USP/ Instituto Butantan / IPT, para a obtenção do título de Mestre em Ciências.

São Paulo

2019 


\section{Bruno Rodrigues Alves Russo}

Análise in silico dos homólogos do receptor de TNF-alfa em helmintos

Dissertação apresentada ao Programa de Pós-graduação Interunidades em Biotecnologia USP/ Instituto Butantan / IPT, para a obtenção do título de Mestre em Ciências.

Área de concentração: Biotecnologia

Orientadora: Profa. Dra. Katia Cristina Pereira Oliveira Santos

Versão corrigida. A versão original eletrônica, encontra-se disponível tanto na Biblioteca no ICB quanto na Biblioteca Digital de Teses e Dissertações da USP (BDTD).

São Paulo 


\section{CATALOGAÇÃO NA PUBLICAÇÃO (CIP) Serviço de Biblioteca e informação Biomédica do Instituto de Ciências Biomédicas da Universidade de São Paulo}

Ficha Catalográfica elaborada pelo(a) autor(a)

RUSSO, BRUNO RODRIGUES ALVES

ANÄLISE IN SILICO DOS HOMÖLOGOS DO RECEPTOR DE TNF-ALFA EM HELMINTOS / BRUNO RODRIGUES ALVES RUSSo; orientador Katia Cristina Pereira oliveira Santos. - São Paulo, 2019.

$116 \mathrm{p}$.

Dissertação (Mestrado) ) - Universidade de são Paulo, Instituto de Ciências Biomédicas.

1. Interação parasita-hospedeiro. 2. Sinalização celular. 3, Helmintos, 4, Receptores TNF-alfa, 5. Ligantes TNF-alfa. I, Oliveira Santos, Katia Cristina Pereira, orientador. II, Título. 
UNIVERSIDADE DE SÃO PAULO

Programa de Pós-Graduação Interunidades em Biotecnologia

Universidade de São Paulo, Instituto Butantan, Instituto de Pesquisas Tecnológicas

Candidato(a): Bruno Rodrigues Alves Russo

Título da Dissertação: Análise in silico dos homólogos do receptor de TNF-alfa em helmintos

Orientador: Profa. Dra. Katia Cristina Pereira Oliveira Santos

A Comissão Julgadora dos trabalhos de Defesa da Dissertação de Mestrado, em sessão pública realizada a ............................., considerou o(a) candidato(a):

\section{( ) Aprovado(a) ( ) Reprovado(a)}

Examinador(a): $\quad$ Assinatura:

Nome:

Instituição:

Examinador(a): Assinatura:

Nome:

Instituição:

Examinador(a): $\quad$ Assinatura:

Nome:

Instituição:

Presidente:

Assinatura:

Nome:

Instituição: 


\section{CERTIFICADO DA COMISSÃO DE ÉTICA}

\section{UNIFESP \\ IIIIIिIIII \\ IIIIIIIIIIII \\ vivesout hotes of sto bast \\ vio}

Comitê de Ética em Pesquisa SP

Săo Paulo, 29 de julho de 2019

CEP N 8826200715

IImo(a). $\operatorname{Sr}(a)$.

Pesquisador(a): Bruno Rodrigues Alves Russo

Depto/Disc: Dmip

Dra. Katia Cristina Pereira Oliveira Santos (orientador)

Título do projeto: "Análise in silico dos receptores homólogos de TNF-alfa e sua via de sinalização em helmintos".

Parecer Consubstanciado do Comitê de Ética em Pesquisa UNIFESP/HSP

A relação estabelecida entre parasita e hospedeiro é complexa e mediada por uma série de fatores químicos (hormônios e citocinas) produzidos durante o processo da infecçăo por ambos os organismos. Compreender os mecanismos moleculares envolvidos no diálogo entre eles é extremamente importante para o desenvolvimento de novas estratégias de combate aos patógenos.

Recentemente diversas moléculas e vias de sinalização foram descritas no Schistosoma mansoni, principal agente causador da esquistossomose. Entre estas moléculas destacamos o receptor homólogo ao receptor de TNF-alfa (fator de necrose tumoral alfa), o SmTNFR. Na literatura é descrito que o TNF-alfa humano, principal citocina pró-inflamatória, atua sobre os processos de ovoposiçăo, metabolismo e desenvolvimento do parasita. Além disso, induz mudanças em sua expressão gênica e fosforilação de proteinas relacionadas a metabolismo e citoesqueleto. Entendemos que o receptor SmTNFR é a provável molécula responsável por mediar estes efeitos no parasita e isto faz com que os elementos desta via de sinalização sejam alvos interessantes para o desenvolvimento de novas drogas e vacinas.

Neste projeto de mestrado pretendemos executar uma análise in-silico buscando os genes que codificam os homólogos ao SmTNFR em outros helmintos e realizar análises filogenéticas dos domínios proteicos conservados destes receptores.

Almejamos realizar uma busca por sequencias homólogas ao SmTNFR (GQ.222226.1) no

genoma de todos os parasitas disponiveis nos bancos de dados públicos (GenBank, GeneDB e no WormBase), utilizando a ferramenta BLAST (Basic Local Alignment Search Tool) e HMM (Hidden Markov Model).

Após serem identificados todos os possíveis homólogos procederemos à uma busca por domínios conservados em bancos de dados como Pfam, Smart e Interprot. Por fim, alinhamentos múltiplos serăo realizados para a execuçăo de análises filogenéticas por meio dos diversos métodos existentes.

O Comitê de Ética em Pesquisa da Universidade Federal de São Paulo/Hospital São Paulo, na reunião de 25/07/2019, ANALISOU e APROVOU o protocolo de estudo acima referenciado. A partir desta data, é dever do pesquisador:

1. Comunicar toda e qualquer alteraçăo do protocolo.

2. Comunicar imediatamente ao Comitê qualquer evento adverso ocorrido durante o desenvolvimento do protocolo.

3. Os dados individuais de todas as etapas da pesquisa devem ser mantidos em local seguro por 5 anos para possivel auditoria dos órgãos competentes.

4. Relatórios parciais de andamento deverão ser enviados anualmente ao CEP até a conclusão do protocolo.

Atenciosamente,

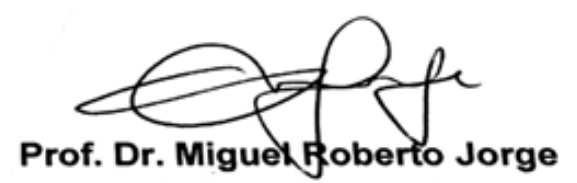

Coordenador do Comitê de Ética em Pesquisa da Universidade Federal de São Paulo/Hospital São Paulo 


\section{AGRADECIMENTOS}

Eu agradeço a todos os colaboradores deste trabalho: ao Prof. Dr. Ricardo de Marco, da Universidade de São Paulo - Campus São Carlos; a Dra. Ana Carolina Tahira, do Instituto de Psiquiatria da Faculdade de Medicina da USP; ao Dr. José Geraldo de Carvalho Pereira do Laboratório de Biociências (LNBio/CNPEM) e ao senhor Claudio Bertevello pelo auxílio prestados nas análises e confecção de figuras.

A toda a equipe do Laboratório de sinalização celular e expressão gênica em parasitas, Schistosig Lab, da Disciplina de Parasitologia do Departamento de Microbiologia, Imunologia e Parasitologia (DMIP) da Escola Paulista de Medicina, Universidade Federal de São Paulo (UNIFESP), inclusive a minha orientadora Profa. Dra. Katia Cristina P. Oliveira Santos que tanto se empenhou a me mostrar o caminho e direcionar os estudos nesta longa jornada.

Agradeço a FAPESP por proporcionar todo o suporte e estrutura para o laboratório que permitiu que este projeto fosse realizado.

A minha família e amigos que sempre estiveram ao meu lado. 
"Não deve haver limites para o esforço humano. Somos todos diferentes. Por pior do que a vida possa parecer, sempre há algo que podemos fazer em que podemos obter sucesso. Enquanto houver vida, haverá esperança." 



\section{RESUMO}

RUSSO, B. R. A., Análise in silico dos homólogos do receptor de TNF-alfa em helmintos. 2019, 112p. Dissertação (Mestrado em Biotecnologia) - Instituto de Ciências Biomédicas, Universidade de São Paulo, São Paulo, 2019.

A relação parasita-hospedeiro é complexa e mediada por uma série de moléculas produzidas por ambos os organismos. Compreender os mecanismos moleculares envolvidos nesta relação é extremamente importante para o desenvolvimento de novas estratégias de combate aos patógenos. Diversas moléculas e vias de sinalização têm sido estudadas e destaca-se a via mediada pelo receptor homólogo ao receptor de TNF-alfa humano em Schistosoma mansoni (SmTNFR). É descrito que o TNF-alfa humano atua sobre os processos de ovoposição, metabolismo e desenvolvimento do parasita. A via de sinalização de SmTNFR pode ser o mecanismo molecular pelo qual o TNF-alfa do hospedeiro exerce seu efeito sobre o parasita, especialmente pela ausência de um homólogo ao ligante (TNF-alfa humano).

Neste trabalho foi realizada a busca por homólogos de SmTNFR nas sequências do genoma e transcriptoma dos helmintos disponíveis nos bancos de dados do GenBank e do Wormbase por meio de análises in silico. Foram identificados 47 genes homólogos ao SmTNFR em 42 espécies de helmintos (22 em Platelmintos e 20 em Nematelmintos) que possuem domínios conservados da família de receptores de TNF (TNFR). Os homólogos de SmTNFR possuem módulos A1/B2 como o NGFR em mamíferos. Diversas análises filogenéticas com 38 homólogos de SmTNFR apontaram para o mesmo contexto evolutivo, o qual sugere a não ocorrência de nenhum grande evento de duplicação, inserção ou deleção nos genes de TNFR que evidenciasse uma evolução molecular diferente da esperada entre os filos, classes e ordens destes helmintos. Uma modelagem molecular comparativa foi realizada com SmTNFR (platelmintos) e TsTNFR (nematelmintos) e foram geradas estruturas similares ao receptor humano devido à conservação das cisteínas e da formação de pontes dissulfeto nos domínios. Estes modelos foram acoplados ao TNF-alfa humano e foi observada a formação de trímeros para a interação com a citocina, como esperado.

A busca por homólogos do próprio ligante, o TNF-alfa, no genoma dos helmintos resultou na identificação de 11 homólogos em 4 espécies de platelmintos da classe Rhabditophora, (organismos de vida livre). Não foram encontrados homólogos do ligante nos demais platelmintos. Isto sugere que o gene do ligante foi perdido ao longo da evolução com a adaptação do parasitismo. Estes dados indicam a importância da investigação da via de sinalização mediada pelos receptores de TNF nos helmintos para a compreensão da 
biologia básica do parasita, da relação molecular estabelecida entre parasita e seu hospedeiro, do papel da via no contexto evolutivo do parasitismo, ou seja, entender como a perda do ligante pode ser um evento relevante para a adaptação no parasitismo.

Palavras chave: Interação parasita-hospedeiro; Sinalização celular; Helmintos; Receptores TNF-alfa; Ligantes TNF-alfa. 


\section{ABSTRACT}

RUSSO, B. R. A., In silico analysis of TNF-alpha receptor homologs in helminths. 2019, 112p. Dissertation (Master thesis in Biotechnology) - Instituto de Ciências Biomédicas, Universidade de São Paulo, São Paulo, 2019.

The host-parasite relationship is complex and mediated by a series of molecules produced by both organisms. Understanding the molecular mechanisms involved in this relationship is extremely important for the development of new pathogen control strategies. Several molecules and signaling pathways have been studied and the signaling pathway mediated by the TNF-alpha receptor homolog in Schistosoma mansoni (SmTNFR) stands out. Human TNF-alpha is reported to act on the parasite's oviposition, metabolism and development processes. The SmTNFR signaling pathway may be the molecular mechanism by which host TNF-alpha exerts its effect on the parasite, especially by the absence of a ligand homolog (human TNF-alpha).

In this work, we searched for SmTNFR homologs in the sequences of helminth genomes and transcriptomes available at GenBank and Wormbase databases by in silico analyzes. 47 SmTNFR homolog genes were identified in 42 helminth species (22 in Platelminths and 20 in Nematelminths) which contain conserved domains of the TNF receptor family (TNFR). SmTNFR homologs have A1 / B2 modules like NGFR in mammalians. Several phylogenetic analyzes with 38 SmTNFR homologs pointed to the same evolutionary context, which suggests that no large events such as duplication, insertion, deletion occurred in the TNFR genes that may show a different molecular evolution from the expected among the phyla, classes, and orders of these helminths. A comparative molecular modeling was performed with SmTNFR (platelminths) and TsTNFR (nematelminths) and structures similar to the human receptor were generated due to the conservation of cysteines and the formation of disulfide bridges in the domains. These models were coupled to human TNF-alpha and the formation of trimers for the cytokine interaction was observed as expected.

The search for homologs of the ligand, TNF-alpha, in the helminth genome resulted in the identification of 11 homologs in 4 species of Rhabditophora platelminths (free-living organisms). No ligand homologs were found in the other flatworms. This suggests that the ligand gene was lost throughout the evolution with the adaptation of parasitism. These data indicate the importance of investigating the TNF receptor-mediated signaling pathway in helminths to understand the basic biology of the parasites, the molecular relationship established between parasites and their hosts, the role of the pathway in the evolutionary context of parasitism, that is to understand how the ligand loss may be a relevant event for the parasitic adaptation. 
Keywords: Parasite-host interaction; Cell signaling; Helminths; TNF-alpha receptors; TNFalpha ligands. 


\section{LISTA DE ILUSTRAÇÕES}

Figura 1. Figura que ilustra o ciclo de vida da Esquistossomose. Traduzido de Centers for Disease Control and Prevention - https://www.cdc.gov/.

Figura 2. Número total de sequências de parasitas presentes (linhas contínuas) e depositadas anualmente (linhas tracejadas) no GenBank no período de 1998 a 2018......... 22

Figura 3. Esquema representativo das relações entre homólogos a partir de um gene ancestral comum.

Figura 4 - Gene homólogo ao receptor de TNF-alfa em S. mansoni (SmTNFR). 29

Figura 5 - Representação esquemática da possível via de sinalização de TNF-alfa em $S$. mansoni.

Figura 6. Efeito in vitro do TNF-alfa humano recombinante sobre casais de vermes adultos de $S$. mansoni.

Figura 7. Concentração de lactado no meio de cultura de 10 casais de vermes adultos incubados com $20 \mathrm{ng} / \mathrm{ml}$ de TNF-alfa humano por 5 dias.

Figura 8. Representação esquemática do gene homólogo de T. solium a SmTNFR.

Figura 9. Representação esquemática do gene de E. granulosus homólogo ao SmTNFR. 43

Figura 10. Matriz de comparação dos E-values dos alinhamentos feitos por BLASTp entre os homólogos de receptores de TNF de helmintos e os receptores de TNF humanos.

Figura 11. Matriz de comparação dos Scores dos alinhamentos obtidos por BLASTp entre os homólogos dos receptores de TNF de helmintos e os receptores de TNF-alfa humano........ 51

Figura 12. Matriz de comparação da porcentagem de identidades dos alinhamos feitos por BLASTp entre os receptores de helmintos homólogos aos receptores de TNF e os receptores de TNF-alfa humanos..

Figura 13. Matriz de comparação da porcentagem de similaridade dos alinhamentos feitos por BLASTp entre os receptores de helmintos homólogos aos receptores de TNF e os receptores de TNF-alfa humanos.

Figura 14. Matriz de comparação da porcentagem de cobertura dos alinhamentos feitos por BLASTp entre os receptores de helmintos homólogos aos receptores de TNF e os receptores de TNF-alfa humanos..

Figura 15- Representação gráfica dos resultados dos programas para análise de Peptídeo Sinal (Signal IP em A) e Domínios Transmembranas (TMHMM em B) 
Figura 16. Representação esquemática dos domínios conservados reconhecidos receptores homólogos ao SmTNFR.

Figura 17. Alinhamento dos homólogos de SmTNFR de helmintos que possuem três e quatro domínios de TNFR (CRD) identificados.

Figura 18. Alinhamento dos homólogos de SmTNFR de helmintos que possuem três e quatro domínios de TNFR (CRD) identificados.

Figura 19. Análise da filogenia molecular dos homólogos de SmTNFR que contêm 3 e 4 domínios TNFR pelo Método de Máxima Parcimônia.

Figura 20. Análise da Filogenia Molecular pelo Método da Máxima Verossimilhança.

Figura 21. Análise da filogenia molecular de 38 homólogos de SmTNFR realizada por Inferência Bayesiana..

Figura 22. Análise da filogenia molecular dos homólogos de SmTNFR pelo Método de Evolução Mínima [62]..

Figura 23. Análise da filogenia molecular dos homólogos de SmTNFR inferida pelo método de Neighbor-Joining [64]....

Figura 24. Análise da filogenia molecular dos homólogos de SmTNFR usando o método UPGMA [65].

Figura 25. Modelagem molecular (visualização 3D) dos receptores SmTNFR (S. mansoni, Platelminto) (A) e TsTNFR (T. spiralis, Nematelminto) (B). A representação das figuras ilustra a superfície da molécula.

Figura 26. Modelagem molecular com o homólogo do receptor de TNF em platelminto ( $S$. mansoni SmTNFR) acoplado com o TNF-alfa humano.

Figura 27. Modelagem molecular com o homólogo do receptor de TNF em nematelminto ( $T$. spiralis, TsTNFR) acoplado com o TNF-alfa humaNo..

Figura 28. Matrix dos E-values (-log10 E-value) dos alinhamentos dos homólogos de ligantes de TNF-alfa de helmintos com os ligantes da família de TNF humano por BLASTp.

Figura 29. Matrix dos scores dos alinhamentos dos homólogos de ligantes de TNF-alfa de helmintos com os ligantes da família de TNF humanos por BLASTp.

Figura 30. Matrix das porcentagens de identidades dos alinhamentos dos homólogos dos ligantes de TNF-alfa de helmintos com os ligantes da família de TNF humano.

Figura 31. Matrix das porcentagens de similaridade dos alinhamentos dos homólogos dos ligantes de TNF-alfa de helmintos com os ligantes da família de TNF humanos por BLASTp. 
Figura 32. Matrix das porcentagens de cobertura das sequências dos ligantes humanos pelos homólogos de ligantes dos helmintos por BLASTp..

Figura 33. Representação esquemática dos domínios conservados reconhecidos nos homólogos dos ligantes da família de TNF-alfa em helmintos.

Figura 34. Alinhamento dos domínios conservados de TNF dos homólogos dos ligantes da família de TNF em helmintos. 105

Figura 35. Análise da filogenia molecular de 11 homólogos de TNFR realizada por Inferência Bayesiana.

Figura 36. Relação do N50 e do número de contigs dos genomas dos organismos que possuem homólogos de SmTNFR e o número de domínios TNFR codificados pelo respectivo gene homólogos. 


\section{LISTA DE TABELAS}

Tabela 1. Genes / Proteínas homólogos a SmTNFR em helmintos $\left(E\right.$-value $\left.<10^{-10}\right)$. Os resultados foram obtidos por Blastp realizado no GenBank.

Tabela 2. Homólogos de SmTNFR em Helmintos identificados pelo programa HMMER nas bases de dados Wormbase Parasite

Tabela 3. Domínios conservados nos homólogos de SmTNFR de helmintos

Tabela 4. Número de pontes dissulfetos encontradas em cada domínio TNFR dos homólogos de TNFR.

Tabela 5. Homólogos dos ligantes de TNF humanos em helmintos identificados pelas abordagens de HMMer e BLAST.

94

Tabela 6. Domínios conservados encontrados nos homólogos de TNF (ligante) em helmintos 


\section{LISTA DE ABREVIATURAS E SIGLAS}

BLAST: Basic Local Alignment Search Tool, em português: Ferramenta de busca por alinhamento local básico.

CDR: Cistein Rich Domain, em português: Domínios Ricos em Cisteína.

DTN: Doenças Tropicais Negligenciadas.

EST: Expressed sequenced tag, em português: Etiquetas de sequencias transcritas.

LSCEGP: Laboratório de sinalização celular e expressão gênica em parasitas.

NCBI: National Center for Biotechnology Information, em português Centro Nacional para Informação Biotecnológica.

ORF: Open Reading Frame, em português: Fase de Leitura Aberta.

TNF-alfa: Tumor Necrosis Factor alpha, em português Fator de Necrose Tumoral alfa. 


\section{SUMÁRIO}

1. Introdução

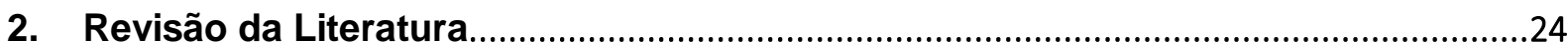

2.1. Helmintíases como problema de Saúde Pública ........................................................... 24

2.2. Genes homólogos e ferramentas de bioinformática para sua identificação .............. 25

2.3. Relação molecular estabelecida entre parasita-hospedeiro ……................................. 27

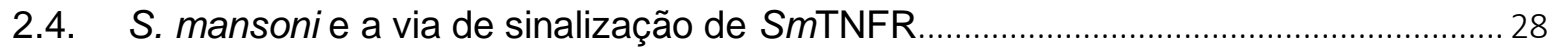

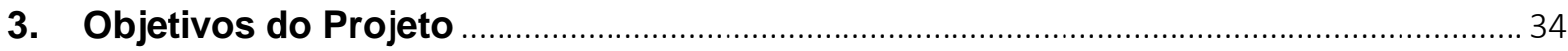

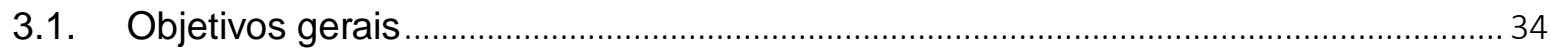

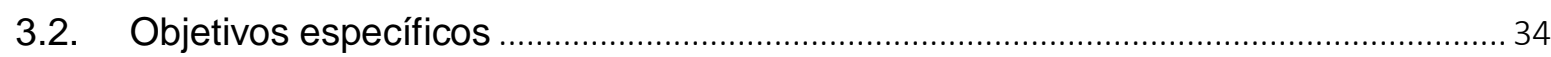

4. Materiais e Métodos

4.1. Identificação dos homólogos de SmTNFR em helmintos e homólogos de TNF-alfa

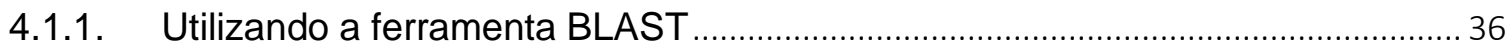

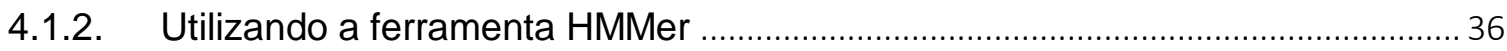

4.2. Identificação dos domínios conservados nos homólogos de SmTNFR ...................... 37

4.3. Alinhamento dos domínios ricos em cisteínas dos homólogos de SmTNFR e dos homólogos de TNF

4.4. Comparação dos alinhamentos dos homólogos de SmTNFR e os receptores humanos da família de TNF-alfa e dos homólogos de ligantes de TNF-alfa e os ligantes da humanos.

4.5. Análise dos módulos dos domínios ricos em cisteínas dos homólogos de SmTNFR.

4.6. Análise filogenética do alinhamento dos homólogos de SmTNFR e homólogos de

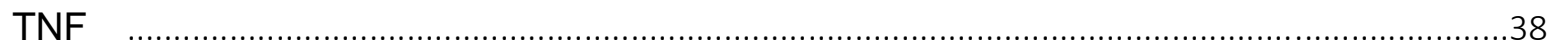

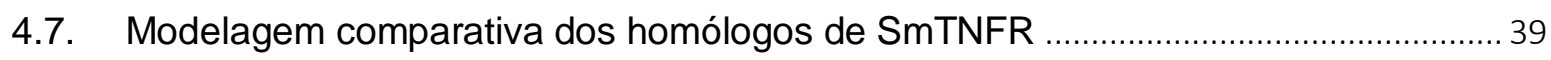

5. Resultados

5.1. Identificação dos homólogos de SmTNFR em helmintos ............................................ 40

5.2. Comparação dos receptores homólogos dos parasitas com os receptores da família

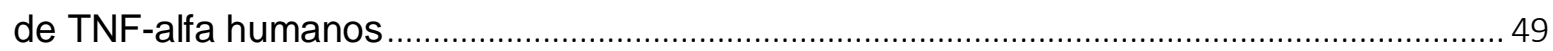

5.3. Identificação e alinhamento dos domínios conservados nos homólogos de SmTNFR.

5.4. Análise dos módulos dos domínios ricos em cisteínas dos homólogos de SmTNFR

5.5. Análise filogenética do alinhamento dos homólogos de SmTNFR 


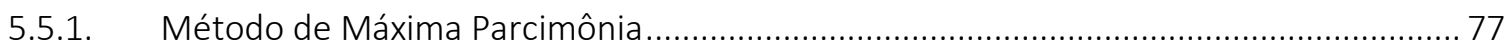

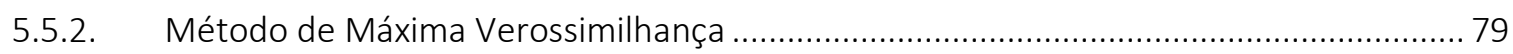

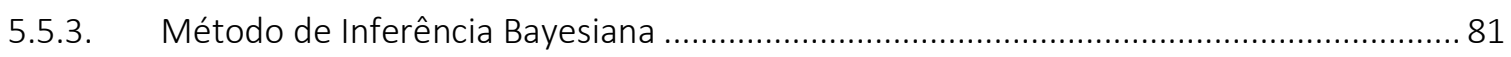

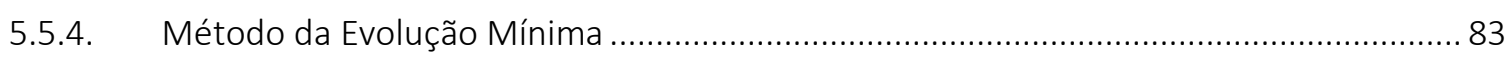

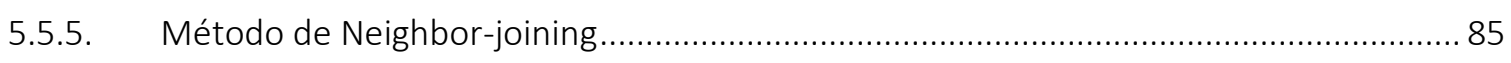

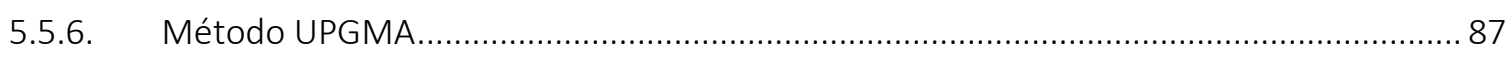

5.6. Modelagem molecular comparativa dos receptores de TNF-alfa de platelmintos e

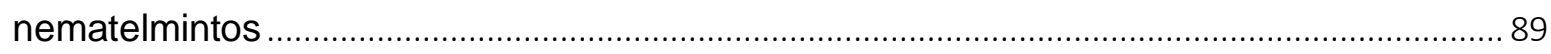

5.7. Identificação dos homólogos de ligantes da família de TNF-alfa humanos em helmintos

5.8. Comparação dos homólogos de ligantes dos helmintos os ligantes da família de TNF-alfa humanos.

5.9. Identificação e alinhamento dos domínios conservados dos homólogos de ligantes da família de TNF-alfa humanos.

5.10. Análise filogenética dos ligantes de helmintos homólogos aos ligantes de TNF humano .

6. Discussão 106

7. Conclusões

8. Referências Bibliográficas.

9. Lista de Anexos 


\section{INTRODUÇÃo}

Nosso grupo de pesquisa, o Laboratório de sinalização celular e expressão gênica em parasitas (LSCEGP), coordenado pela Profa. Dra. Katia Cristina Pereira Oliveira Santos, da Disciplina de Parasitologia do Departamento de Microbiologia, Imunologia e Parasitologia da Escola Paulista de Medicina, UNIFESP, se dedica a investigar a relação existente entre o parasita e seu hospedeiro sob uma perspectiva molecular. Nosso principal interesse é compreender os efeitos das moléculas produzidas pelos hospedeiros definitivos no desenvolvimento, fisiologia e homeostase dos parasitas, especialmente o platelminto Schistosoma mansoni.

S. mansoni é um trematodo que apresenta dimorfismo sexual e um complexo ciclo biológico, no qual possui seis estágios de desenvolvimento distintos que vivem no ambiente aquático e em dois hospedeiros: um caramujo do gênero Biomphalaria (hospedeiro intermediário) e o homem (hospedeiro definitivo) [1]. Alvo do nosso estudo cientifico, $S$. mansoni, tem um ciclo de vida complexo que se inicia com os ovos desse parasita sendo eliminados pelas fezes de um homem infectado. Estes ovos são liberados nos rios ou lagos de locais sem saneamento básico e, em condições favoráveis, eclodem liberando o miracídeo. Os miracídeos nadam em direção de moluscos gastrópodes (hospedeiro intermediário) e penetram ativamente, se desenvolvem em esporocistos primários (cabeça e manto), secundários (no hepatopâncreas e ovoteste do molusco) e cercarias num processo que leva em torno de 30 dias. Com o estímulo luminoso as cercarias, estagio infectante, são eliminadas do molusco e na agua e são capazes de penetrar na pele humana (hospedeiro definitivo). Agora, em seu hospedeiro definitivo, se diferencia para esquistossômulo, que migram via circulação venosa para os pulmões, depois para o coração e se estabelecem e atingindo a maturação sexual no fígado, depois migram pelo sistema da veia porta quando atingem o estágio maduro para o plexo das veias mesentéricas onde inicia-se o processo de oviposição [1] (Figura 1). 


\section{ESQUISTOSSOMOSE}

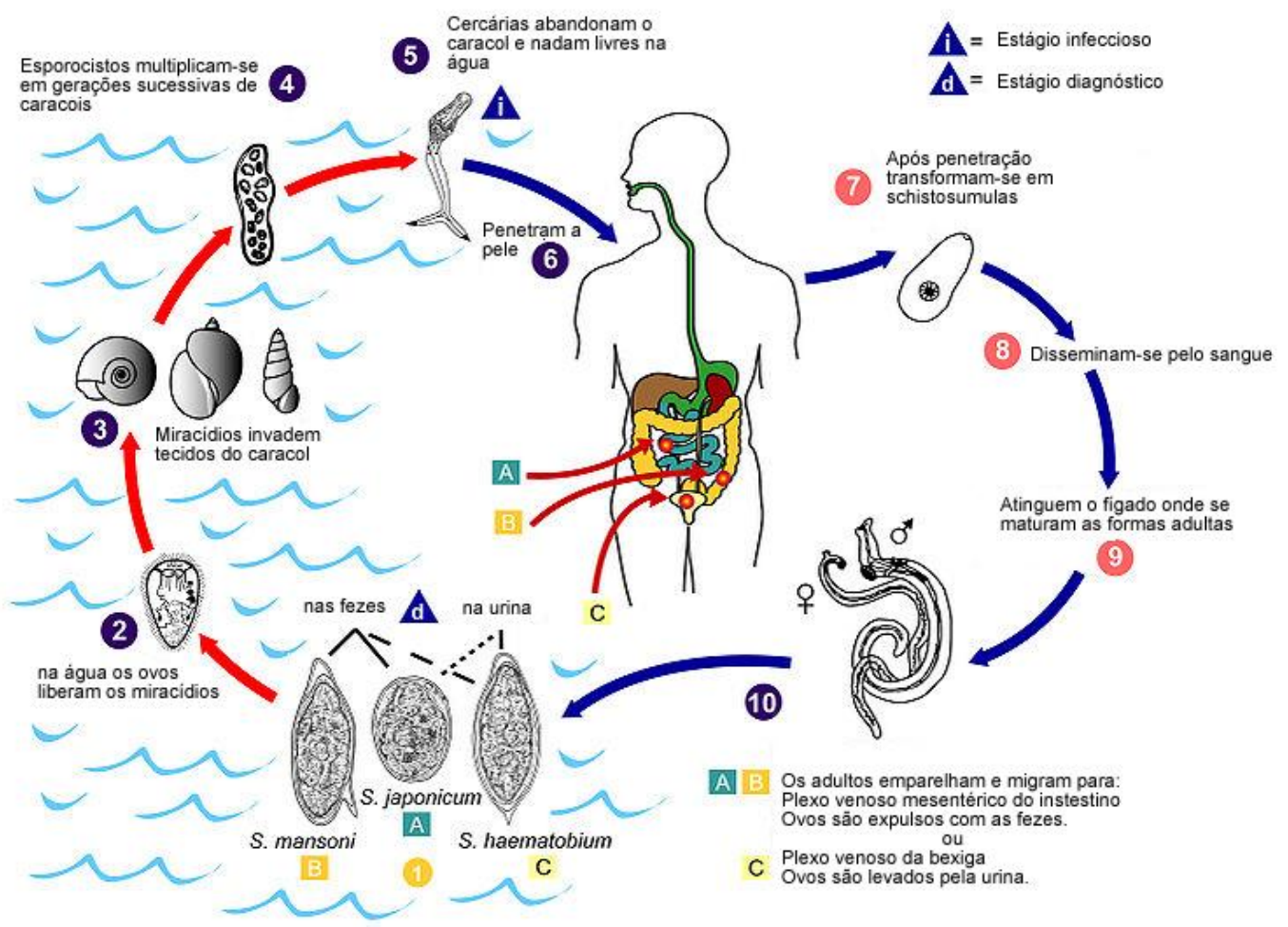

Figura 1. Ciclo biológico do Schistosoma spp. As setas e números indicam os estágios de desenvolvimento conforme descrito na figura. Setas vermelhas indicam estágios de vida livre, setas azuis estágios no interior do hospedeiro definitivo. i: estágio infectante, d: estágio que permite o diagnóstico por meio de exame parasitológico das fezes. A, B e C indicam o local de habitat definitivo do parasita nos humanos, conforme indicado na figura. Traduzido de Centers for Disease Control and Prevention - https://www.cdc.gov/

A esquistossomose (parasitose causada pelo $S$. mansoni) é uma doença crônica e debilitante que afeta milhares de pessoas em mais de 70 países e no Brasil continua sendo um problema de saúde pública, especialmente nos estados mais pobres da federação [2].

Há alguns anos nosso grupo de pesquisa tem se dedicado a investigar a via de sinalização mediada pelo receptor de TNF-alfa (Fator de Necrose Tumoral alfa) em $S$. mansoni (SmTNFR). O gene que codifica o receptor SmTNFR foi descrito em 2009 e é o único possível homólogo na espécie [3]. Conforme será descrito a seguir, muitos efeitos do TNF-alfa humano no parasita têm sido descritos, até o presente momento, nenhum gene homólogo do ligante do receptor, ou seja, o próprio TNF-alfa, foi identificado em S. mansoni.

Resultados obtidos por nosso grupo de pesquisa (que serão apresentados a seguir) têm confirmado a importância desta via de sinalização na regulação do metabolismo e processo reprodutivo do parasita. Estes dados, em conjunto com os dados da literatura, sugerem que a via mediada por SmTNFR é importante para a o desenvolvimento deste platelminto que, 
potencialmente, utiliza o ligante do hospedeiro (TNF-alfa humano) para acioná-la. Isto torna esta via interessante para que possa ser explorada futuramente para o desenvolvimento de novas estratégias no combate da esquistossomose.

Além da esquistossomose, outras helmintíases (doenças causadas por helmintos) são consideradas doenças tropicais negligenciadas (DTN) e consequentemente são relevantes agravos na saúde pública. DTN são definidas como um grupo de infecções tropicais que são endêmicas especialmente em populações de baixa renda em regiões em desenvolvimento como América do Sul, África e Ásia [4]. Segundo a Organização Mundial da Saúde (OMS) 17 doenças estão na lista de DTN e estas acometem mais de um bilhão de pessoas no planeta. Entre as DTN estão seis helmintíases: cisticercose/teníase, dracunculíase, equinococose, oncocercose, esquistossomose e helmintíases transmitidas pelo solo (geohelmíntiases) [4]. É importante e necessário que a comunidade científica se dedique a encontrar novas abordagens no combate e controle das DTN para a promoção do bem-estar e da saúde da população mundial.

Uma das formas de desenvolvimento de estratégias para o combate às DTN é a compreensão da biologia básica dos patógenos e para isto, o estudo do conteúdo genético destes organismos é uma abordagem extremamente poderosa e promissora. Com o advento do sequenciamento automático de DNA / RNA e o surgimento dos sequenciadores de nova geração, o custo e a dificuldade para sequenciar o genoma / transcriptoma de um determinado organismo reduziram drasticamente promovendo uma grande expansão dos dados disponíveis nos bancos públicos [5].

Esta expansão de dados também ocorreu com os parasitas e centenas de espécies e cepas tiveram seus genomas [6][7][8][9][10][11][12] e transcriptomas [13][14][15][16] sequenciados nos últimos anos. A Figura 2 ilustra o número de sequências presentes e anualmente depositadas no GenBank associadas à palavra "Parasite" nos últimos 20 anos. Pode-se notar que houve um expressivo aumento de sequências depositadas neste banco de dados particularmente em dois momentos distintos, os quais coincidem com o surgimento dos sequenciadores de segunda (2004) e terceira geração (2011-2012) (indicados Figura 2) 
A)

Sequências de Nucleotídeos

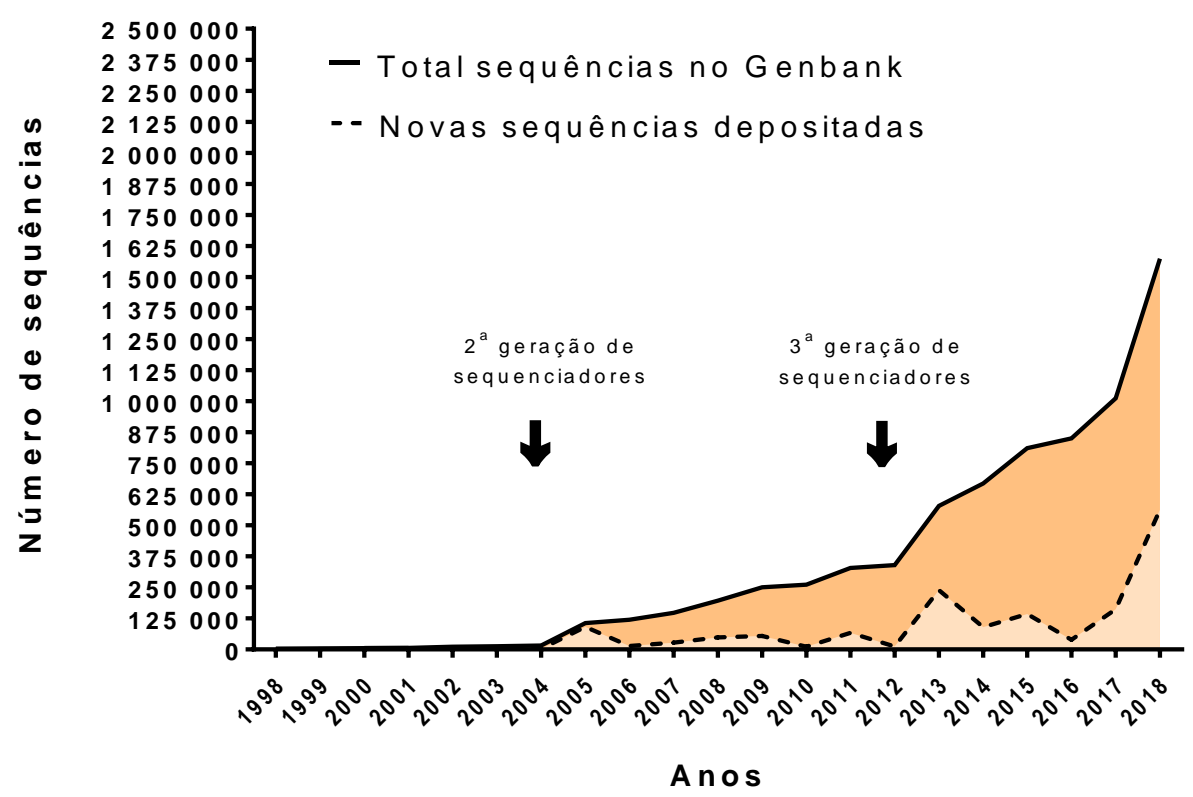

B)

Sequências de Proteínas

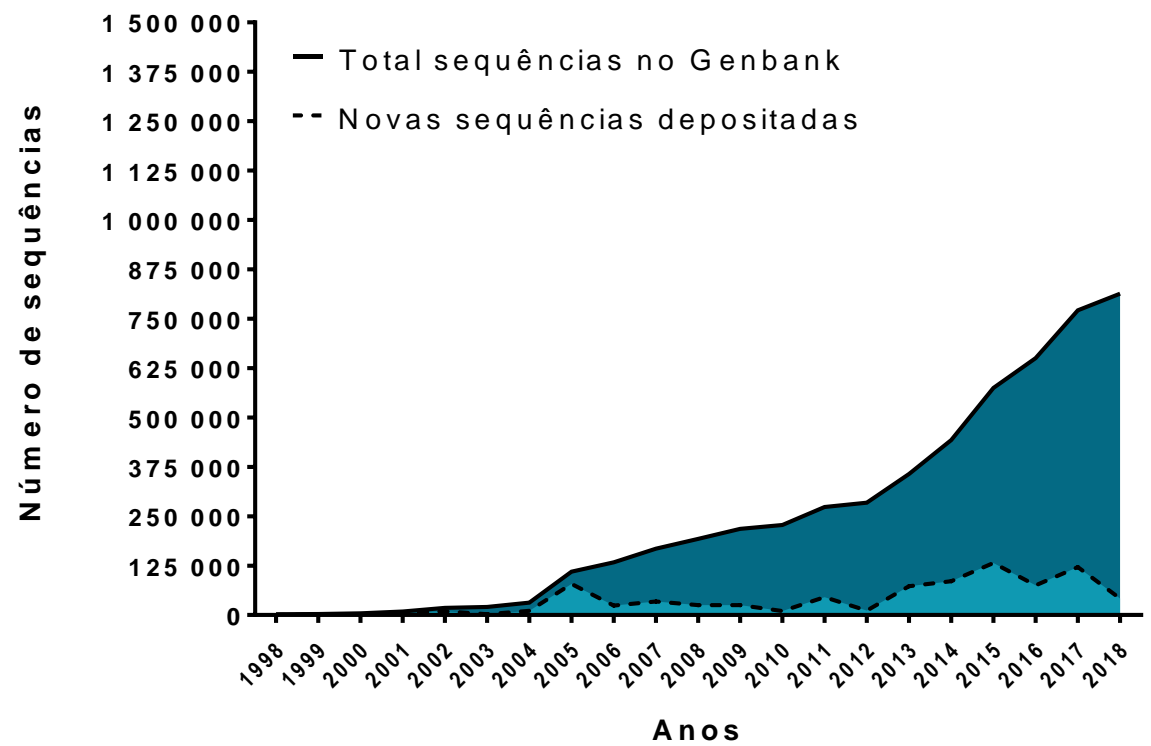

Figura 2. Número total de sequências de parasitas presentes (linhas contínuas) e depositadas anualmente (linhas tracejadas) no GenBank no período de 1998 a 2018. (A) Número de sequências de nucleotídeos e (B) proteínas. Estes dados foram coletados do Genbank-NCBI (https://www.ncbi.nlm.nih.gov/) utilizando a palavra "Parasite" como critério de busca e selecionando os períodos anuais. As setas indicam o momento correspondente à introdução dos sequenciadores de nova geração ( $2^{\underline{a}}$ e $3^{\underline{a}}$ geração).

Como consequência da expansão destes dados foram criados bancos específicos para deposição das sequências dos genomas e transcriptomas dos parasitas, os quais estão 
disponíveis para a consulta de toda a comunidade científica. Muitas vezes as sequencias depositadas nestes bancos de dados ainda não estão disponíveis em sua totalidade em bancos de dados centrais, como o GenBank (https://www.ncbi.nlm.nih.gov/genbank/). Neste cenário destacamos os bancos: GeneDB (www.geneDB.org), Wormbase (www.wormbase.org), Wormbase parasite (https://parasite.wormbase.org/index.html) e o banco Nematode.net (http://nematode.net/NN3_frontpage.cgi).

Este novo conjunto de dados permitiu à comunidade científica realizar a busca e a caracterização de genes de interesse para maior compreensão dos processos moleculares e biológicos dos parasitas. Esta expansão de dados também possibilitou a realização de estudos filogenéticos mais abrangentes permitindo a inferência do contexto evolutivo de determinadas famílias de genes homólogos entre os organismos, como também o contexto evolutivo das espécies [17][18].

Neste contexto, estudar a via de sinalização mediada por SmTNFR em outros parasitas é possível e importante a fim de compreender aspectos da biologia básica e da conservação dos mecanismos moleculares de interação e regulação existentes entre os parasitas e seus hospedeiros. 


\section{REVISÃO DA LITERATURA}

\subsection{Helmintíases como problema de Saúde Pública}

As helmintíases são importantes agravos na saúde pública pois afetam grande número de indivíduos especialmente em países em desenvolvimento. Segundo dados de 2018 provenientes da OMS, 1,5 bilhões de pessoas (24\% da população mundial) têm alguma das geo-helmintíases [19]. Estas doenças são transmitidas por ovos ou larvas dos parasitas presentes nas fezes humanas que contaminam o solo em locais cujo saneamento básico é precário. As principais espécies que infectam os indivíduos são nematóides: Ascaris lumbricoides, Trichuris trichiura, Necator americanos e Ancylostoma duodenale. Um aspecto importante a ser ressaltado é que as crianças infectadas por helmintos são seriamente prejudicadas sob a perspectiva física e nutricional; em 2016 mais de 267 milhões de crianças em idade pré-escolar e 568 milhões de crianças em idade escolar (em áreas de alta endemicidade) necessitaram de tratamento em massa para geo-helmintíases [19].

A esquistossomose (já mencionada anteriormente) é considerada uma doença de alta morbidade em virtude do acometimento hepático que ocorre nos casos crônicos dos indivíduos infectados [2]. No ano de 2016 mais de 206,5 milhões de pessoas receberam tratamento em massa para a esquistossomose, das quais 89 milhões foram tratadas devido ao diagnóstico confirmado [20]. A doença já foi notificada em mais de 78 países, dos quais 52 deles possuem altas e moderadas taxas de endemicidade; estima-se que a esquistossomose seja responsável por 200 mil óbitos anuais [21].

Outro exemplo que merece ser mencionado é a equinococose, DTN causada por platelmintos do gênero Echinococcus que afeta mais de 1 milhão de indivíduos. Esta parasitose, embora não seja muito prevalente, é uma doença cística grave cujo tratamento é complicado, caro e requer extensas cirurgias e quimioterapia prolongada [22]. O tratamento embora possível compromete seriamente a qualidade de vida do indivíduo afetado.

Estes dados nos permitem afirmar que as helmintíases são importantes problemas de saúde pública que acometem pelo menos um a cada sete habitantes do planeta. Neste contexto o esforço para o controle e a erradicação destas doenças é prioridade para a OMS que possui estratégias e uma agenda de ações de combate estabelecidas [23]. Por isso voltamos a mencionar que o entendimento da biologia básica destes parasitas e seus hospedeiros é relevante para o desenvolvimento de novas abordagens terapêuticas e profiláticas porque apesar de distintas formas de vida, os helmintos compartilham um 
semelhante ciclo biológico. Em grande parte dos organismos, como os da classe Cestoda, Nematoda e Trematoda, são necessários hospedeiros para seus estágios de vida sigam o desenvolvimento completo e perpetuem a espécie [4], neste contexto muitos mecanismos moleculares são conservados entre eles.

\subsection{Genes homólogos e ferramentas de bioinformática para sua identificação}

Conforme mencionado anteriormente, a expansão dos dados disponíveis dos genomas e transcriptomas possibilitou à comunidade científica a busca e caracterização de genes homólogos.

Genes homólogos são genes em espécies distintas ou na mesma espécie que foram herdados a partir de um ancestral comum; suas sequências são similares e conservadas. Diferentes eventos ao longo da evolução levaram a divergência das sequências dos homólogos, em virtude disto existem diferentes definições e tipos de homologia. Os genes homólogos podem classificados ser ortólogos ou parálogos. Os ortólogos são genes de espécies diferentes que sofreram um evento de especiação, ou seja, evoluíram a partir de um gene ancestral comum e possuem a mesma função nos respectivos organismos. Os genes parálogos são genes resultantes de eventos de duplicação gênica, o que culmina na presença de dois homólogos no mesmo genoma de uma espécie, no qual um deles é um ortólogo e o outro, um gene parálogo. Diferentemente dos ortólogos, os genes parálogos sofrem uma maior taxa de mutação e podem assumir uma nova função no organismo ao longo da evolução [24].

Um exemplo clássico para explicar o conceito de genes homólogos é o gene da globina. (Figura 3). O gene ancestral da globina sofreu evento de duplicação e originou a genes que codificam cadeia alfa e beta. Ao longo da evolução ocorreram eventos de especiação que culminou na presença destes genes em diferentes espécies (rã, camundongo e homem). Os genes das cadeias alfa nas diferentes espécies são ortólogos entre si assim como os genes da cadeia beta, pois desempenham a mesma função biológica nos diferentes organismos, porém os genes da cadeia alfa são parálogos em relação aos genes da cadeia beta numa mesma espécie e entre as espécies, pois desempenham outra função embora tenham surgido de um ancestral comum. Todos os ortólogos e parálogos entre si são definidos como homólogos por possuírem similaridade de sequência, exercendo ou não a mesma função biológica. 


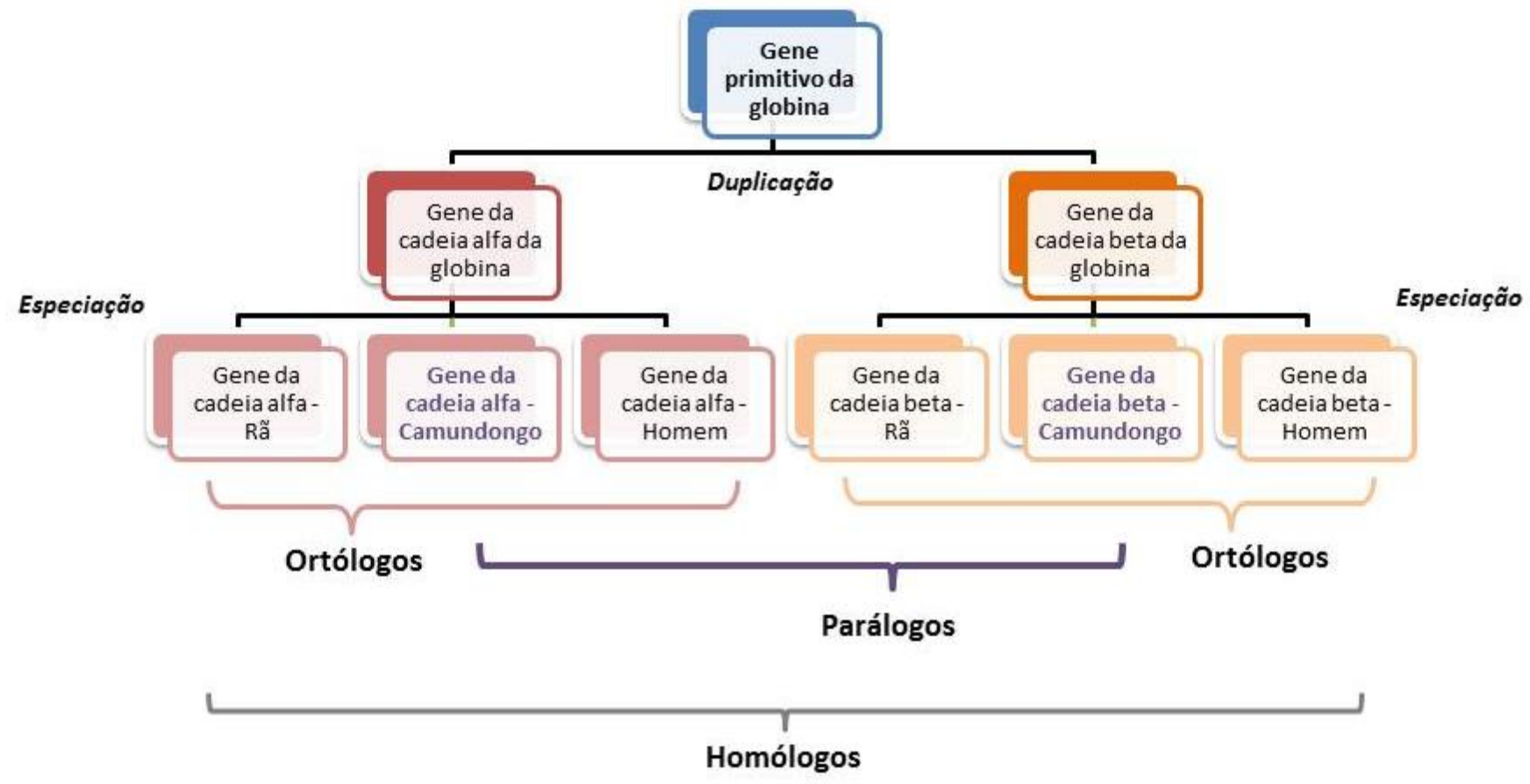

Figura 3. Esquema representativo das relações entre homólogos a partir de um gene ancestral comum. O gene ancestral da globina sofreu evento de duplicação e originou a genes que codificam cadeia alfa e beta. Ao longo da evolução ocorreram eventos de especiação que culminou na presença destes genes em diferentes espécies (rã, camundongo e homem). Os genes das cadeias alfa nas diferentes espécies são ortólogos entre si (indicados pela cor vermelho claro) assim como os genes da cadeia beta (indicados pela cor laranja claro), pois desempenham a mesma função biológica nos diferentes organismos. Exemplos de parálogos são indicados pela chave em roxo (Gene da cadeia alfa e beta em camundongo ou outras espécies), estes genes descenderam de um gene ancestral comum, entretanto, possuem funções diferentes. Os genes homólogos são todos os genes que descendem de um ancestral comum, logo possuem similaridade de sequência, exercendo ou não a mesma função biológica (conforme indicado na chave cinza).

Concomitantemente à evolução das tecnologias e capacidades de sequenciamento de DNA ocorreu o desenvolvimento dos algoritmos e ferramentas para a análise de sequências a fim de identificar e anotar genes nos diversos organismos, ampliando o conhecimento acerca destes em nível molecular. 
Dentre estas ferramentas destacamos o BLAST (Basic Local Alingment Search Tool), disponibilizado pelo NCBI (National Center for Biotechnology Information) em https://blast.ncbi.nlm.nih.gov/Blast.cgi. O BLAST encontra regiões de similaridade local entre sequências; o programa compara sequências de nucleotídeos ou proteínas a bancos de dados de sequências e calcula a significância estatística das correspondências. Esta ferramenta pode ser usada para inferir relações funcionais e evolutivas entre sequências, bem como ajudar a identificar membros de famílias de genes [25]. Sem dúvida alguma é um dos programas que revolucionaram a pesquisa na área das ciências biomédicas / biológicas. Foi e ainda é essencial para o contexto da evolução da era genômica e pós-genômica; uma medida da importância desta ferramenta na área é o altíssimo número de citações que o artigo científico [25] que a descreve possui: mais de 78000 (segundo pesquisa no Google acadêmico).

Outra ferramenta muito utilizada para a identificação de sequências é o HMMER (http://hmmer.org/). O HMMER faz alinhamentos de sequências e constrói um modelo probabilístico e para procurar em um determinado banco de dados as sequências de um homólogo. O programa implementa o método de busca usando modelos probabilísticos chamados Modelos Ocultos de Markov (perfis HMM) [26][27]. O algoritmo é projetado para detectar homólogos remotos da forma mais sensível possível em virtude de seus modelos de probabilidade [28]. O programa faz um perfil HMM a partir de um alinhamento de sequências múltiplas que gera uma query e atribui um sistema de pontuação posiçãoespecífico para substituições, inserções e deleções. Por meio desta query as sequências que têm uma pontuação significativamente maior com o perfil HMM do que com o modelo nulo são consideradas potencialmente homólogas. As probabilidades posteriores de alinhamento são relatadas, permitindo a avaliação da base ou aminoácido resíduo por resíduo [28].

\subsection{Relação molecular estabelecida entre parasita-hospedeiro}

A relação estabelecida entre parasita e hospedeiro é intima, duradoura, complexa e repleta de troca de sinais entre os dois organismos. Como mencionado, a expansão do conhecimento por meio dos dados do genoma e do transcriptoma permitiu aos pesquisadores buscarem novos alvos terapêuticos e vacinais no combate de vários patógenos, entre eles o S. mansoni [6][13][29][30][31][32][33]. 
A identificação e o estudo dos elementos envolvidos na transdução de sinal e a relação destes com o desenvolvimento do parasita (como espermatogênese, ovogênese, desenvolvimento da maturidade sexual, etc) cresceu abundantemente nos últimos anos [17][34][35]. Já foram identificadas (preditas) diversas vias de transdução de sinal em $S$. mansoni, em geral elas são bem conservadas em relação às vias já descritas em outros organismos [36][37][38]. Muitos grupos de pesquisa focam seus esforços para confirmar a predição e identificação de novos elementos destas vias e interações entre proteína exclusivas do parasita. Além disso, tem sido alvo de investigação a compreensão dos processos biológicos que são regulados através destas vias de sinalização no parasita. Isto permitiria a identificação de novos alvos diagnósticos, terapêuticos e vacinais. [32].

\subsection{S. mansoni e a via de sinalização de SmTNFR}

Nas últimas décadas alguns trabalhos na literatura descreveram o efeito da citocina próinflamatória TNF-alfa sobre diversos processos biológicos do $S$. mansoni, como ovoposição, metabolismo, desenvolvimento [39][40][41][42][43].

O TNF-alfa tem um papel crucial no sistema imunológico, sendo responsável pelo recrutamento de células de defesa, sendo uma das primeiras citocinas envolvidas no processo inflamatório. Ele é produzido por diferentes tipos de tecidos e células como: Leucócitos (Neutrófilos, Eosinófilos, Linfócitos, Monócitos e Macrófagos), células mastócitas, células endoteliais, cardiomiócitos, tecido adiposo, fibroblastos tecido nervoso, entre outros. [48]. E conforme mencionado anteriormente, o gene homólogo ao receptor de TNF-alfa humano em S. mansoni (SmTNFR) já foi identificado e caracterizado juntamente com os elementos putativos que compõem a respectiva via de sinalização [3].

SmTNFR (Figura ) gera um transcrito de 1967 nucleotídeos que codifica um receptor composto de 599 aminoácidos; 260 aminoácidos compõem a porção extracelular que possui quatro domínios de receptores de TNF-alfa (TNFR), ricos em Cisteína (CRD - Cistein Rich Domains), principal característica destes receptores.

A Figura A mostra uma representação esquemática do SmTNFR, o gene, o transcito e a ORF (Open Reading Frame) codificada por este. A ORF possui 32\% de identidade e $57 \%$ de similaridade com o receptor CD40 de humanos; a região do SmTNFR que possui a maior similaridade é a região extracelular, e não foi encontrado nenhum domínio conservado na porção intracelular. A Figura 4B ilustra esquematicamente a composição de módulos dos domínios TNFR do SmTNFR e dos demais receptores da família de TNF [44]; é possível 
notar a presença de módulos A1 e B2 de forma semelhante aos receptores de TNFR tipo 1 e 2 e o receptor de NGF (Neural Grow Factor). Também é possível notar a ausência do Death domain na sua porção intracelular de SmTNFR, o que o torna relativamente

A)

Smp_scaff 001950 (reverse complement) 118665 bp Smp_scaff $00035776133 \mathrm{bp}$

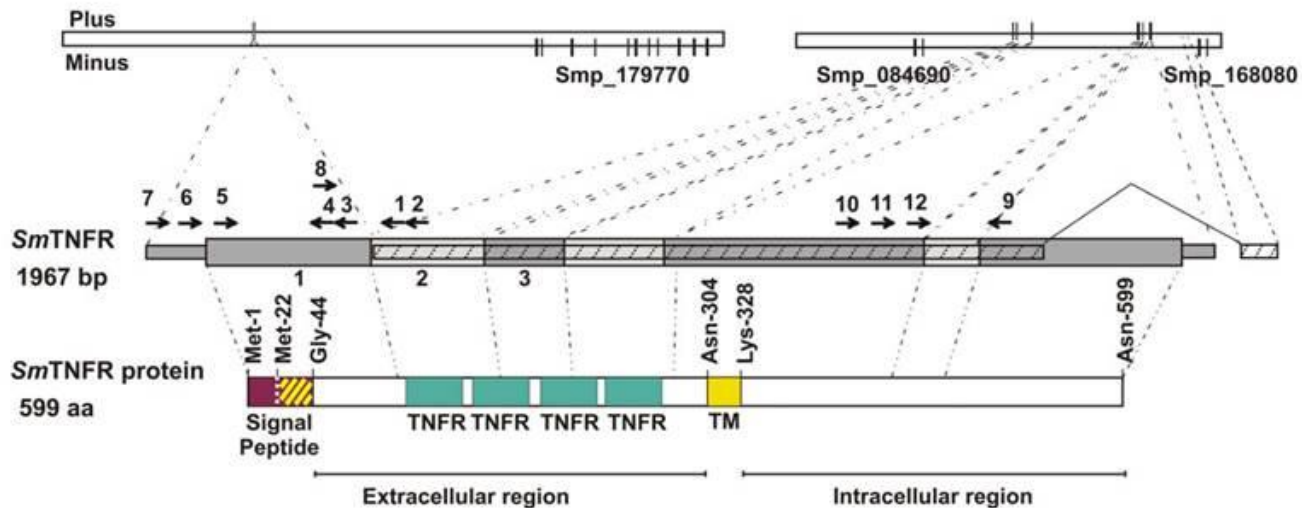

B)
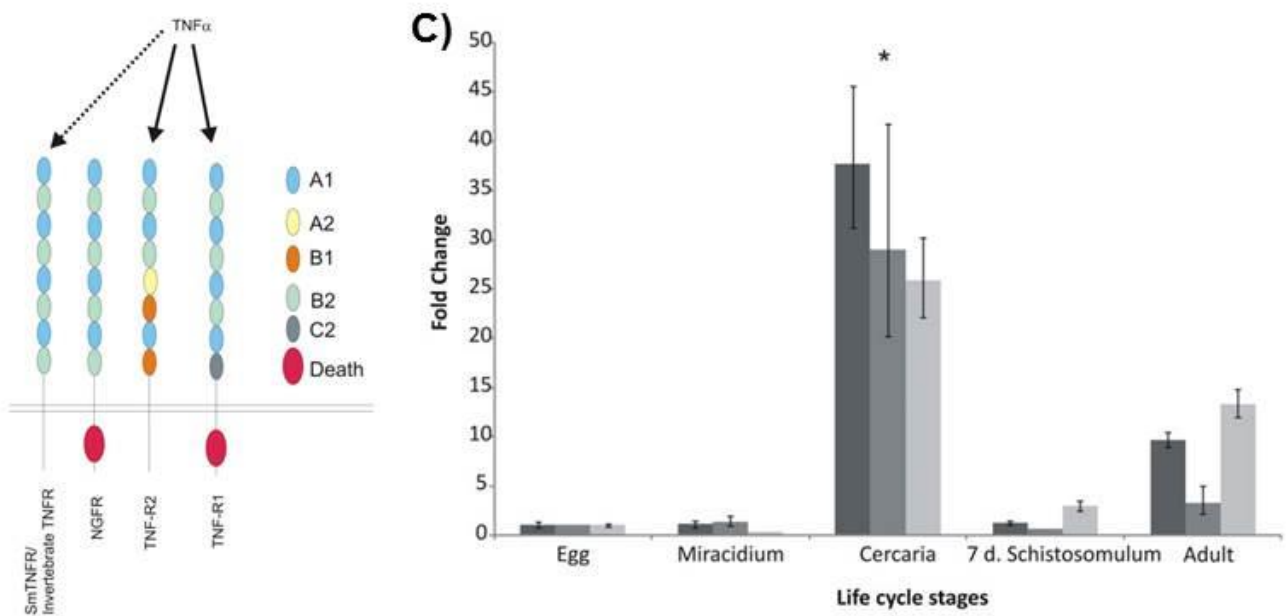

semelhante ao receptor do tipo TNF-R2 humano. Por fim, a Figura 4C mostra os níveis de expressão do mRNA de SmTNFR ao longo dos estágios de desenvolvimento obtidos por PCR em Tempo Real. Este gene é mais expresso em cercaria, estágio infectante para o hospedeiro definitivo, o homem [3].

Figura 4 - Gene homólogo ao receptor de TNF-alfa em S. mansoni (SmTNFR). A) Representação esquemática do gene SmTNFR e a respectiva ORF. Cada barra cinza representa um éxon diferente e é mostrada sua respectiva localização nos scaffolds do genoma (versão 5.2). O gene SmTNFR é codificado na fita mais (senso). A barra hachurada representa a predição gênica (in silico) Smp_168070 original do projeto genoma (versão 5.2), agora representada na versão atual do genoma pelo Smp_332480. As barras coloridas representam domínios proteicos conservados da ORF codificadapelo gene SmTNFR; TNFR, Domínio Rico em Cisteína (CRD), característico da superfamília dos receptores de TNF; MT, Motivo de domínio transmembrana. B) Representação esquemática de alguns receptores humanos da superfamília dos receptores de TNF-alfa e o novo ortólogo encontrado em $S$. mansoni (SmTNFR). O esquema dos receptores humanos foi adaptado de Bodmer et al., 2002. Cada círculo representa um modulo descrito para receptores desta família, e o círculo vermelho representa um death domain, o motivo descrito para algumas proteínas desta 
família. Acima está representado o TNFa e as setas indicam para qual dos receptores foi demonstrada ligação. A seta pontilhada indica uma possível ligação entre o receptor de Schistosoma e o ligante humano. C) Níveis de expressão do gene SmTNFR entre os diferentes estágios de desenvolvimento detectados por experimentos de RT-PCR em Tempo Real. As barras de cores diferentes representam cada uma de três réplicas biológicas. Adaptado de [3].

Até o momento não foi identificado no parasita um gene com similaridade de sequência ao ligante humano do receptor, ou seja, o próprio TNF-alfa. Estes achados sugerem que a cercaria, estágio que encontrará o hospedeiro vertebrado, está com todo o repertório de transcritos prontos para serem utilizados no processo de transformação, e assim, o TNF-alfa do hospedeiro, liberado desde o contato com as cercarias na pele durante a resposta inflamatória pode se ligar e exercer algum efeito sobre o desenvolvimento do parasita. Este evento pode ser um mecanismo molecular importante para o sucesso da infecção e transformação de cercaria para o estágio de esquistossômulo.

A Figura esquematiza a via de sinalização de TNF-alfa em S. mansoni postulada até o momento. Esta via putativa de sinalização foi identificada por análise in silico e apresenta um conjunto de genes com alta similaridade para todos os elementos da cascata ativada por meio do TNF-R2 humano (representados em laranja na figura). O receptor TNF-R2 não possui Death Domain e não está envolvido na via que culmina na indução de apoptose (via ativação de caspases), ele está envolvido no processo de sinalização relacionado à proliferação celular e desenvolvimento [3]. 


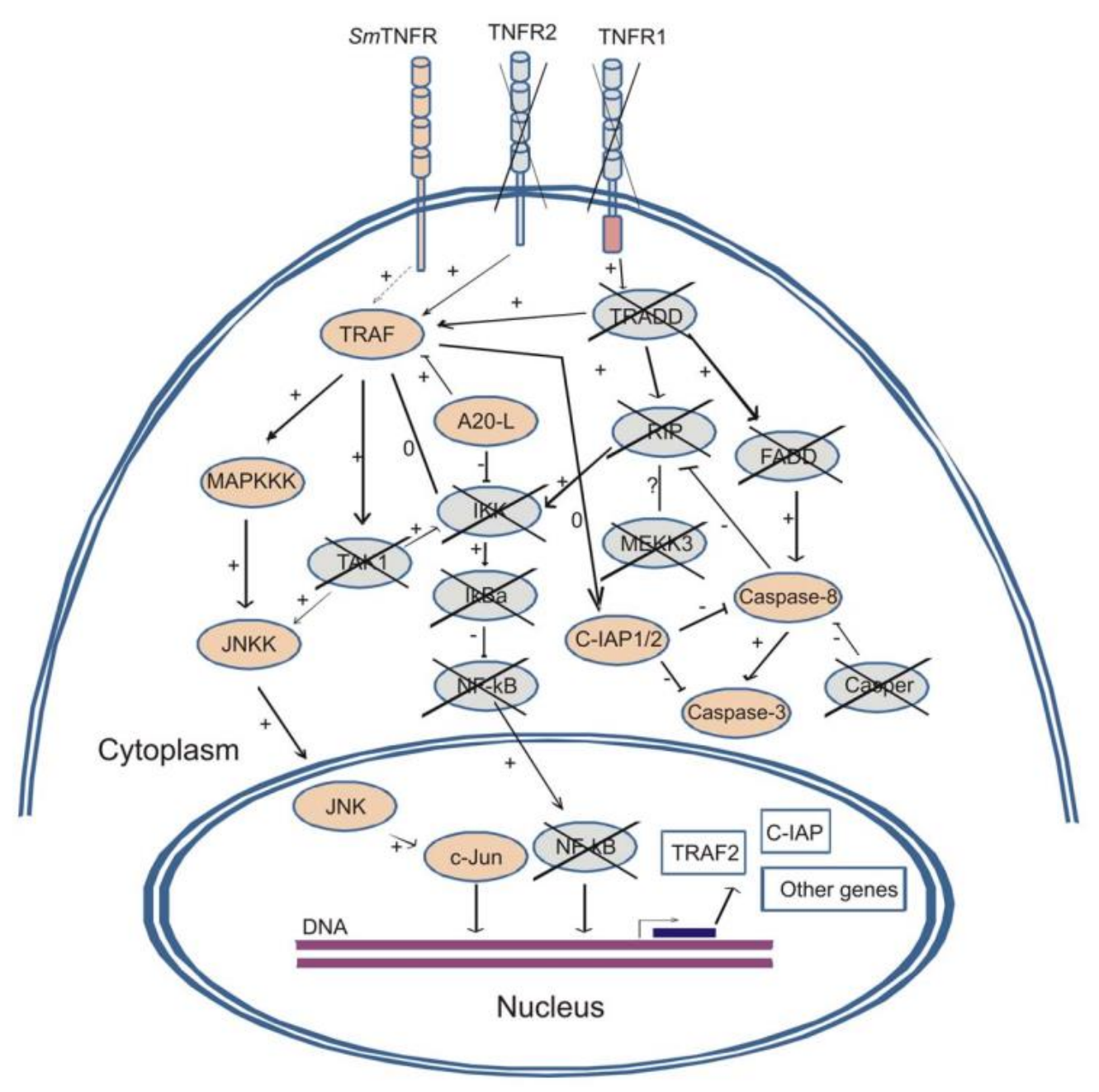

Figura 5 - Representação esquemática da possível via de sinalização de TNF-alfa em S. mansoni. Elementos representados em laranja foram identificados em S. mansoni pela análise in silico, em azul estão representados os elementos que não foram encontrados. Símbolos $(\rightarrow)$ indicam modificação covalente: fosforilação de proteína; $(-)$ indicam interação não covalente: associação proteína-proteína. Relação: (+) estimulatória; (-) inibitória; (0) neutra; (?) indefinida. Extraído de [3].

Nosso grupo de pesquisa demonstrou recentemente a alteração da ovoposição de casais de vermes adultos frente ao tratamento in vitro com TNF-alfa humano recombinante de forma dose e tempo dependente (Figura ). Cabe ressaltar que, no modelo mantido em nosso laboratório, a citocina humana causa uma diminuição significativa da ovoposição nos dias 1 e 2 de tratamento com $5 \mathrm{ng} / \mathrm{ml}$ e controversamente causa um aumento da ovoposição nos dias 4 e 5 de tratamento com $40 \mathrm{ng} / \mathrm{ml}$. Este efeito dose dependente pode explicar o porquê da discrepância existente entre os diferentes trabalhos da literatura a respeito do efeito do TNF-alfa na ovoposição do parasita em virtude de terem sido utilizados tempo e doses diferentes. 

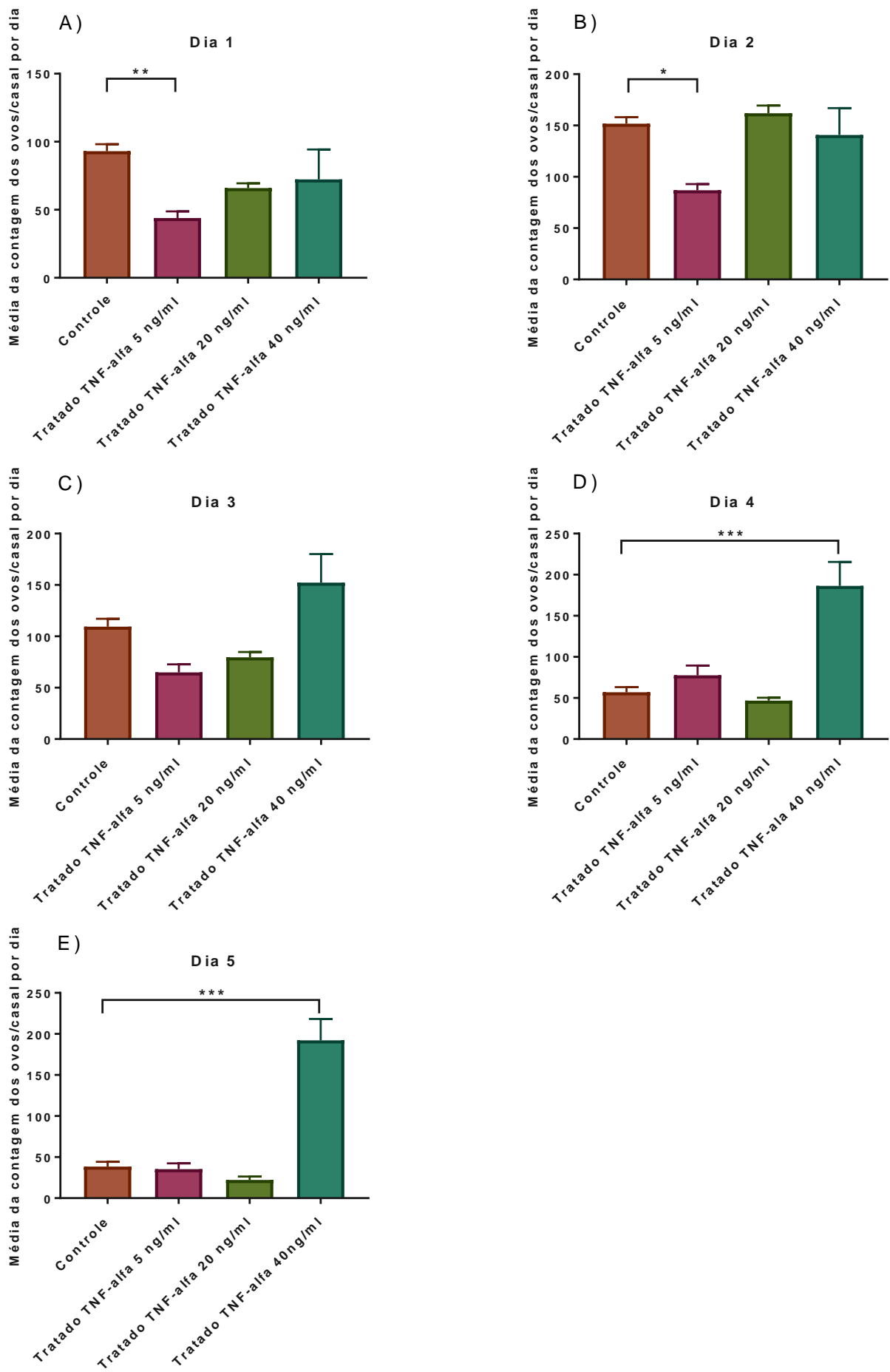

Figura 6. Efeito in vitro do TNF-alfa humano recombinante sobre casais de vermes adultos de S. mansoni. Média do número de ovos por casal por dia tratados com TNF-alfa humano nas doses 5, 20 e $40 \mathrm{ng} / \mathrm{ml}$ ao longo de 5 dias. A) Dia 1; B) Dia 2; C) Dia 3; D) Dia 4 e E) Dia 5 (conforme indicado na figura). Foram realizadas 3 réplicas biológicas e foi aplicado o teste Kruskal-Wallis, $p$-value $<0,05$. 
Além disso, pode-se considerar que exista um efeito relacionado à cepa de $S$. mansoni utilizada em outros trabalhos. Uma questão crucial é que é difícil estimar a real concentração local de TNF-alfa no microambiente do hospedeiro.

Já foi descrito que o tratamento do parasita com a citocina humana induz a fosforilação de dezenas de proteínas, dentre elas a Lactato desidrogenase [45], também já foi relatado que ocorre a alteração em seu nível de expressão (mRNA) [3]. Com base nestes resultados foi averiguado a quantidade de lactato nos meios de cultura produzidos pelos parasitas incubados com 20 ng/ml TNF-alfa humano por 5 dias. Foi possível observar a alteração significativa na concentração deste metabólito em virtude do tratamento (Figura 7); isto sugere que a citocina humana é capaz de regular alguns aspectos fisiológicos e metabólicos do parasita.

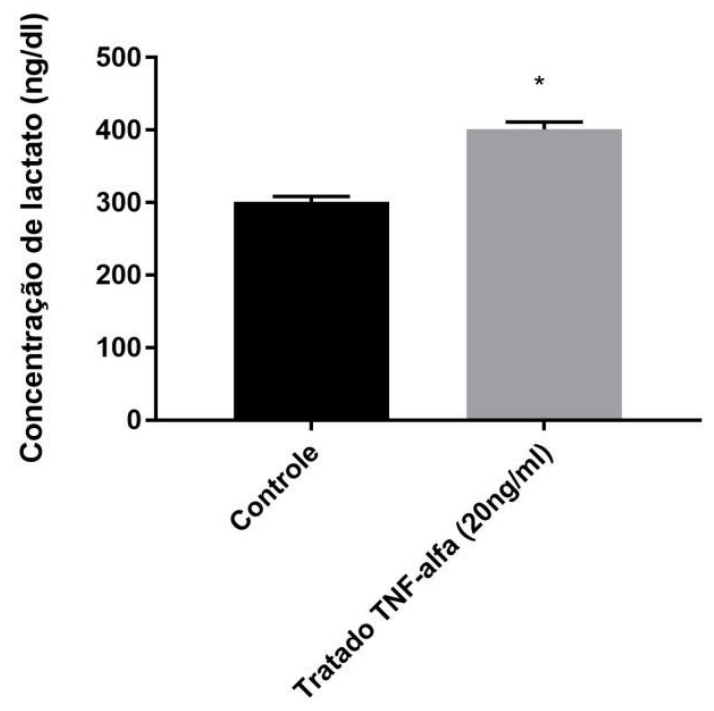

Figura 7. Concentração de lactado no meio de cultura de $\mathbf{1 0}$ casais de vermes adultos incubados com $20 \mathrm{ng} / \mathrm{ml}$ de TNF-alfa humano por 5 dias. Teste-t não pareado. ${ }^{*} \mathrm{p}$. valor > 0,05 .

Este conjunto de dados abre uma nova perspectiva sobre o cenário das vias de sinalização até outrora conhecidas no parasita. O fato da ausência de um ligante endógeno do parasita, mais a presença do receptor homólogo ao receptor do hospedeiro e uma possível via de sinalização sugerem que este pode ser um dos mecanismos envolvidos na complexa interação existente entre parasita-hospedeiro. Este é um ótimo exemplo do crosstalk molecular existente entre estes organismos. 
Diante de todos estes dados expostos e a relevância da via mediada por SmTNFR em $S$. mansoni é perfeitamente justificável o interesse em identificar e caracterizar os potenciais homólogos desta via de sinalização em outros parasitas, particularmente helmintos. É neste contexto que os objetivos que nos dedicamos a seguir a apresentar e discutir os objetivos deste trabalho.

\section{Objetivos do Projeto}

\subsection{Objetivos gerais}

Identificar e caracterizar os genes homólogos ao SmTNFR em helmintos, especialmente em parasitas de interesse médico.

\subsection{Objetivos específicos}

- Buscar os genes homólogos de SmTNFR em outros invertebrados, de modo particular em espécies de parasitas de interesse médico;

- Caracterizar os domínios proteicos conservados das proteínas codificadas pelos homólogos de SmTNFR realizando buscas em bancos de dados públicos

- Alinhar os domínios conservados para estudar a similaridade das sequências

- Realizar a construção de árvores filogenéticas para discussão e entendimento do contexto evolutivo dos receptores homólogos ao TNFR em invertebrados.

- Identificar e caracterizar eventuais genes homólogos aos ligantes dos receptores de TNFR nos helmintos. 


\section{MATERIAIS E MÉTODOS}

A Figura 8 a seguir representa esquematicamente a abordagem de analise realizada ao longo deste trabalho. Cada passo será descrito nos itens a seguir.

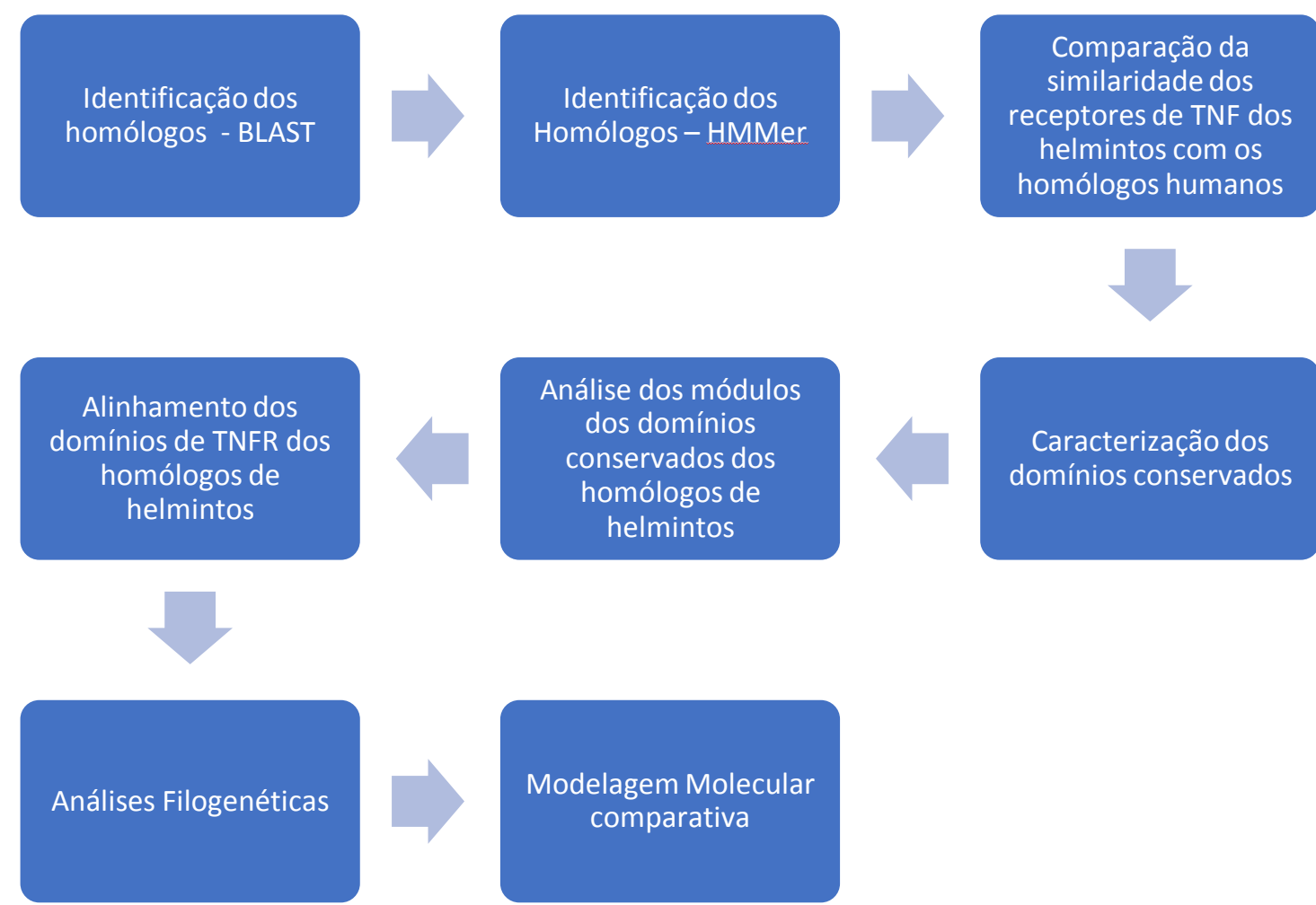

Figura 8. Fluxograma de trabalho. Etapas de realização e caracterização do projeto.

\subsection{Identificação dos homólogos de SmTNFR em helmintos e homólogos de TNF-alfa}

Num contexto geral, atualmente a comunidade cientifica está bem aparamentada com ferramentas, bancos de dados e softwares capazes de aprimorar e aprofundar as pesquisas. Precisamos nos esforçar para cada vez mais para explorar e divulgar estes novos métodos de avaliação curagem de dados.

Destacamos aqui os bancos de dados utilizados por este trabalho: o GenBank no NCBI (National Center for Biotechnology Information, http://www.ncbi.nlm.nih.gov/genbank), é uma coleção de todas as sequencias de DNA públicas disponíveis [46], é parte da Colaboração internacional de banco de dados de sequencias de nucleotídeos que, além dele, é 
composta também pelo Banco de dados de DNA do Japão (DDBJ - DNA Database of Japan), o arquivo de nucleotídeos europeu (ENA - European Nucleotide Archive), estas organizações fazem um intercambio de dados diários. O NCBI disponibiliza diferentes ferramentas para a análise destas sequencias. A ferramenta BLAST (Basic Local Alignment Search Tool), replicada por outros bancos, é a forma rápida e prática de analisar similaridade de sequencias altamente utilizada. Interrogando sua sequência contra o banco de dados selecionado, o programa fornece importantes informações e dados, que serão analisados neste trabalho.

O banco de dados GeneDB (www.genedb.org) é fundado e mantido pelo Wellcome Sanger Institute que contem depositados os dados dos genomas de protozoários do filo apicomplexa, da classe cinetoplastideos, fungos e platelmintos. Por fim, o Wormbase Parasite [47] (https://parasite.wormbase.org/index.html), também amplamente utilizado neste trabalho, é um banco de dados no qual estão depositadas as sequencias dos genomas de helmintos (134 nematóides e 39 platelmintos).

\subsubsection{UTILIZANDO A FERRAMENTA BLAST}

A busca inicial por sequências homólogas ao SmTNFR foi realizada utilizando a ferramenta BLAST (Basic Local Alignment Search Tool)[25], na modalidade BLASTp e tBLASTn. A sequência GQ222226.1. foi usada como query em buscas nos bancos de dados públicos: Genbank no NCBI (National Center for Biotechnology Information http://www.ncbi.nlm.nih.gov/genbank), GeneDB (www.genedb.org) e Wormbase Parasite (https://parasite.wormbase.org/index.html). Como o GenBank possui o depósito de todos os organismos foi selecionado o taxid:6157 (Platyhelminthes) e o taxid: 6331 (Nematodes) no campo de organismos da ferramenta utilizando o banco de dados $\mathrm{nr} / \mathrm{nt}$ (non-redundant nucleotide colection). Foi considerado potencial homólogo às sequências que obtinham um e-value $<10^{-10}$.

\subsubsection{UTILIZANDO A FERRAMENTA HMMER}

As sequências encontradas na busca com o BLAST foram utilizadas para construir um padrão probabilístico de busca (HMM, construído pelo HMM build) no programa HMMER v 3.2.1 (http://hmmer.org/).que foi utilizado para interrogar todos os genomas depositados no 
Wormbase parasite (https://parasite.wormbase.org/index.html) [12], assemblies versão WBPS10. O cut-off para ser considerado um homólogo de SmTNFR foi e-value $<10^{-04}$.

O teste do chi-quadrado (2x2) [48] foi realizado para confirmar que a proporção dos genomas de platelmintos na qual foi encontrada homólogos de SmTNFR foi significativamente superior à proporção encontrada nos genomas dos nematelmintos. $O$ teste foi realizado on line no site https://www.socscistatistics.com/tests/chisquare/default.aspx.

\subsection{Identificação dos domínios conservados nos homólogos de SmTNFR}

A identificação dos domínios conservados foi realizada utilizando as ferramentas e bancos de dados: SMART-PRO (Simple Modular Architecture Research Tool, disponível em http://smart.embl-heidelberg.de/); PFAM (The Protein Families Database, disponível em http://pfam.xfam.org/ ), Interpro (disponível em http://www.ebi.ac.uk/interpro/) e Prosite (https://prosite.expasy.org/). Além disso, o HMMER também foi utilizado para encontrar domínios de TNFR em helmintos. Para este fim todos os domínios identificados pelos programas mencionados anteriormente foram utilizados para gerar um novo HMM com domínios de TNFR de helmintos e uma nova busca foi realizada nas sequencias dos homólogos.

A identificação de Peptídeo sinal foi feita com o auxílio do programa SignallP 5.0 (http://www.cbs.dtu.dk/services/SignalP/) e a busca de domínios transmembrana foi realizada com os programas TMHMM Server v. 2.0 (http://www.cbs.dtu.dk/services/TMHMM/) e $\quad$ TmPred https://embnet.vitalit.ch/software/TMPRED_form.html).

\subsection{Alinhamento dos domínios ricos em cisteínas dos homólogos de SmTNFR e dos homólogos de TNF}

As sequências das proteínas homólogas correspondentes aos domínios ricos em cisteínas (CRD), ou seja, os domínios de TNFR foram selecionados e alinhados no programa MUSCLE [49] seguindo os parâmetros default do programa no software MEGA 7 [50]. No programa Jalview o alinhamento foi colorido de acordo a conservação dos resíduos 
conforme método de AMAS[51]. Regiões de possíveis estruturas secundárias foram preditas pelo algoritmo Jpred [52].

\subsection{Comparação dos alinhamentos dos homólogos de SmTNFR e os receptores humanos da família de TNF-alfa e dos homólogos de ligantes de TNF-alfa e os ligantes da humanos.}

O programa BLAST foi localmente instalado e foram criados dois arquivos multifasta: um arquivo com todas as sequências dos 47 homólogos de SmTNFR de helmintos e o outro com as sequências dos 25 principais receptores da família de TNF-alfa humano. Foi realizado um BLASTp utilizado o arquivo com as sequências dos helmintos como query e o arquivo das sequências humanas como subject. O resultado geral foi tabulado em uma tabela e foram criadas matrizes com os valores de -log10 E-value, bit score, porcentagem de identidade e similaridade e cobertura do subject pela query. O programa $\mathrm{R}$ foi utilizado para criar as figuras das matrizes dos dados dos alinhamentos.

\subsection{Análise dos módulos dos domínios ricos em cisteínas dos homólogos de SmTNFR}

A identificação e análise dos módulos dos domínios ricos em cisteínas (CRD) dos receptores dos helmintos foram realizadas por meio da utilização do programa HMMER. As sequências dos módulos dos CRD já conhecidos dos receptores da família de TNF-alfa humanos foram utilizadas para a construção de um HMM para cada módulo (A1, A2, B1, B2, $N 1, C 2, X 2)$. Em seguida foi realizada uma busca nas sequências dos helmintos utilizando o HMM. As pontes dissulfetos foram identificadas pelo programa Prosite (https://prosite.expasy.org/).

\subsection{Análise filogenética do alinhamento dos homólogos de SmTNFR e homólogos de TNF}

As análises filogenéticas foram realizadas com o programa MEGA7 [50] para os métodos de Máxima Parcimônia; Máxima Verossimilhança e Evolução Mínima; Métodos geométricos (calculados pelo método de Poisson) cujas topologias foram reconstruídas pelo método UPGMA (Unweighted Pair Group Method with Arithmetic Means), e pelo método Neighbor-joining utilizando o teste de confiança de Bootstraping (1000 permutações). A 
análise filogenética realizada por Inferência Baysiana foi realizada com o programa Mr. Bayes (http://nbisweden.github.io/MrBayes/index.html) [53].

\subsection{Modelagem comparativa dos homólogos de SmTNFR}

A modelagem comparativa dos homólogos de SmTNFR com estrutura dos receptor humano foi realizada utilizando o programa Yasara homology modeling (http://www.yasara.org/homologymodeling.htm) seguindo os parâmetro default do programa. A modelagem com a melhor pontuação foi visualizada no programa Swiss-PDb viewer disponível para download em (https://spdlbv.vital-it.ch/). 


\section{RESULtAdOS}

\subsection{Identificação dos homólogos de SmTNFR em helmintos}

O BLAST, conforme mencionado anteriormente, é uma das ferramentas de busca mais utilizadas para identificação e anotação de sequências e é extremamente eficiente [25]. Esta ferramenta faz a busca de sequências similares utilizando uma sequência de busca query e um banco de dados. A comparação de sequências (nucleotídeos ou proteínas) é calcula baseando-se em matrizes de pontuação referente a taxas de mutação entre nucleotídeos e proteínas. Portanto, regiões bem conservadas terão taxas de mutação bem menores e assim podemos identificar similaridade de sequencias e inferir possível similaridade de função. Baseado no número de bases / aminoácidos alinhados e na sua identidade é calculado um score para o alinhamento, baseado na probabilidade deste alinhamento ter acontecido ao acaso no banco de dados selecionado é calculado o e-value.

Inicialmente a busca por homólogos de SmTNFR foi realizada por BLAST procurando nas sequencias das principais categorias de parasitas, tanto protozoários como helmintos, utilizando como query a sequência GQ222226.1 nos banco de dados GenBank (http://www.ncbi.nlm.nih.gov/genbank) e o banco Gene DB (www.genedb.org).

Como resultado desta primeira abordagem foram encontrados homólogos em sete organismos cujos alinhamentos possuíam E-value $<10^{-10}$, seis platelmintos e um nematelminto. Não foi encontrada nenhuma sequência homóloga em protozoários. A Tabela 1 sumariza os resultados obtidos com esta abordagem. 
Tabela 1. Genes / Proteínas homólogos a SmTNFR em helmintos (E-value $<10^{-10}$ ). Os resultados foram obtidos por Blastp realizado no GenBank.

\begin{tabular}{|c|c|c|c|c|}
\hline Gene ID & $\begin{array}{l}\text { Número de } \\
\text { acesso }\end{array}$ & Produto & Organismo & Filo \\
\hline EgrG 000990500 & CDS17169.1 & $\begin{array}{l}\text { tumor necrosis } \\
\text { factor receptor } \\
\text { superfamily }\end{array}$ & $\begin{array}{l}\text { Echinococcus } \\
\text { granulosus }\end{array}$ & Platelminto \\
\hline EmuJ 000990500 & CDS42197.1 & $\begin{array}{l}\text { tumor necrosis } \\
\text { factor receptor } \\
\text { superfamily }\end{array}$ & E. multilocularis & Platelminto \\
\hline HmN 000322000 & CDJ12165.1 & $\begin{array}{l}\text { tumor necrosis } \\
\text { factor receptor } \\
\text { superfamily }\end{array}$ & $\begin{array}{l}\text { Hymenolepis. } \\
\text { microstoma }\end{array}$ & Platelminto \\
\hline TsM 000678000 & & $\begin{array}{l}\text { tumor necrosis } \\
\text { factor receptor } \\
\text { superfamily }\end{array}$ & Taenia solium & Platelminto \\
\hline XP 003371690.1 & & $\begin{array}{l}\text { tumor necrosis } \\
\text { factor receptor } \\
\text { superfamily } \\
\text { member } 16\end{array}$ & Trichinella spiralis & Nematelminto \\
\hline GAA49741.1 & DF142982.1 & $\begin{array}{l}\text { tumor necrosis } \\
\text { factor receptor } \\
\text { superfamily } \\
\text { member } 16\end{array}$ & Clonorchis sinensis & Platelminto \\
\hline XM 009173815.1 & & $\begin{array}{l}\text { hypothetical } \\
\text { protein partial } \\
\text { mRNA }\end{array}$ & Opisthorchis viverrini & Platelminto \\
\hline
\end{tabular}

A partir dos resultados acima, notamos que a maior parte das sequências se tratava de predições gênicas. Assim, foi analisado o contexto genômico destas predições gênicas (coordenadas introns e exons) e foi realizada uma busca por ESTs (Etiquetas de sequências transcritas), ou seja, fragmentos de mRNA sequenciados, para confirmação destas predições. Isto é necessário, pois uma predição gênica é gerada por meio de algoritmos computacionais e pode conter erros nas extremidades dos exons, especialmente ao utilizar métodos ab initio [54] que muitas vezes não levam em conta os dados de transcrição como os obtidos pelo sequenciamento ESTs para definir os introns e exons. Desta forma, é possível que pequenos erros ocorram na definição das extremidades dos exons, que podem causar erro no produto codificado pelo gene pelos programas preditores, o que comprometeria análises de domínios proteicos feitas a posteriori. 
Neste contexto foi realizado um tBLASTn com a sequência de proteína do SmTNFR nas sequências disponíveis de $T$. solium encontramos um alinhamento com a predição gênica TsM 000678000 (bit score 538, e-value<3,1×10-52, 64\% similaridade, 49\% identidade, cobertura de $30 \%$ da predição no SmTNFR, e cobertura de $90 \%$ do SmTNFR na predição). Buscando SmTNFR no genoma no banco GeneDB (www.genedb.og) encontramos que o supercontig "pathogen TSM contig 00102"; a predição TsM 000678000 alinhava-se perfeitamente ao supercontig genômico e foi observado que o gene era composto por 4 exons. Por fim a busca por ESTs no Genbank revelou 5 ESTs que se sobrepõem à predição e entre si (JZ052942.1; JZ071773.1; JZ058596.1; JZ038140.1 e EL748777.1). A

Figura 9 ilustra o alinhamento destas sequências (genoma, predição genica e ESTs) de T. solium. O maior EST alinhado confirma a maior parte da predição, mas não foi possível estende-la para as extremidades 5'UTR ou 3'UTR.

\section{Taenia solium}

A)

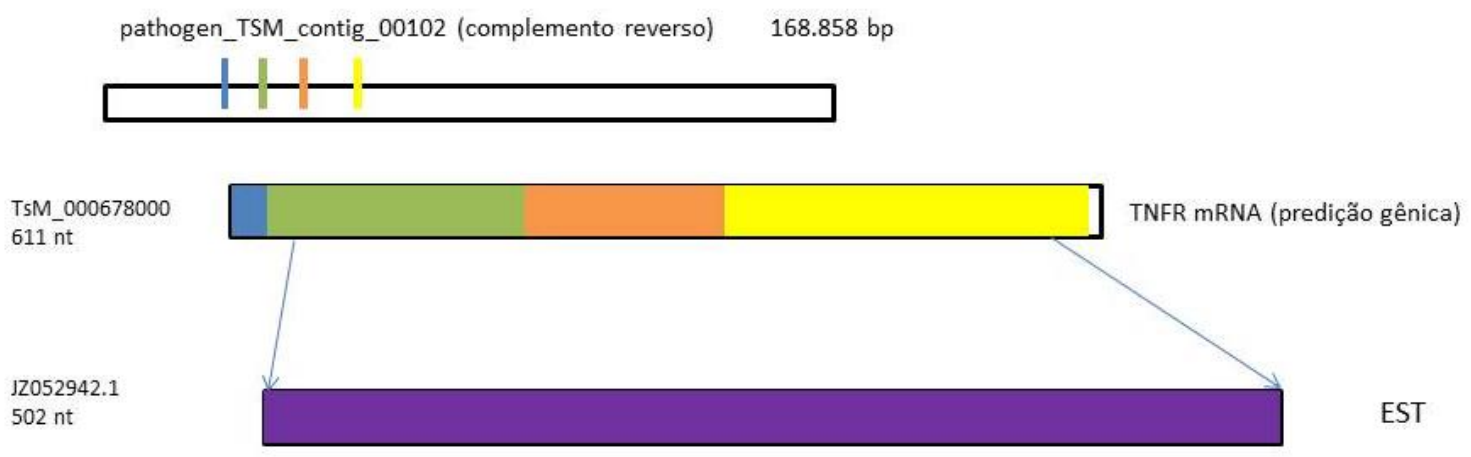

B)

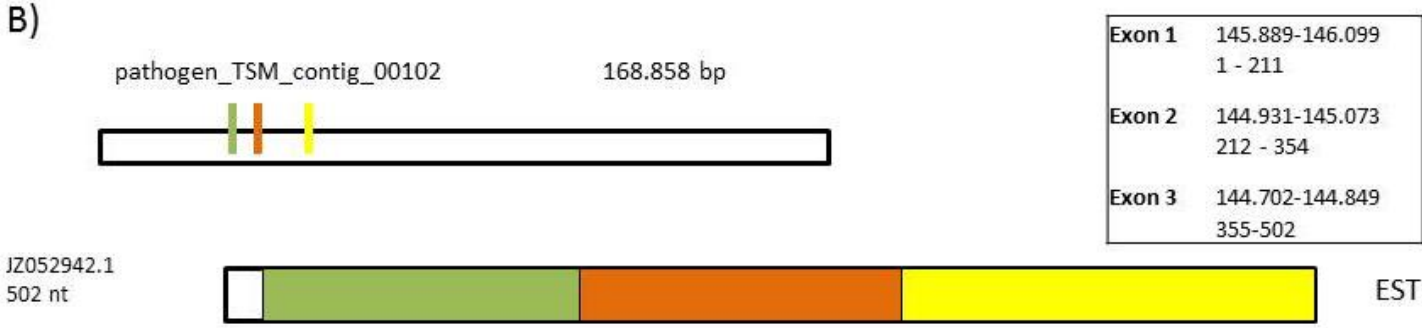

Figura 9. Representação esquemática do gene homólogo de T. solium a SmTNFR. A) Alinhamento da predição gênica no genoma e alinhamento dos EST na predição. B) Alinhamento do EST no genoma. Em detalhes no quadro são mostradas as coordenadas dos exons do genoma confirmados pelo EST. 
De forma similar, foi realizado um tBLASTn com a sequência traduzida do SmTNFR nas sequências disponíveis de $E$. granulosus. O resultado indicou um alimento com a predição gênica EgrG 000990500 (bit score 527, e-value<3,6×10-51, 62\% similaridade, 48\% identidade, cobertura de $29 \%$ da predição no SmTNFR, e cobertura de $73 \%$ do SmTNFR na predição). A busca no genoma revelou que o gene está contido no supercontig "pathogen EgG scaffold 0002". A Figura ilustra a posição dos exons preditos no contig genômico. Não foram encontrados ESTS nos bancos de dados públicos que se alinhassem à predição gênica.

\section{Echinococcus granulosus}

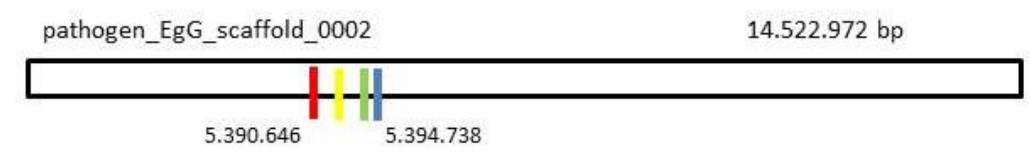

HG328392.1

EgrG_000990500 $244 \overline{\mathrm{nt}}$

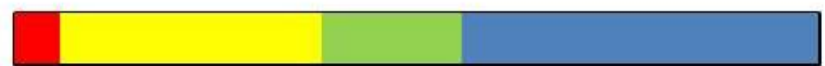

TNFR mRNA (predição gênica)

Figura 10. Representação esquemática do gene de E. granulosus homólogo ao SmTNFR. A figura mostra a localização dos exons da predição gênica no genoma.

No caso de E. multilocularis o alinhamento utilizando SmTNFR nas bases de dados encontrou a predição gênica EmuJ 000990500.1 (bit score 509, e-value $<3,1 \times 10^{-49}, 61 \%$ similaridade, $47 \%$ identidade, cobertura de $29 \%$ da predição no SmTNFR, e cobertura de $72 \%$ do SmTNFR em relação a predição), contida no supercontig genômico "pathogen EMU scaffold 007780", assim como no caso de E. granulosos, não existiam ESTs nos bancos de dados público.

A busca de homólogos nas sequências de $H$. microstoma resultou na predição

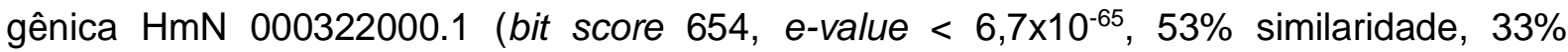
identidade, cobertura de $69 \%$ da predição no SmTNFR, e cobertura de $91 \%$ do SmTNFR na predição), que está situada no supercontig genômico pathogen HYM scaffold 37.

Entre as sequências de $T$. spiralis, único nematelminto que possuía homologia com SmTNFR, foi encontrada similaridade de sequência em dois trechos do supercontig genômico Scfld9 (hit 93, e-value 2x 10-21, similaridade 48\%, identidade 35\%, cobertura do trecho no SmTNFR de 34\%). 
O homólogo do organismo Clonorchis sinensis (GAA49741.1), representante da mesma classe do S. mansoni, os Trematodos, foi o que obteve melhor valor de e-value, $6 \mathrm{x}$ $10^{-77}$. Sua sequência possui 281 aminoácidos e tem uma cobertura de quase $37 \%$. Seus respectivos valores de identidade e similaridade são: $56 \%$ e $69 \%$.

Todo este esforço para analisar o contexto genômicos destes homólogos e buscar ESTs nos bancos de dados para melhorar a montagem/estrutura do gene não resultou numa melhora significativa das sequências analisadas.

A fim de aprimorar a estratégia de busca de homólogos, em colaboração com o Dr. Ricardo DeMarco do Instituto de Física da Universidade de São Paulo em São Carlos, foi realizada a busca por meio da ferramenta HMMER (http://hmmer.org/). Conforme mencionado anteriormente, o HMMER é baseado na construção de modelos probabilísticos (HMM) utilizando os Modelos Ocultos de Marcov [28][27]. Para a construção do HMM (uma "query" ajustada) foram utilizadas todas as sequências homólogas de receptores de TNF de helmintos que se possuía até aquele momento, com este HMM foram interrogados todos os genomas de platelminto e de Nematelmintos que estavam depositados no Wormbase Parasite (https://parasite.wormbase.org/species.html) [12] que foram baixados localmente.

O resultado desta abordagem nos possibilitou identificados 47 genes homólogos em 42 espécies; 22 platelmintos (Clonorchis sinensis, Echinococcus canadenses, Echinococcus granulosus, Echinococcus multilocularis, Gyrodactylus salaris, Hydatigera taeniaeformis, Hymenolepis diminuta, Hymenolepis micróstoma, Hymenolepis nana, Macrostomum lignano, Mesocestoides corti, Opisthorchis viverrini, Schistosoma curassoni, Schistosoma haematobium, Schistosoma japonicum, Schistosoma mansoni, Schistosoma margrebowiei, Schistosoma mattheei, Taenia asiatica, Taenia saginata, Taenia solium, Trichobilharzia regenti) e 22 nematelmintos (Ascaris lumbricoides, Ascaris suum, Haemonchus contortus, Heligmosomoides polygyrus, Panagrellus redivivus, Romanomermis culicivorax, Soboliphyme baturini, Trichinella britovi, Trichinella murrelli, Trichinella nativa, Trichinella nelsoni, Trichinella papuae, Trichinella pseudospiralis, Trichinella spiralis, Trichinella zimbabwensis, Trichuris muris, Trichuris suis, Trichuris trichiura). Os resultados da busca estão sumarizados na Tabela 2.

Em quatro espécies de nematelmintos existem duas isoformas de homólogos de receptor (T. britovi, T. murrelli, T. nelsoni, T. patagoniensis) e em duas espécies ocorre duplicação gênica ( $S$. baturini e $R$. culicivorax). Outro aspecto interessante é que entre estes helmintos, dois são de vida livre: o nematelminto $P$. redivivus e o platelminto $M$. lignano. 
É notável uma proporção significativamente maior de presença de homólogos de SmTNFR nos genomas de platelmintos do que nos genomas de nematelmintos (teste chiquadrado $p<0.05$ ). As sequências dos homólogos dos receptores de TNF em helmintos estão disponibilizadas no Arquivo suplementar 1 no CD-ROM dos arquivos anexos. 
Tabela 2. Homólogos de SmTNFR em Helmintos identificados pelo programa HMMER nas bases de dados Wormbase Parasite

\begin{tabular}{|c|c|c|c|c|c|c|c|c|}
\hline Filo & Classe & Espécie & Gene ID & $\begin{array}{l}\text { HMMER e- } \\
\text { value }\end{array}$ & $\begin{array}{c}\text { Hosp. } \\
\text { definitivo }\end{array}$ & $\begin{array}{l}\text { Hosp. } \\
\text { Interm. }\end{array}$ & Contig ou scaffold genômco & $\begin{array}{l}\text { Coordenadas } \\
\text { do contig ou } \\
\text { scaffold }\end{array}$ \\
\hline Nematelm. & Chromadorea & Ascaris lumbricoides & ALUE_0000490301 & $1,70 \mathrm{E}-004$ & Homem & & ALUE_scaffold0000075 & $\begin{array}{l}261182- \\
263560\end{array}$ \\
\hline Nematelm. & Chromadorea & Ascaris suum & GS_05866 & $1,90 \mathrm{E}-004$ & Homem & & Scaffold122 & $\begin{array}{l}3366962- \\
3376678\end{array}$ \\
\hline Nematelm. & Chromadorea & Haemonchus contortus & HCOI_01488400 & $7,30 \mathrm{E}-004$ & Bovinos & & scaffold19559 & $\begin{array}{l}12712- \\
87806\end{array}$ \\
\hline Nematelm. & Chromadorea & $\begin{array}{l}\text { Heligmosomoides } \\
\text { polygyrus }\end{array}$ & HPOL_0001721401 & $1,70 \mathrm{E}-004$ & Roedores & & nHp.2.0.scaf02404 & $5956-16030$ \\
\hline Nematelm. & Chromadorea & Panagrellus redivivus & Pan_g18397.t1 & $5,80 \mathrm{E}-005$ & Vida livre & & KB455497 & $\begin{array}{l}87715- \\
89534\end{array}$ \\
\hline Nematelm. & Enoplea & Romanomermis culicivorax & nRc.2.0.1.t36941 & $2,50 \mathrm{E}-025$ & Insetos & & nRc.2.0.scaf00177 & $\begin{array}{l}24041- \\
28863\end{array}$ \\
\hline Nematelm. & Enoplea & Romanomermis culicivorax & nRc.2.0.1.t36199 & $1,20 \mathrm{E}-008$ & Insetos & & nRc.2.0.scaf04968 & $6107-12691$ \\
\hline Nematelm. & Enoplea & Soboliphyme baturini & SBAD_0000868101 & $1,50 \mathrm{E}-040$ & Roedores & & SBAD_scaffold0004921 & $871-9934$ \\
\hline Nematelm. & Enoplea & Soboliphyme baturini & SBAD_0000418301 & $3,10 \mathrm{E}-010$ & Roedores & & SBAD_scaffold0001457 & $\begin{array}{l}24268- \\
28359\end{array}$ \\
\hline Nematelm. & Enoplea & Trichinella britovi & T03_11861.2 & 8,90E-062 & Homem & & scaffold126s & $6774-13329$ \\
\hline Nematelm. & Enoplea & Trichinella britovi & T03_11861.1 & $1,10 \mathrm{E}-061$ & Homem & & scaffold126s & $6774-13329$ \\
\hline Nematelm. & Enoplea & Trichinella murrelli & T05_14779.2 & $1,10 \mathrm{E}-061$ & Homem & & scaffold100s & $\begin{array}{l}13984- \\
21377\end{array}$ \\
\hline Nematelm. & Enoplea & Trichinella murrelli & T05_14779.1 & $1,30 \mathrm{E}-061$ & Homem & & scaffold100s & $\begin{array}{l}13984- \\
21377\end{array}$ \\
\hline Nematelm. & Enoplea & Trichinella nativa & T02_15720.1 & $1,20 \mathrm{E}-061$ & Homem & & scaffold143s & $\begin{array}{l}16295- \\
22917\end{array}$ \\
\hline Nematelm. & Enoplea & Trichinella nelsoni & T07_5892.1 & $1,20 \mathrm{E}-061$ & Homem & & scaffold112s & $\begin{array}{l}109927- \\
116990\end{array}$ \\
\hline Nematelm. & Enoplea & Trichinella nelsoni & T07_5892.2 & $1,40 \mathrm{E}-061$ & Homem & & scaffold112s & $\begin{array}{l}109927- \\
116990\end{array}$ \\
\hline Nematelm. & Enoplea & Trichinella papuae & T10_10435.1 & $2,50 \mathrm{E}-061$ & Homem & & scaffold135s & $6447-15161$ \\
\hline Nematelm. & Enoplea & Trichinella patagoniensis & T12_9130.1 & 1,00E-062 & Homem & & scaffold68s & $\begin{array}{l}92641- \\
99578\end{array}$ \\
\hline
\end{tabular}




\begin{tabular}{|c|c|c|c|c|c|c|c|c|}
\hline Filo & Classe & Espécie & Gene ID & $\begin{array}{l}\text { HMMER e- } \\
\text { value }\end{array}$ & $\begin{array}{l}\text { Hosp. } \\
\text { definitivo }\end{array}$ & $\begin{array}{l}\text { Hosp. } \\
\text { Interm. }\end{array}$ & Contig ou scaffold genômco & $\begin{array}{l}\text { Coordenadas } \\
\text { do contig ou } \\
\text { scaffold }\end{array}$ \\
\hline Nematelm. & Enoplea & Trichinella patagoniensis & T12_9130.2 & $1,20 \mathrm{E}-061$ & Homem & & scaffold68s & $\begin{array}{l}92641- \\
99578\end{array}$ \\
\hline Nematelm. & Enoplea & Trichinella pseudospiralis & T4C_4529.1 & $8,40 \mathrm{E}-062$ & Homem & & scaffold100s & $\begin{array}{l}53283- \\
62481\end{array}$ \\
\hline Nematelm. & Enoplea & Trichinella spiralis & EFV52365 & $5,50 \mathrm{E}-062$ & Homem & & GL622792 & $\begin{array}{l}2889997- \\
2892469\end{array}$ \\
\hline Nematelm. & Enoplea & Trichinella zimbabwensis & T11_2900.1 & $2,40 \mathrm{E}-061$ & Homem & & scaffold110s & $\begin{array}{l}126241- \\
133382\end{array}$ \\
\hline Nematelm. & Enoplea & Trichuris muris & TMUE_s0039006400 & $4,60 \mathrm{E}-046$ & Roedores & & scaffold39 & $\begin{array}{l}405718- \\
412107\end{array}$ \\
\hline Nematelm. & Enoplea & Trichuris suis & D918_09580 & $6,60 \mathrm{E}-046$ & Porcos & Homem & T_suis-1.0_Cont66 & $\begin{array}{l}160847- \\
162342\end{array}$ \\
\hline Nematelm. & Enoplea & Trichuris trichiura & TTRE_0000068601 & $1,60 \mathrm{E}-046$ & Homem & & TTRE_000014 & $\begin{array}{l}145236- \\
146647\end{array}$ \\
\hline Platelm. & Cestoidea & Echinococcus canadensis & EcG7_03322 & $1,70 \mathrm{E}-076$ & Canídeos & Homem & E.canG7_contigs_7443 & $\begin{array}{l}87849- \\
100282\end{array}$ \\
\hline Platelm. & Cestoidea & Echinococcus granulosus & EgrG_000990500 & $1,10 \mathrm{E}-080$ & Canídeos & & pathogen_EgG_scaffold_0002 & $\begin{array}{l}5390646- \\
5394738\end{array}$ \\
\hline Platelm. & Cestoidea & Echinococcus multilocularis & EmuJ_000990500.1 & $6,50 \mathrm{E}-079$ & Canídeos & Homem & pathogen_EmW_scaffold_02 & $\begin{array}{l}6649326- \\
6653148\end{array}$ \\
\hline Platelm. & Cestoidea & Hydatigera taeniaeformis & TTAC_0000849801 & $3,20 \mathrm{E}-080$ & Felinos & & TTAC_scaffold0000222 & $\begin{array}{l}15995- \\
19748\end{array}$ \\
\hline Platelm. & Cestoidea & Hymenolepis diminuta & HDID_0000395701 & $8,50 \mathrm{E}-078$ & Roedores & Homem & HDID_contig0001343 & $3982-16728$ \\
\hline Platelm. & Cestoidea & Hymenolepis microstoma & HmN_000322000.1 & $5,50 \mathrm{E}-079$ & Roedores & & pathogens_HYM_scaffold_0001 & $\begin{array}{l}9615856- \\
9627912\end{array}$ \\
\hline Platelm. & Cestoidea & Hymenolepis nana & HNAJ_0000370201 & $4,80 \mathrm{E}-065$ & Homem & & HNAJ_contig0002253 & $977-9675$ \\
\hline Platelm. & Cestoidea & Mesocestoides corti & MCOS__0000285501 & $1,60 \mathrm{E}-071$ & Roedores & & MCOS_contig0000529 & $\begin{array}{l}18911- \\
27821\end{array}$ \\
\hline Platelm. & Cestoidea & Taenia asiatica & TASs00007g01877 & $3,80 \mathrm{E}-078$ & Homem & & Scaffold00007 & $\begin{array}{l}1401409- \\
1413855\end{array}$ \\
\hline Platelm. & Cestoidea & Taenia saginata & TSAs00042g05847 & $3,60 \mathrm{E}-079$ & Homem & & Scaffold00042 & $\begin{array}{l}735538 \text { - } \\
747274\end{array}$ \\
\hline Filo & Classe & Espécie & Gene ID & HMMER e- & Hosp. & Hosp. & Contig ou scaffold genômco & Coordenadas \\
\hline
\end{tabular}




\begin{tabular}{lllllll}
\hline & & & value & definitivo & Interm. & do contig ou \\
scaffold
\end{tabular}

Platelm. = Platelminto; Nematelm. = Nematelminto; Hosp. Definitivo = Hospedeiro definitivo; Hosp. Interm. = Hospedeiro intermediário 


\subsection{Comparação dos receptores homólogos dos parasitas com os receptores da família de TNF-alfa humanos}

Existem diversos tipos de receptores de TNF-alfa em humanos, mais de 25 membros que compartilham entre si os domínios ricos em cisteínas (CRD ou TNFR domain) [44]. Estes receptores possuem uma gama distinta de ligantes, não somente o TNF-alfa propriamente dito. O que os define como pertencentes à família dos receptes de TNF-alfa é a presença dos domínios TNFR e a organização modular destes conforme será discutido mais adiante.

A fim de avaliar o nível de identidade e similaridade entre as sequências dos receptores de TNF-alfa de helmintos com os receptores da família de TNF-alfa humanos foi realizado um BLASTp com as 47 sequências de todos os receptores de helmintos contra 25 sequências de receptores humanos. Estas análises foram feitas em colaboração com a Dra. Ana Carolina Tahira do Instituto de Psiquiatria da Universidade de São Paulo.

Os resultados obtidos com as 1132 combinações de alinhamento estão sumarizados na Tabela Suplementar 1, disponível no CD anexo a esta dissertação. Para a fácil visualização de todos os resultados dos alinhamentos por BLAST foram geradas matrizes nas quais o parâmetro e resultado de cada combinação foi preenchido com cores distintas e intensidades proporcionais, respectivamente.

A Figura 11 mostra a matriz dos valores de E-value transformados em logaritmo ($\log _{10} E$-value); isto permite a fácil visualização do resultado: quanto menor o valor de $E$ value, maior a intensidade e a área preenchida com a cor preta.

A Figura 12 mostra a matriz do score dos alinhamentos entre as sequências dos homólogos dos helmintos e os receptores da família de TNF-alfa humanos e, de maneira semelhante, as Figura 3 e Figura 4 mostram a porcentagem de identidade e similaridade dos alinhamentos respectivamente. Por fim, a Figura mostra a matriz das coberturas dos homólogos dos helmintos em relação aos receptores humanos.

É possível observar que, em geral, os homólogos dos receptores de helmintos têm melhor E-value e Score com o receptor de NGF humano e o segundo melhor E-value e Score é com o receptor de TNF tipo 2 (TNFR1B) o qual se liga realmente TNF-alfa. 


\section{E-value}

TNFR Hymenolepis diminuta TNFR Trichinella nelsoni TO7 5892.2 TNFR Trichinella murrelli TO5 $\overline{1} 4779.1$ TNFR_Trichinella_murrelli_TO5_14779.2 TMFR Trichine $\bar{l}$ a nativa

TNFR Trichinella patagoniensis T12 91301 TNFR_Trichinella_patagoniensis_T12_9130.2 TNFR_Trichinella_spiralis TNFR Trichinella britovi TO3 11861.1 TNFR Trichinella pseudospiralis TNFR_Echinococcus_granulosus TNFR_Trichuris_muris TNFT_Trichuris_suis TNFR Gyrodactylus salaris TNFR-Opisthorchis viverrini TNFR Hymenolepis nana TNFR__Mesocestoides_corti TNFR Hydatigera taenjaeformis TNFR Schistosoma mansoni TNFR_Soboliphyme_baturini_SBAD_000̄0868101 TNFR__Schistosoma_margrebowiei TNFR Trichuris trichiura TNFR_Clonorchis_sinensis TNNF_Taenia_solium TNFR_Trichinella nelsoni_TO7_5892.1

TNFR Echinococcus multilocularis TNFR_Hymenolepis_microstoma TNFR_Romanomermis_culicivorax_nRc.2.0.1.t36941 TNFR Taenia_asiatica TNFR_Romanomermis_culicivorax_nRc.2.0.1.t36199 $T N \bar{F}$ _Echinococcus_canadensis TNFR Trichinella_papuae

TNFR Trichinella zimbabwensis TNFR_Schistosoma japonicum TNFR_Trichinella_britovi_T03_11861.2 TNFR Tíchobi Wharzia regent

TNFR Schistosoma haematobium TNFR_Schistosoma_matthee TNFR_Haemonchus_contortus TNFR_Panagrellus redivivus
TNFR_Soboliphyme baturini SBAD 0000418301 TNFR_Heligmosomoides_polygyrus
TNFR_Ascaris surum TNFR_Ascaris_lumbricoides TNFR_Macrostomum_lignano

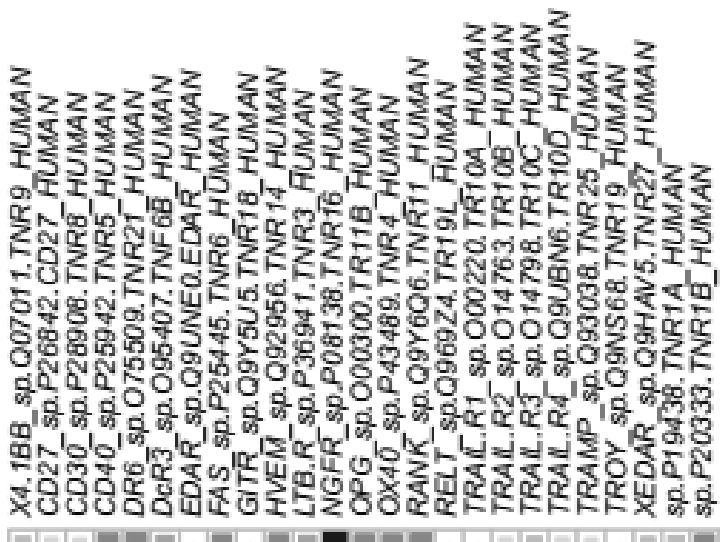

33.1

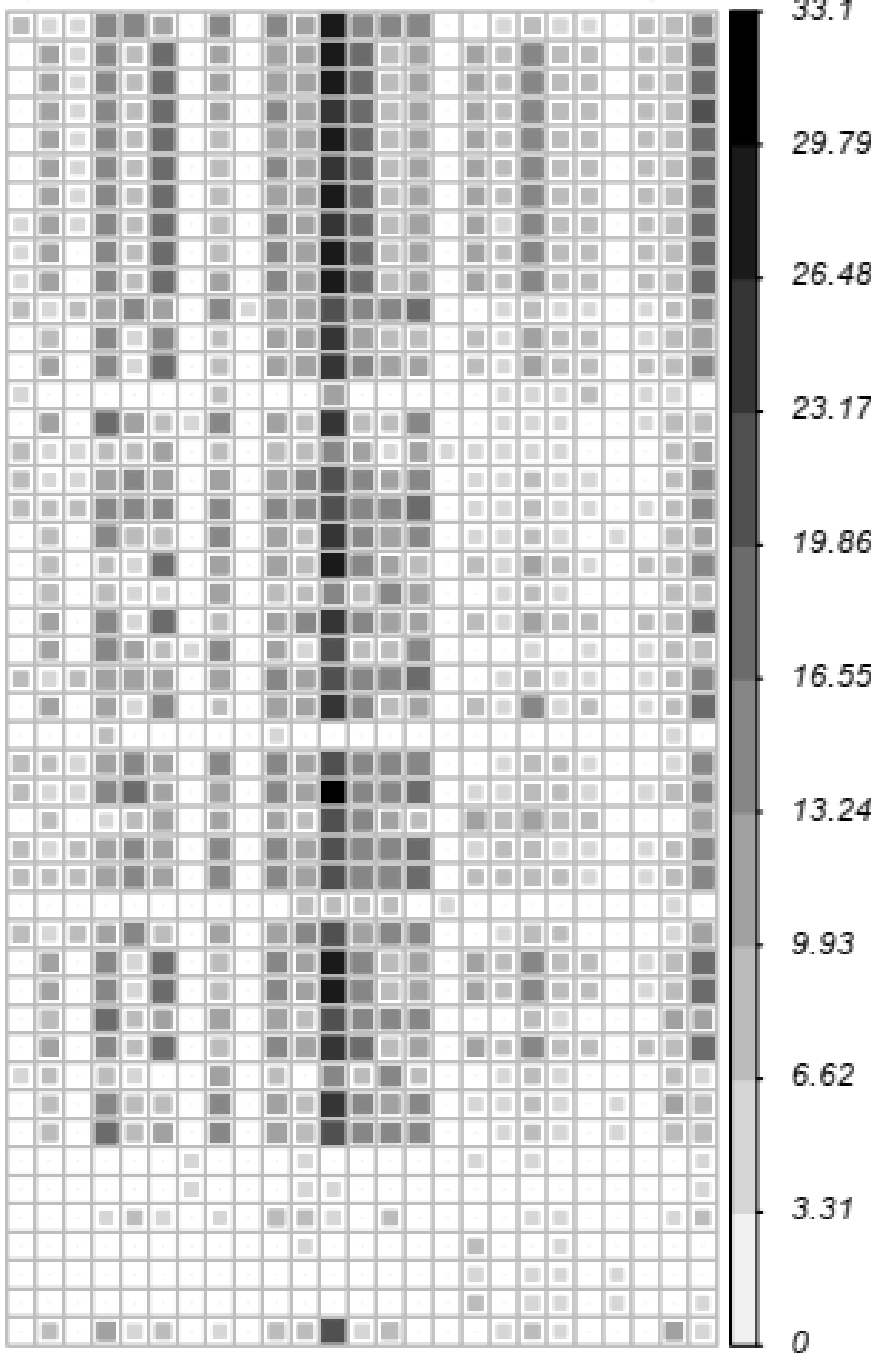

Figura 11. Matriz de comparação dos E-values dos alinhamentos feitos por BLASTp entre os homólogos de receptores de TNF de helmintos e os receptores de TNF humanos. Nas linhas estão identificados os homólogos de TNFR dos helmintos e nas colunas estão identificados 25 membros da família dos receptores de TNF-alfa humanos. Quanto maior a intensidade e a área preenchida com preta menor o valor de E-value, à direita encontra-se uma escala de cor aplicada aos valores - $\log _{10} \mathrm{E}$-value. 


\section{Bit score}
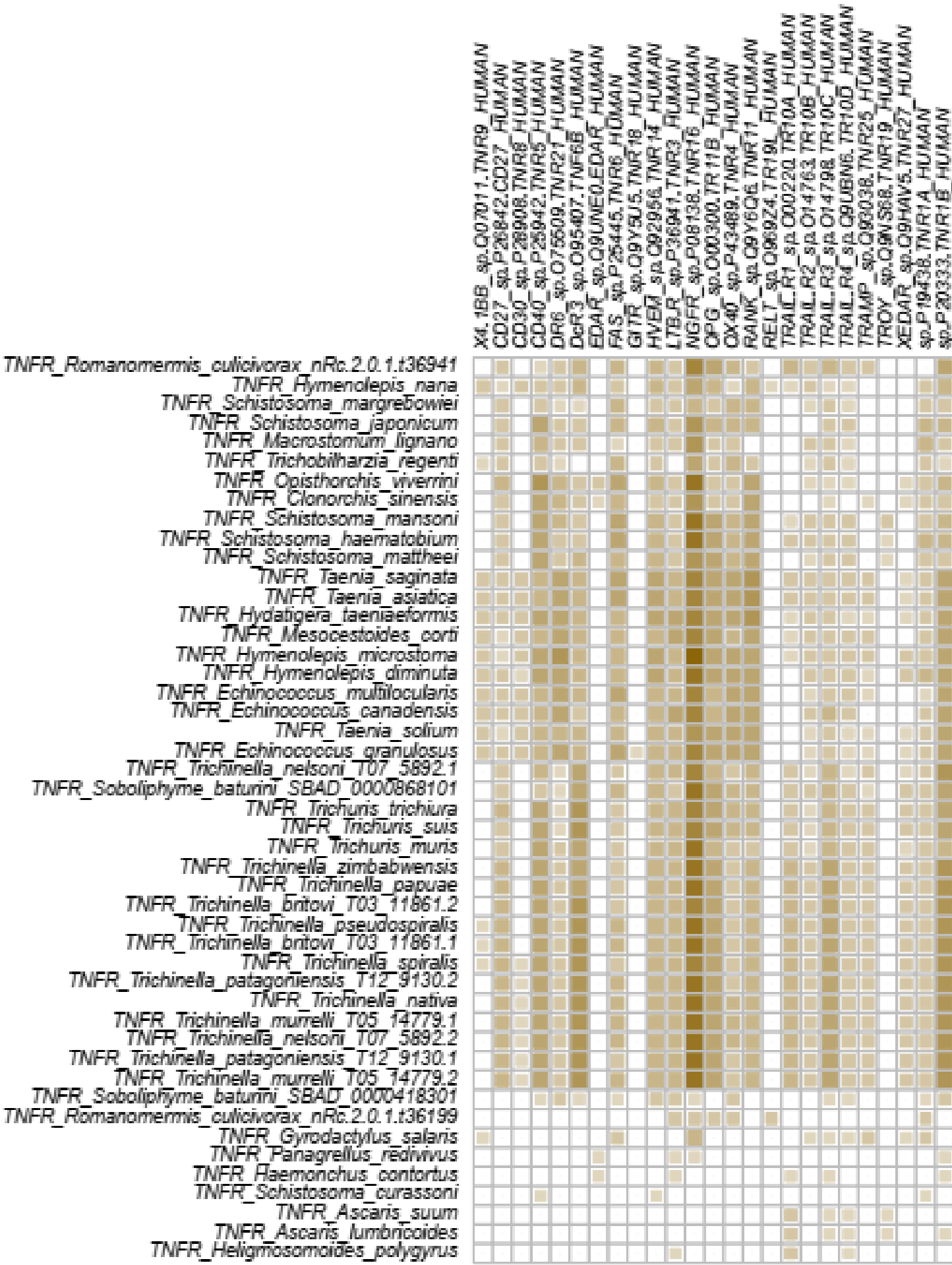

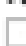

107.1

95.2

83.3

71.4

59.5

47.6

35.7

23.8

11.9

Figura 12. Matriz de comparação dos Scores dos alinhamentos obtidos por BLASTp entre os homólogos dos receptores de TNF de helmintos e os receptores de TNF-alfa humano. Nas linhas estão identificados os homólogos de TNFR dos helmintos e nas colunas estão identificados 25 membros da família dos receptores de TNF-alfa humanos. Quanto maior a intensidade e a área preenchida com marrom maior o valor do Score, à direita encontra-se uma escala de cor aplicada aos valores de Score dos alinhamentos. 


\section{Porcentagem de Identidade}

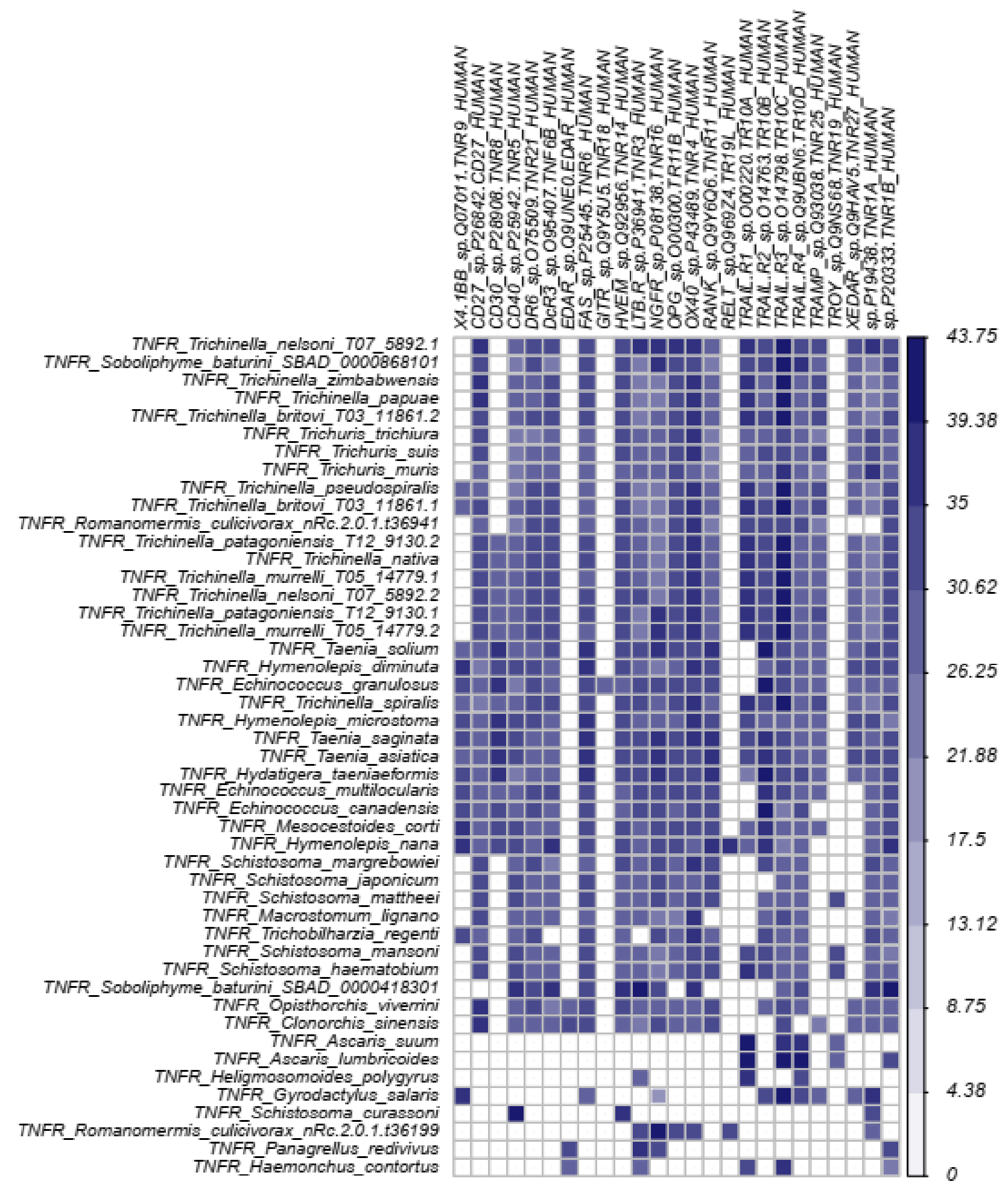

Figura 13. Matriz de comparação da porcentagem de identidades dos alinhamos feitos por BLASTp entre os receptores de helmintos homólogos aos receptores de TNF e os receptores de TNF-alfa humanos. Nas linhas estão identificados os homólogos de TNFR dos helmintos e nas colunas estão identificados 25 membros da família dos receptores de TNF-alfa humanos. Quanto maior a intensidade e a área preenchida com azul maior a porcentagem de identidade dos alinhamentos; à direita encontra-se uma escala de cor aplicada as porcentagens de identidades dos alinhamentos. 


\section{Porcentagem de Similaridade}

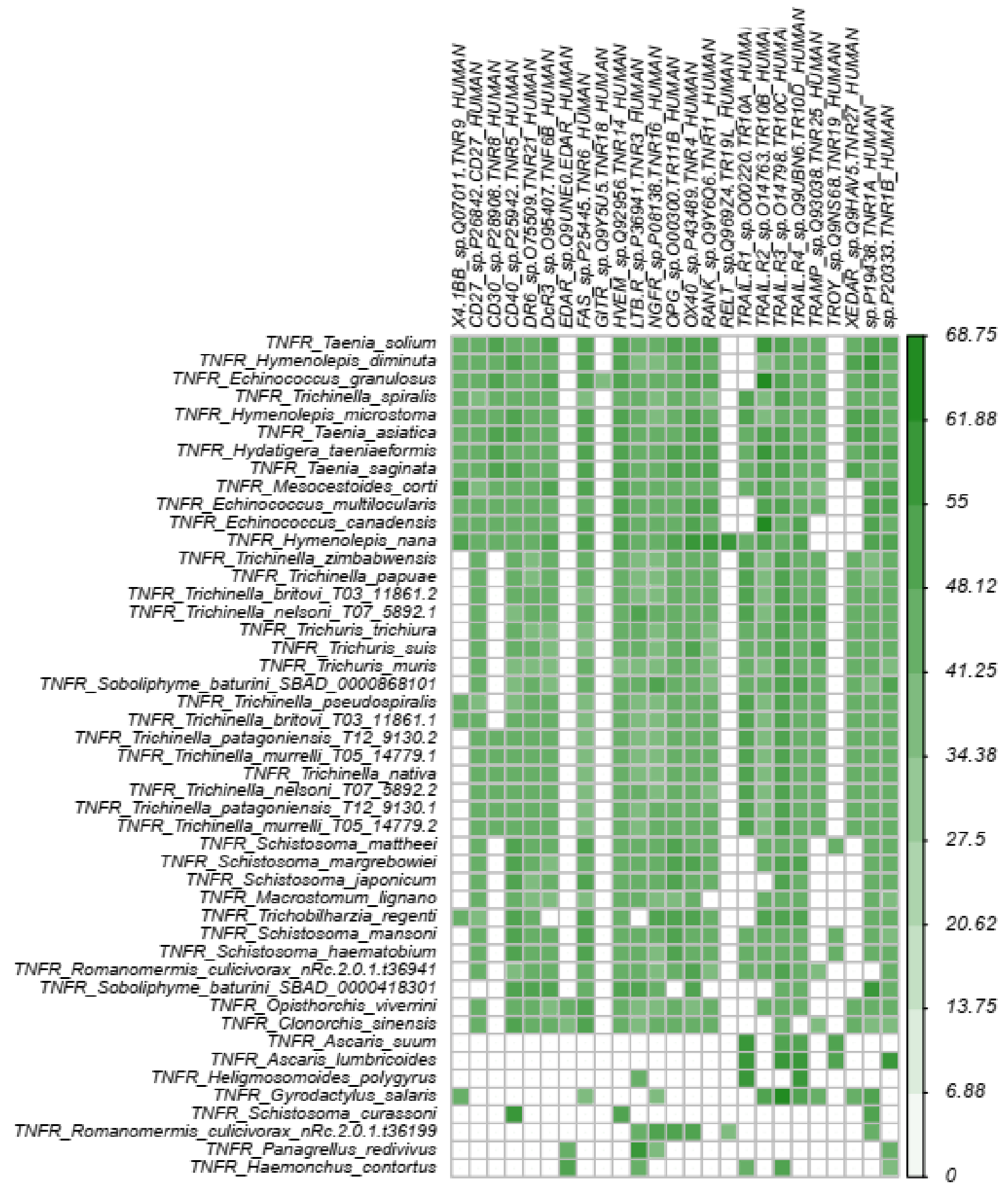

Figura 14. Matriz de comparação da porcentagem de similaridade dos alinhamentos feitos por BLASTp entre os receptores de helmintos homólogos aos receptores de TNF e os receptores de TNF-alfa humanos. Nas linhas estão identificados os homólogos de TNFR dos helmintos e nas colunas estão identificados 25 membros da família dos receptores de TNF-alfa humanos. Quanto maior a intensidade e a área preenchida com verde maior a porcentagem de similaridade dos alinhamentos; à direita encontra-se uma escala de cor aplicada as porcentagens de identidades dos alinhamentos. 


\section{\% Cobertura do homólogo humano pelo homólogo do helminto}

TNFR Trichinella nelsoni_TO7 5892. TNFR Romanomermis culicivorax RRC.20.1. 36941 $T N \bar{F} R \_$Hymenōepis_microstoma TNFR_Hymenolepis_diminuta TNFR Schistosoma matthee TNFR S̄chistosoma japonicum TNFP_Schistosoma_manson TNFR Schistosoma haematobium TNFR Macrostomum lignano TNFR Echinococcus multīocularis TNFR_Echinococcus_canadensis TNFR_Mesocestoides_corti TNFR Taenia saginata TNF $\bar{R}$ Taenia asiatica TNFR_Hydatigera_taeniaeformis
TNFR_Taenia_solium

TNFR Echinococcus grañulosus

TNFR_Šchistosoma_margrebowiej TNFR_Hymenolepis_nana TNFR Trichobilharzia regent TNFR Soboliphyme baturini SBAD $000 \overline{0} 418301$ TNFR_Trichuris_trichiura $T \bar{N} F R$ Trichuris_suis
TNFR Trichuris muris

TNFR Soboliphyme baturini SBĀD $0000 \overline{8} 6810$ TNFR Trichinel/a patagóniensis T12 9130 . TNFR Trichinella murrelli TO5 $\overline{1}$ 14779.2 TNF $\bar{R}$ Trichineli $\bar{a}$ britovi TO3 11861.2 TNFR_Opisthorchis_vivernin TNF $\bar{R}$ Clonorchis_sinensis TNFR_Trichinella_pseudospiralis TNFR Trichinella britovi TO3 11861.1 TNFR Trichinella spiralis TNFR_Trichinella_patagoniensis_T12_9130.2 TNFR_Trichinella_nativa

TNFR_Trichinella murrelli TO5 14779 .

TNFR Trichinelli nelsoni TO $\overline{7} 5892.2$

TNFR_Trichinella_zimbabuwensis TNFR_Trichinella_papuae TNFR Heligmosomoides polygyrus TNFR Haemonchus contortus TNFR_Panagrellus_redivivus TNFR_Ascaris_suum TNFR Ascaris lumbricoides TNFR Schistosoma curassonj TNFR_Romanomermis_culicivorax_nRc.2.0.1.t36199 TNFR_Gyrodactylus_salaris
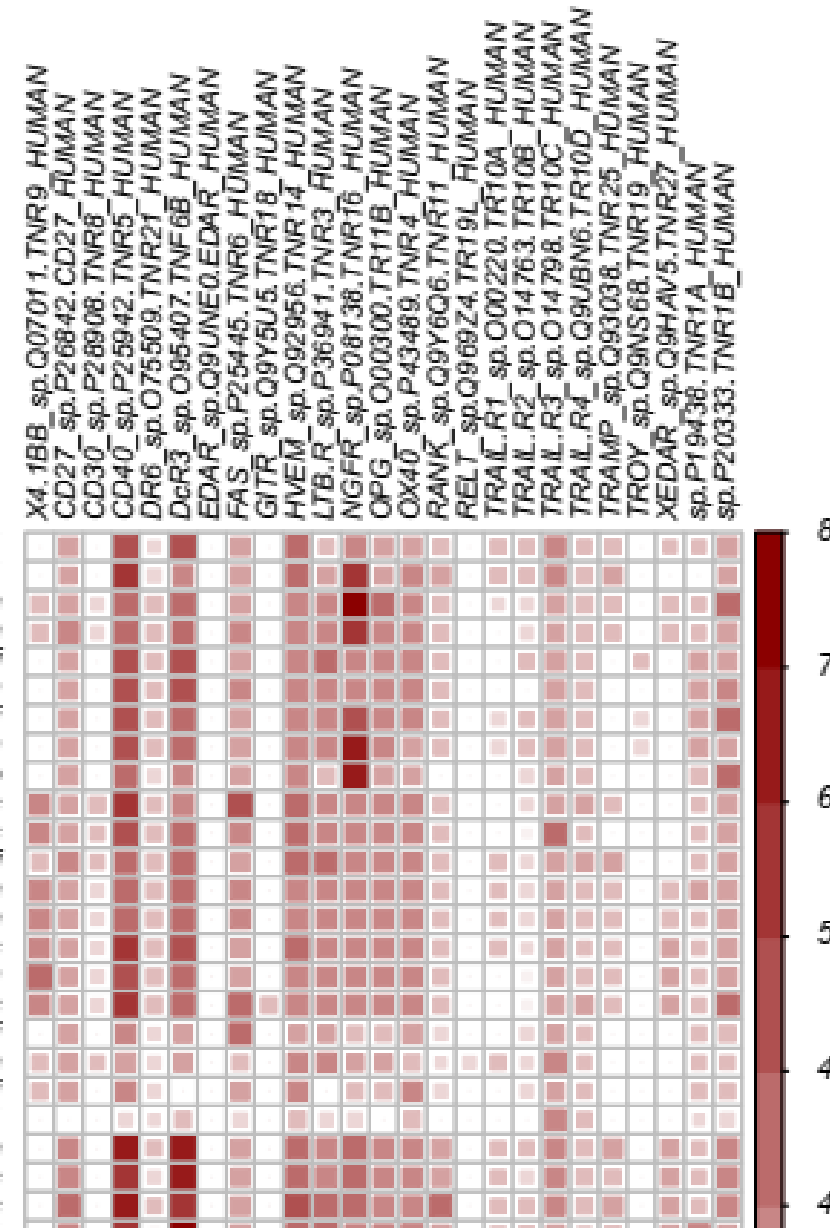

Figura 15. Matriz de comparação da porcentagem de cobertura dos alinhamentos feitos por BLASTp entre os receptores de helmintos homólogos aos receptores de TNF e os receptores de TNF-alfa humanos. Nas linhas estão identificados os homólogos de TNFR dos helmintos e nas colunas estão identificados 25 membros da família dos receptores de TNF-alfa humanos. Quanto maior a intensidade e a área preenchida com vermelho maior a porcentagem de cobertura dos alinhamentos; à direita encontra-se uma escala de cor aplicada as porcentagens de cobertura dos alinhamentos. 
Ao analisarmos a porcentagem de identidade e similaridade entre os receptores dos helmintos e humanos, é possível observar que estas taxas são próximas e não muito altas (entre 22 e $40 \%$ de identidade e entre 30 e 60\% de similaridade) entre todos os homólogos de helmintos e os humanos. Destaca-se as maiores identidades e similaridades TRAIL-R4 (especialmente nematelmintos) e TNFR4. A taxa de identidade é um critério especialmente importante para abordagens de modelagem molecular comparativa in silico, como será apresentado e discutido adiante.

Por fim observamos que as melhores taxas de cobertura dos homólogos humanos pelos homólogos dos parasitas são para TNFR5, TNFR6B e NGFR. Novamente destacamos que todos estes dados em detalhe estão disponíveis na Tabela Suplementar 1, nos anexos desta dissertação.

\subsection{Identificação e alinhamento dos domínios conservados nos homólogos de SmTNFR}

A fim de caracterizar os domínios conservados nas sequências de proteína dos homólogos foi realizada uma busca utilizando os bancos de dados SMART-PRO, Pfam, Prosite, Interprot. Além disso, foi realizada uma busca com HMMER utilizando os domínios TNFR dos helmintos encontrados para gerar novos HMM a fim de buscar domínios ricos em cisteína que eventualmente fossem menos conservados, conforme mencionado em materiais e métodos.

Para melhor caracterização dos receptores foi realizada uma busca de domínios transmembrana utilizando os programas TMHMM e TMPred e o programa SignallP nos permitiu identificar os peptídeos sinal e os pontos de clivagem das sequências. A Figura 2 ilustra um resultado representativo que foi obtido pelo programa TMHMM e Signal IP. 
A)

SignalP.5.50 prediction (Eukarya): Sequence

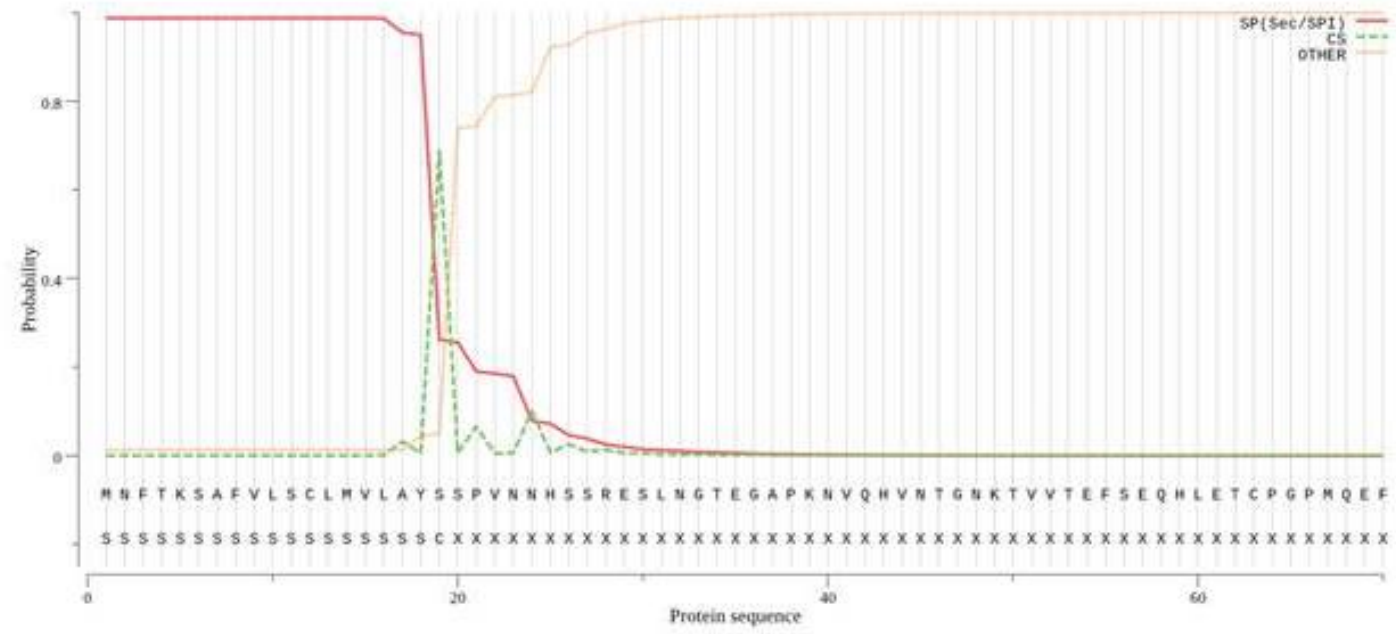

B)

TMHMM posterior probabilities for WEBSEQUENCE

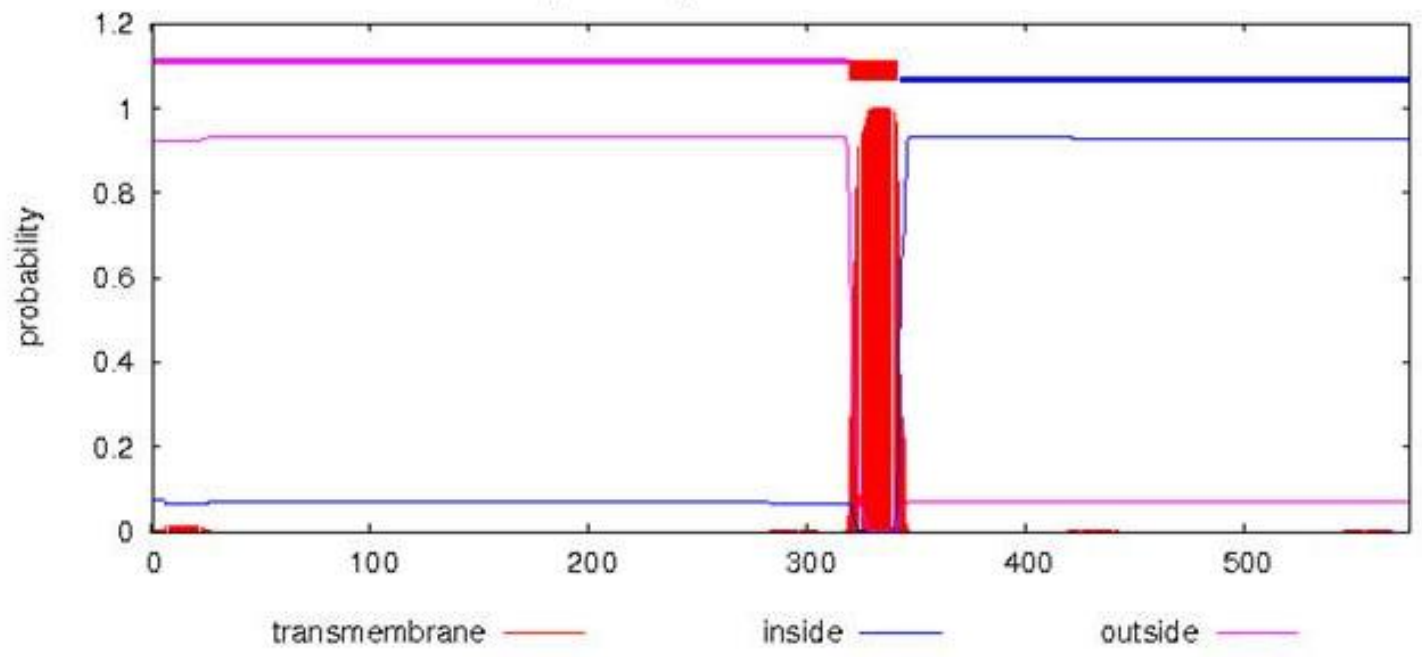

Figura 26 - Representação gráfica dos resultados dos programas para análise de Peptídeo Sinal (Signal IP em A) e Domínios Transmembranas (TMHMM em B).

Os resultados obtidos com estas abordagens de busca são mostrados na Tabela $\mathbf{3}$, nela é possível identificar os elementos conservados que foram reconhecidos nos homólogos do receptor de TNF-alfa em helmintos. Como é esperado para receptores de TNF foram encontrados quatro domínios de TNFR, ou CRD (Cistein Rich Domains) na maioria dos homólogos (33 dos 47 homólogos), também foram encontrados domínios transmembrana e sítios de clivagem de peptídeo sinal e, em três homólogos ( $H$. nana, $M$. lignano e R. culiciforax 36941) foram encontrados Death Domain (Domínio de Morte), característicos de serem presentes na porção intracelular do receptor de TNF tipo 1 e receptor de NGF (Neural Grow Factor) [44]. 
Tabela 3. Domínios conservados nos homólogos de SmTNFR de helmintos

\begin{tabular}{|c|c|c|c|c|c|c|c|c|c|c|c|c|c|c|c|c|}
\hline Organismo & Gene ID & $\begin{array}{c}\# \\
\text { AA }\end{array}$ & $\begin{array}{c}\text { DT } \\
\text { NH3 }\end{array}$ & $\begin{array}{c}\text { DT } \\
\text { NH3 } \\
\text { Coord. }\end{array}$ & $\begin{array}{l}\text { Pept. } \\
\text { Sinal }\end{array}$ & Prob. & $\begin{array}{c}\text { Sítio } \\
\text { Clivag. }\end{array}$ & $\begin{array}{l}\text { \# D. } \\
\text { TNFR }\end{array}$ & $\begin{array}{c}\text { D1 } \\
\text { Coord. }\end{array}$ & $\begin{array}{c}\text { D2 } \\
\text { Coord. }\end{array}$ & $\begin{array}{c}\text { D3 } \\
\text { Coord. }\end{array}$ & $\begin{array}{c}\text { D4 } \\
\text { Coord. }\end{array}$ & $\begin{array}{c}\text { DT } \\
\mathrm{COOH}\end{array}$ & $\begin{array}{c}\text { DT } \\
\text { COOH } \\
\text { Coord. }\end{array}$ & D.D. & $\begin{array}{c}\text { DD } \\
\text { Coord. }\end{array}$ \\
\hline A. lumbricoides & ALUE_0000490301 & 164 & Não & & Não & & & 1 & $41-79$ & & & & Não & & & \\
\hline A. suum & GS_0 5866 & 305 & Sim & $1-27$ & Não & & & 1 & $\begin{array}{l}100- \\
137\end{array}$ & & & & Sim & $\begin{array}{l}227- \\
249\end{array}$ & & \\
\hline C. sinensis & $\operatorname{csin} 103507$ & 281 & Sim & $6-27$ & Sim & 0.72 & $24-25$ & 4 & 68-107 & $\begin{array}{l}110- \\
153\end{array}$ & $\begin{array}{l}155- \\
192\end{array}$ & $\begin{array}{l}195- \\
234\end{array}$ & & & & \\
\hline E. canadensis & EcG7_03322 & 753 & Sim & $42-64$ & Não & & & 4 & 63-102 & $\begin{array}{l}105- \\
150\end{array}$ & $\begin{array}{l}152- \\
190\end{array}$ & $\begin{array}{l}193- \\
232\end{array}$ & Sim & $\begin{array}{l}479- \\
501\end{array}$ & & \\
\hline E. granulosus & EgrG_000990500 & 244 & Sim & $1-18$ & Sim & 0.89 & $18-19$ & 4 & $40-79$ & $82-125$ & $\begin{array}{l}127- \\
164\end{array}$ & $\begin{array}{l}167- \\
206\end{array}$ & Sim & $\begin{array}{l}228- \\
244\end{array}$ & & \\
\hline E. multilocularis & EmuJ_000990500.1 & 244 & Sim & $2-18$ & Sim & 0.91 & $18-19$ & 4 & $40-79$ & $82-125$ & $\begin{array}{l}127- \\
164\end{array}$ & $\begin{array}{l}167- \\
206\end{array}$ & & & & \\
\hline G. salaris & scf7180006950899 & 367 & Não & & Não & & & 4 & $1-13$ & $16-43$ & $88-127$ & $\begin{array}{l}130- \\
171\end{array}$ & Sim & $\begin{array}{l}211- \\
233\end{array}$ & & \\
\hline H. contortus & HCOI_01488400 & 295 & Sim & $1-17$ & Sim & 0.94 & $19-20$ & 1 & $29-67$ & & & & & & & \\
\hline H. polygyrus & HPOL_0001721401 & 175 & Sim & $1-22$ & Sim & 0.78 & $21-22$ & 1 & $30-68$ & & & & & & & \\
\hline H. taeniaeformis & TTAC_0000849801 & 248 & Não & & Não & & & 4 & $22-61$ & 64-107 & $\begin{array}{l}109- \\
146\end{array}$ & $\begin{array}{l}149- \\
188\end{array}$ & & & & \\
\hline H. diminuta & HDID_0000395701 & 518 & Sim & $3-23$ & Sim & 0.38 & $25-26$ & 4 & $42-81$ & 84-127 & $\begin{array}{l}129- \\
166\end{array}$ & $\begin{array}{l}169- \\
208\end{array}$ & Sim & $\begin{array}{l}316- \\
338\end{array}$ & & \\
\hline H. microstoma & HmN_000322000.1 & 456 & Sim & $7-29$ & Sim & 0.54 & $25-26$ & 4 & $42-81$ & $84-127$ & $\begin{array}{l}129- \\
166\end{array}$ & $\begin{array}{l}169- \\
208\end{array}$ & Sim & $\begin{array}{l}252- \\
274\end{array}$ & & \\
\hline H. nana & HNAJ_0000370201 & 580 & Não & & Não & & & 3 & $1-41$ & $43-80$ & $83-122$ & & Sim & $\begin{array}{l}360- \\
382\end{array}$ & Sim & $\begin{array}{l}482- \\
549\end{array}$ \\
\hline M. lignano & BOX15_Mlig018038g1 & 513 & Não & & Não & & & 4 & $19-58$ & $61-104$ & $\begin{array}{l}106- \\
144\end{array}$ & $\begin{array}{l}147- \\
190\end{array}$ & Sim & $\begin{array}{l}299- \\
310\end{array}$ & Sim & $\begin{array}{l}373- \\
468\end{array}$ \\
\hline M. corti & MCOS_0000285501 & 820 & Sim & $1-22$ & Sim & 0.79 & $21-22$ & 4 & $\begin{array}{l}196- \\
235\end{array}$ & $\begin{array}{l}238- \\
281\end{array}$ & $\begin{array}{l}283- \\
320\end{array}$ & $\begin{array}{l}323- \\
362\end{array}$ & Sim & $\begin{array}{l}600- \\
622\end{array}$ & & \\
\hline O. viverrini & T265_08108 & 576 & Sim & $1-21$ & Sim & 0.68 & $19-20$ & 4 & $63-102$ & $\begin{array}{l}105- \\
148\end{array}$ & $\begin{array}{l}150- \\
187\end{array}$ & $\begin{array}{l}190- \\
229\end{array}$ & Sim & $\begin{array}{l}320- \\
342\end{array}$ & & \\
\hline P. redivivus & Pan_g18397.t1 & 464 & Sim & $29-47$ & Sim * & 0.89 & $43-44$ & 1 & $68-105$ & & & & Sim & $\begin{array}{l}393- \\
415\end{array}$ & & \\
\hline
\end{tabular}




\begin{tabular}{|c|c|c|c|c|c|c|c|c|c|c|c|c|c|c|c|c|}
\hline Organismo & Gene ID & $\begin{array}{c}\# \\
\text { AA }\end{array}$ & $\begin{array}{c}\text { DT } \\
\text { NH3 }\end{array}$ & $\begin{array}{c}\text { DT } \\
\text { NH3 } \\
\text { Coord. }\end{array}$ & $\begin{array}{l}\text { Pept. } \\
\text { Sinal }\end{array}$ & Prob. & $\begin{array}{c}\text { Sítio } \\
\text { Clivag. }\end{array}$ & $\begin{array}{c}\text { \# D. } \\
\text { TNFR }\end{array}$ & $\begin{array}{c}\text { D1 } \\
\text { Coord. }\end{array}$ & $\begin{array}{c}\text { D2 } \\
\text { Coord. }\end{array}$ & $\begin{array}{c}\text { D3 } \\
\text { Coord. }\end{array}$ & $\begin{array}{c}\text { D4 } \\
\text { Coord. }\end{array}$ & $\begin{array}{c}\text { DT } \\
\text { COOH }\end{array}$ & $\begin{array}{c}\text { DT } \\
\text { COOH } \\
\text { Coord. }\end{array}$ & D.D. & $\begin{array}{c}\text { DD } \\
\text { Coord. }\end{array}$ \\
\hline R. culicivorax & nRc.2.0.1.t36199 & 425 & Sim & $30-47$ & Não & & & 2 & $\begin{array}{l}102- \\
134\end{array}$ & $\begin{array}{l}137- \\
177\end{array}$ & & & Sim & $\begin{array}{l}327- \\
344\end{array}$ & & \\
\hline R. culicivorax & nRc.2.0.1.t36941 & 465 & Sim & $18-36$ & Sim & 0.26 & $35-36$ & 3 & $39-75$ & $78-118$ & $\begin{array}{l}120- \\
158\end{array}$ & & Sim & $\begin{array}{l}209- \\
230\end{array}$ & Sim & $\begin{array}{l}320- \\
434\end{array}$ \\
\hline S. curassoni & SCUD_0002227201 & 96 & Não & & Não & & & 1 & & $13-52$ & & & Sim & $72-94$ & & \\
\hline S. haematobium & MS3_00310 & 553 & Sim & 09-31 & Sim & 0.57 & $25-26$ & 4 & $86-125$ & $\begin{array}{l}128- \\
171\end{array}$ & $\begin{array}{l}173- \\
210\end{array}$ & $\begin{array}{l}213- \\
252\end{array}$ & Sim & $\begin{array}{l}288- \\
310\end{array}$ & & \\
\hline S. japonicum & Sjp_0098810 & 200 & Não & & Não & & & 4 & $7-46$ & $49-92$ & $94-131$ & $\begin{array}{l}134- \\
173\end{array}$ & & & & \\
\hline S. mansoni & ACS92719.1 & 599 & Sim & $27-49$ & $\mathrm{Sim}^{\star}$ & 0.11 & $43-44$ & 4 & $\begin{array}{l}103- \\
142\end{array}$ & $\begin{array}{l}145- \\
188\end{array}$ & $\begin{array}{l}190- \\
227\end{array}$ & $\begin{array}{l}230- \\
269\end{array}$ & Sim & $\begin{array}{l}305- \\
327\end{array}$ & & \\
\hline S. margrebowiei & SMRZ_0001145701 & 192 & Sim & $3-23$ & Não & & & 3 & $78-117$ & $\begin{array}{l}120- \\
163\end{array}$ & $\begin{array}{l}165- \\
192\end{array}$ & & & & & \\
\hline S. mattheei & SMTD_0000023901 & 303 & Sim & $1-27$ & Não & & & 4 & $66-105$ & $\begin{array}{l}108- \\
151\end{array}$ & $\begin{array}{l}153- \\
190\end{array}$ & $\begin{array}{l}193- \\
232\end{array}$ & & & & \\
\hline S. baturini & SBAD_0000418301 & 214 & Não & & Não & & & 2 & $07-52$ & $55-94$ & & & & & & \\
\hline S. baturini & SBAD_0000868101 & 367 & Não & & Não & & & 4 & $9-44$ & $47-87$ & $89-126$ & $\begin{array}{l}129- \\
168\end{array}$ & Sim & $\begin{array}{l}187- \\
209\end{array}$ & & \\
\hline T. asiatica & TASs00007g01877 & 659 & Sim & $26-47$ & Não & & & 4 & $\begin{array}{l}113- \\
152\end{array}$ & $\begin{array}{l}155- \\
198\end{array}$ & $\begin{array}{l}200- \\
237\end{array}$ & $\begin{array}{l}240- \\
279\end{array}$ & $\begin{array}{l}435- \\
457\end{array}$ & $\begin{array}{l}435- \\
457\end{array}$ & & \\
\hline T. saginata & TSAs00042g05847 & 659 & Sim & $26-47$ & Não & & & 4 & $\begin{array}{l}113- \\
152\end{array}$ & $\begin{array}{l}155- \\
198\end{array}$ & $\begin{array}{l}200- \\
237\end{array}$ & $\begin{array}{l}240- \\
279\end{array}$ & Sim & $\begin{array}{l}435- \\
457\end{array}$ & & \\
\hline T. solium & TsM_000678000 & 198 & Não & & Não & & & 4 & $11-50$ & $53-96$ & $98-135$ & $\begin{array}{l}138- \\
177\end{array}$ & & & & \\
\hline T. britovi & T03_11861.1 & 469 & Sim & 23-39 & Não & & & 4 & $\begin{array}{l}104- \\
139\end{array}$ & $\begin{array}{l}142- \\
182\end{array}$ & $\begin{array}{l}184- \\
221\end{array}$ & $\begin{array}{l}224- \\
263\end{array}$ & Sim & $\begin{array}{l}283- \\
305\end{array}$ & & \\
\hline T. britovi & T03_11861.2 & 430 & Sim & 23-39 & Não & & & 4 & $\begin{array}{l}104- \\
139\end{array}$ & $\begin{array}{l}142- \\
182\end{array}$ & $\begin{array}{l}184- \\
221\end{array}$ & $\begin{array}{l}224- \\
263\end{array}$ & Sim & $\begin{array}{l}283- \\
305\end{array}$ & & \\
\hline T. murrelli & T05_14779.1 & 503 & Sim & $9-26$ & Não & & & 4 & $\begin{array}{l}138- \\
173\end{array}$ & $\begin{array}{l}176- \\
216\end{array}$ & $\begin{array}{l}218- \\
255\end{array}$ & $\begin{array}{l}258- \\
297\end{array}$ & Sim & $\begin{array}{l}317- \\
339\end{array}$ & & \\
\hline T. murrelli & T05_14779.2 & 464 & Sim & $9-26$ & Não & & & 4 & $\begin{array}{l}138- \\
173\end{array}$ & $\begin{array}{l}176- \\
216\end{array}$ & $\begin{array}{l}218- \\
255\end{array}$ & $\begin{array}{l}258- \\
297\end{array}$ & Sim & $\begin{array}{l}317- \\
339\end{array}$ & & \\
\hline Organismo & Gene ID & \# & DT & DT & Pept. & Prob. & Sítio & \# D. & D1 & D2 & D3 & D4 & DT & DT & D.D. & DD \\
\hline
\end{tabular}




\begin{tabular}{|c|c|c|c|c|c|c|c|c|c|c|c|c|c|c|c|}
\hline & & AA & NH3 & $\begin{array}{l}\text { NH3 } \\
\text { Coord. }\end{array}$ & Sinal & & Clivag. & TNFR & Coord. & Coord. & Coord. & Coord. & $\mathrm{COOH}$ & $\begin{array}{l}\text { COOH } \\
\text { Coord. }\end{array}$ & Coord. \\
\hline T. nativa & T02_15720.1 & 504 & Sim & $9-26$ & Não & & & 4 & $\begin{array}{l}139- \\
174\end{array}$ & $\begin{array}{l}177- \\
217\end{array}$ & $\begin{array}{l}219- \\
256\end{array}$ & $\begin{array}{l}259- \\
298\end{array}$ & Sim & $\begin{array}{l}318- \\
340\end{array}$ & \\
\hline T. nelsoni & T07_5892.1 & 497 & Sim & $9-26$ & Não & & & 4 & $\begin{array}{l}171- \\
206\end{array}$ & $\begin{array}{l}209- \\
249\end{array}$ & $\begin{array}{l}251- \\
288\end{array}$ & $\begin{array}{l}291- \\
330\end{array}$ & Sim & $\begin{array}{l}350- \\
372\end{array}$ & \\
\hline T. nelsoni & T07_5892.2 & 536 & Sim & $9-26$ & Não & & & 4 & $\begin{array}{l}171- \\
206\end{array}$ & $\begin{array}{l}209- \\
249\end{array}$ & $\begin{array}{l}251- \\
288\end{array}$ & $\begin{array}{l}291- \\
330\end{array}$ & Sim & $\begin{array}{l}350- \\
372\end{array}$ & \\
\hline T. papuae & T10_10435.1 & 408 & Sim & $3-22$ & Sim & 0.86 & $22-23$ & 4 & $42-77$ & $80-120$ & $\begin{array}{l}122- \\
159\end{array}$ & $\begin{array}{l}162- \\
201\end{array}$ & Sim & $\begin{array}{l}221- \\
243\end{array}$ & \\
\hline $\begin{array}{l}\text { T. } \\
\text { patagoniensis }\end{array}$ & T12_9130.1 & 465 & Sim & $9-26$ & Não & & & 4 & $\begin{array}{l}139- \\
174\end{array}$ & $\begin{array}{l}177- \\
217\end{array}$ & $\begin{array}{l}219- \\
256\end{array}$ & $\begin{array}{l}259- \\
298\end{array}$ & Sim & $\begin{array}{l}318- \\
340\end{array}$ & \\
\hline patagoniensis & T12_9130.2 & 504 & Sim & $9-26$ & Não & & & 4 & $\begin{array}{l}139- \\
174\end{array}$ & $\begin{array}{l}177- \\
217\end{array}$ & $\begin{array}{l}219- \\
256\end{array}$ & $\begin{array}{l}259- \\
298\end{array}$ & Sim & $\begin{array}{l}318- \\
340\end{array}$ & \\
\hline $\begin{array}{l}\text { T. } \\
\text { pseudospiralis }\end{array}$ & T4C_4529.1 & 413 & Sim & $12-33$ & Sim & 0.27 & $33-34$ & 4 & $49-84$ & $87-127$ & $\begin{array}{l}129- \\
166\end{array}$ & $\begin{array}{l}169- \\
208\end{array}$ & Sim & $\begin{array}{l}228- \\
250\end{array}$ & \\
\hline T. spiralis & EFV52365 & 349 & Não & & Não & & & 4 & $23-58$ & $61-101$ & $\begin{array}{l}103- \\
140\end{array}$ & $\begin{array}{l}143- \\
182\end{array}$ & Sim & $\begin{array}{l}202- \\
224\end{array}$ & \\
\hline $\begin{array}{l}\text { T. } \\
\text { zimbabwensis }\end{array}$ & T11_2900.1 & 408 & Sim & $1-17$ & Sim & 0.86 & $22-23$ & 4 & $42-77$ & $80-120$ & $\begin{array}{l}122- \\
159\end{array}$ & $\begin{array}{l}162- \\
201\end{array}$ & Sim & $\begin{array}{l}221- \\
243\end{array}$ & \\
\hline T. regenti & TRE_0000228301 & 174 & Não & & Não & & & 3 & $60-99$ & $\begin{array}{l}102- \\
145\end{array}$ & $\begin{array}{l}147- \\
174\end{array}$ & & & & \\
\hline T. muris & TMUE_s0039006400 & 409 & Sim & $4-25$ & Sim & 0.36 & $25-26$ & 4 & $48-83$ & $86-126$ & $\begin{array}{l}128- \\
165\end{array}$ & $\begin{array}{l}168- \\
207\end{array}$ & Sim & $\begin{array}{l}226- \\
248\end{array}$ & \\
\hline T. suis & D918_09580 & 399 & Não & & Não & & & 4 & $38-73$ & $76-116$ & $\begin{array}{l}118- \\
155\end{array}$ & $\begin{array}{l}158- \\
197\end{array}$ & Sim & $\begin{array}{l}216- \\
238\end{array}$ & \\
\hline T. trichiura & TTRE_0000068601 & 372 & Não & & Não & & & 4 & $11-46$ & $49-89$ & $91-128$ & $\begin{array}{l}131- \\
170\end{array}$ & Sim & $\begin{array}{l}189- \\
211\end{array}$ & \\
\hline
\end{tabular}

\# AA= Número de aminoácidos na proteína completa; DT NH3= Domínio transmembrana amino-terminal; DT NH3 Coord.= Coordenadas do domínio transmembrana amino-terminal; Pept. Sinal= Peptídeo Sinal; Prob= Probabilidade do Peptídeo Sinal; \# D. TNFR= Número de domínios de TNFR; Coord Dom TNFR = Coordenadas dos domínios de TNFR na proteína; D1 - D4 Coord. = Coordenadas dos respectivo domínios de TNFR na proteína, Domínio 1, 2, 3 ou 4; DT COOH= Domínio Transmembrana carboxi-terminal; DT COOH Coord. = Coordenada Domínio Transmembrana carboxi-terminal; D. D.= Death Domain (Domínio de Morte); DD Coord. = Coordenada do Death Domain na proteína.

*Peptídeo sinal identificado quando considerado o início da proteína a partir da segunda Metionina. 
A Figura 7 ilustra esquematicamente os resultados apresentados na Tabela 3. A identificação e organização das coordenadas dos elementos conservados encontrados nos homólogos de SmTNFR nos permitem visualizar facilmente a existência de muitos casos de genes incompletos ou erroneamente preditos. Isto se deve, conforme havia sido mencionado anteriormente, à limitações nos programas que fazem as predições gênicas. Podemos citar, por exemplo, de genes incompletos ou erroneamente preditos, os homólogos de $H$. contortus (possui um único domínio TNFR e nenhum domínio transmembrana), $S$. japonicum (não possui domínios transmembrana) e G. salaris (que apresenta domínios truncados e incompletos). Outro fator relevante a ser considerado é a qualidade das montagens (assemblies) dos genomas destes organismos conforme será discutido adiante.

A fim de estudar com maiores detalhes os domínios de TNFR, foi realizado o alinhamento das sequências dos homólogos que possuíam três ou quatro domínios de TNFR (CRD), ou seja, 38 homólogos (cerca de 170 resíduos de aminoácidos) por meio do programa MUSCLE. O resultado obtido é mostrado na Figura 183.

A Figura 4 mostra o mesmo alinhamento com anotações, como nível da qualidade do alinhamento, nível de ocupação de cada posição do alinhamento, nível de conservação nos grupos de platelminto e nematelminto, sequencia consenso de platelmintos e nematelmintos e sequencia consenso geral. 
A. lumbricoides $(N)$

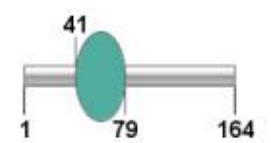

A. suum (N)

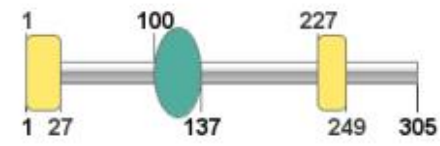

C. sinensis $(P)$

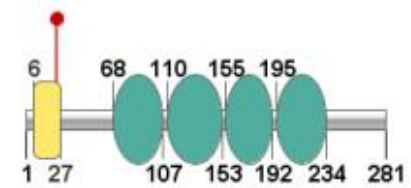

E. canadensis $(P)$

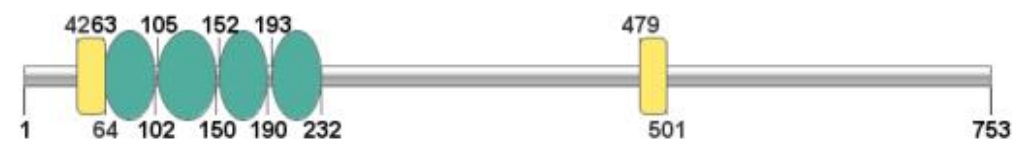

E. granulosus $(P)$

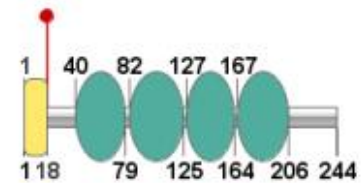

E. multilocularis $(P)$

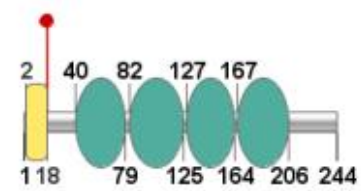

G. salaris $(P)$

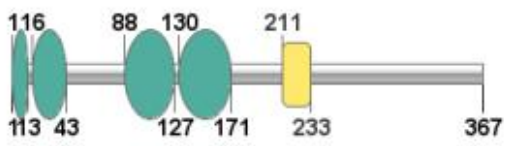

$H$. contortus (N)

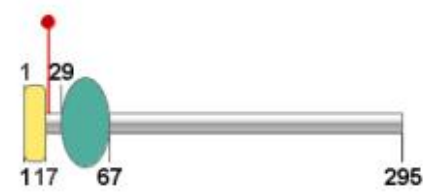


H. polygyrus (N)

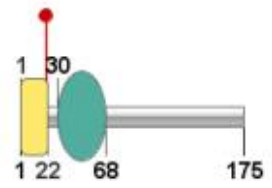

H. taeniaeformis $(P)$

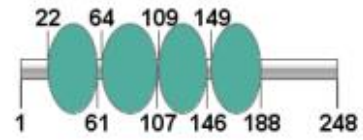

H. diminuta $(P)$

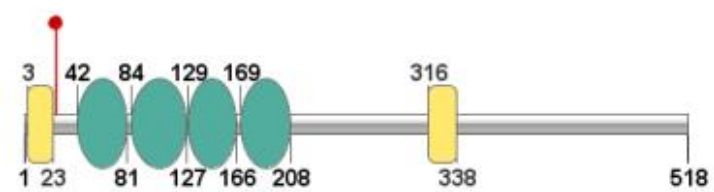

H. microstoma $(P)$

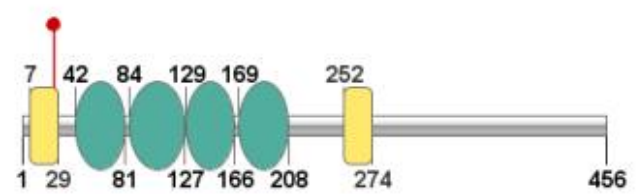

H. nana $(P)$

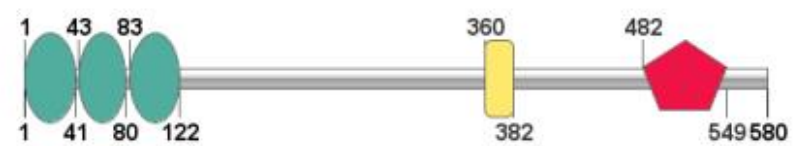

M. lignano $(P)$

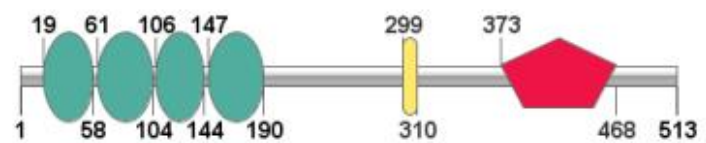

M. $\operatorname{corti}(P)$

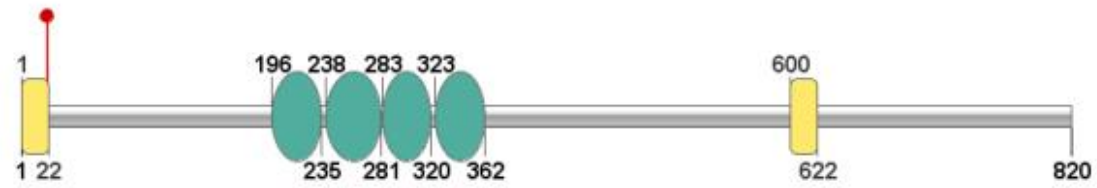

O. viverrini $(P)$

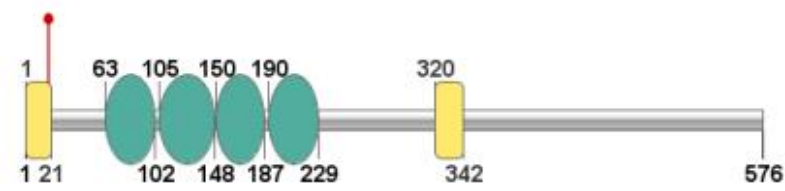


$P$. redivivus (N)

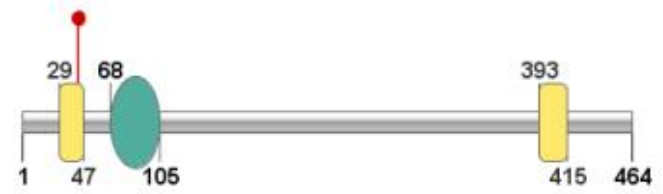

R. culicivorax 36199 (N)

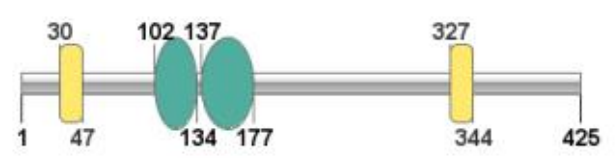

R. culicivorax 36941 (N)

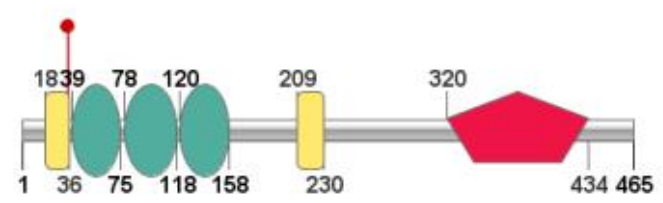

S. curassoni $(P)$

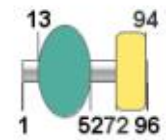

S. haematobium $(P)$

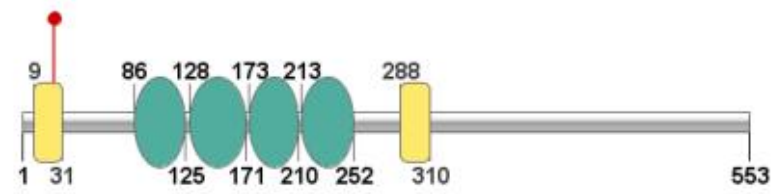

S. japonicum $(P)$

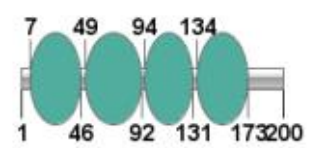

S. mansoni $(P)$

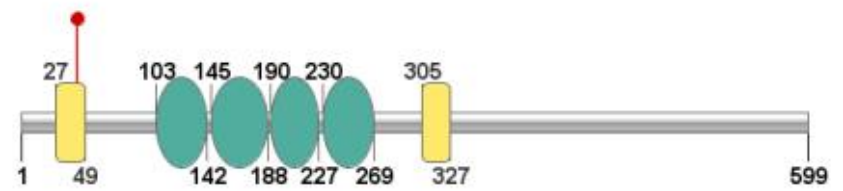

S. margrebowiei $(P)$

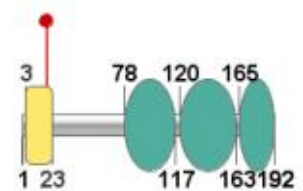


S. mattheei $(P)$

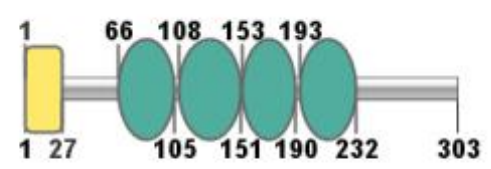

S. baturini $418301(N)$

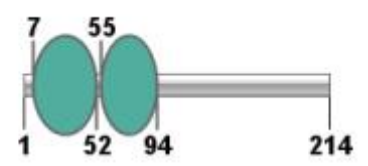

S. baturini 868101 (N)

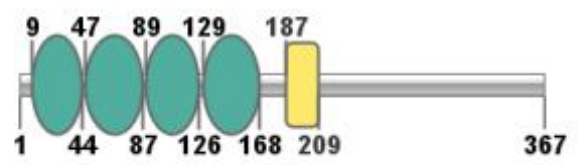

T. asiatica $(P)$

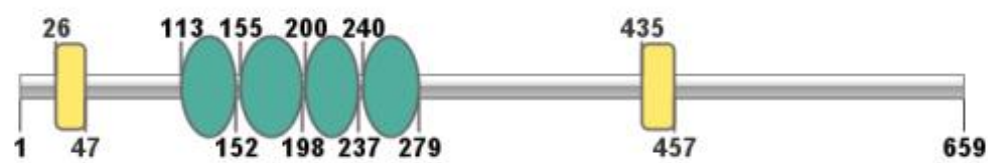

$T$. saginata $(P)$

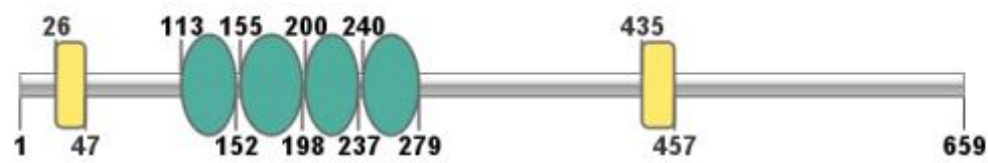

T. solium $(P)$

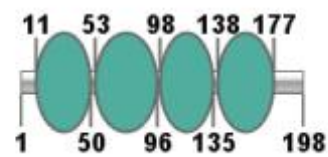

T. britovi .1 (N)

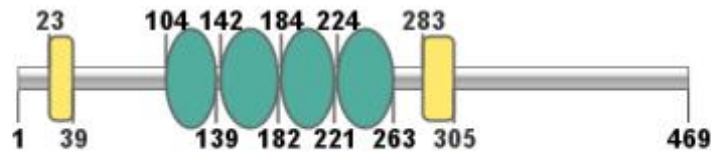

T. britovi $2(N)$

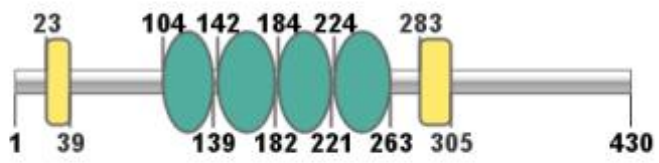


T. murrelli .1 (N)

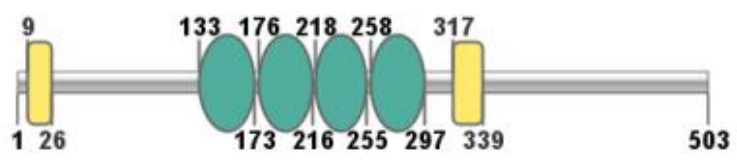

T. murrelli $2(\mathrm{~N})$

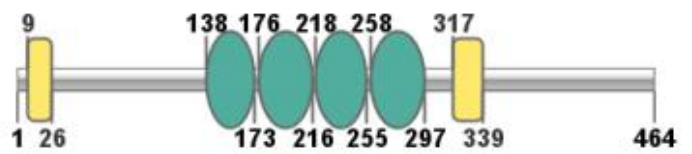

T. nativa (N)

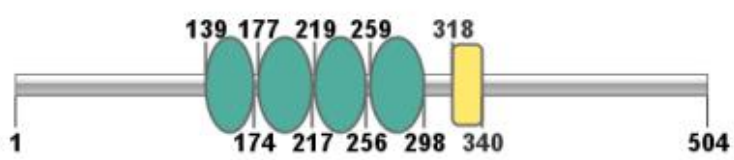

T. nelsoni .1 (N)

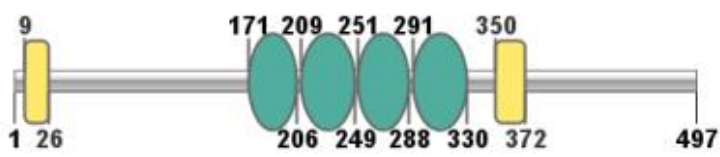

T. nelsoni .2(N)

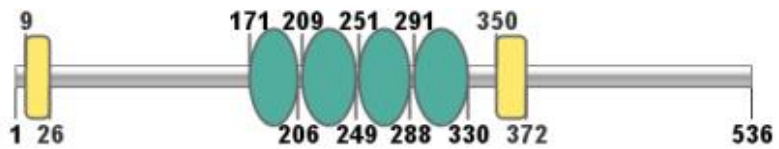

T. papuae (N)

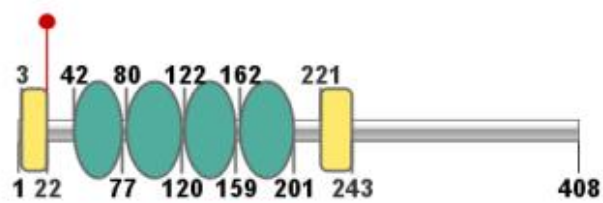

T. patagoniensis .1 (N)

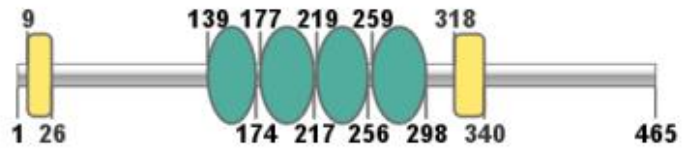

T. patagoniensis $2(N)$

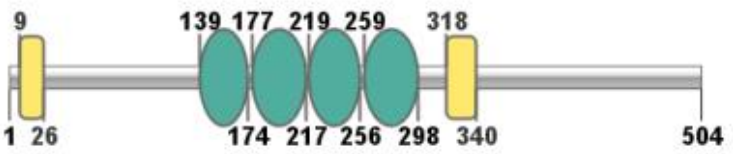


T. pseudospiralis (N)

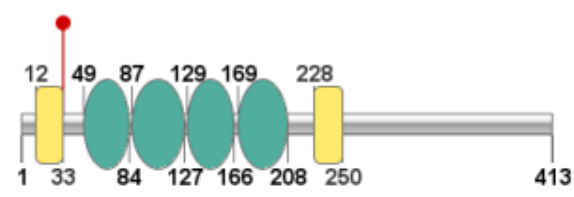

T. spiralis $(N)$

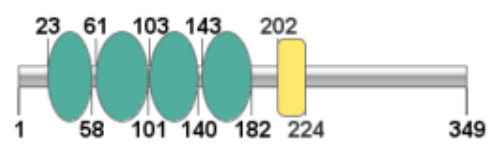

T. zimbabwensis (N)

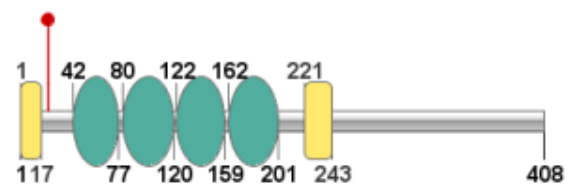

T. regenti $(P)$

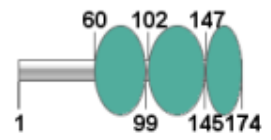

T. muris $(N)$

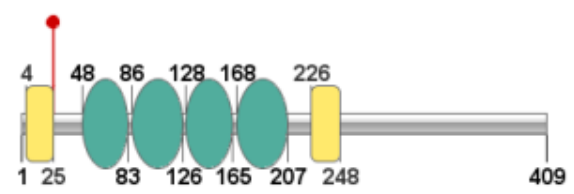

T. suis (N)

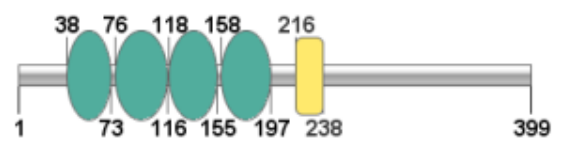

T. trichiura (N)
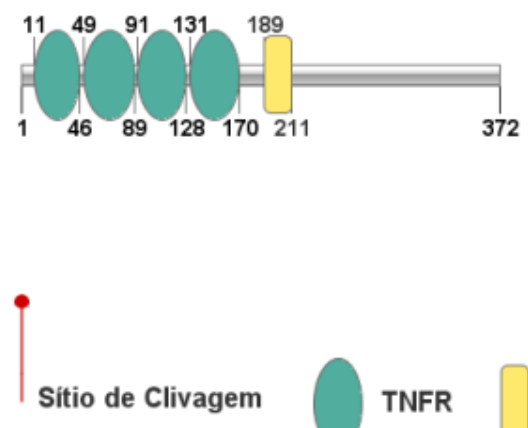

Transmembrana

Figura 17. Representação esquemática dos domínios conservados reconhecidos receptores homólogos ao SmTNFR. As coordenadas de cada domínio ou elemento identificado são indicadas nas bordas das formas geométricas que as representam. Os marcadores vermelhos indicam os sítios de clivagem de peptídeos sinal; os círculos verdes representam os domínios TNFR (CRD), os retângulos amarelos representam as regiões transmembranas, o pentágono vermelho representa o domínio de Morte (Death Domain). O comprimento das linhas e a distância dos elementos representados estão escalonados em cada homólogo. Ao lado do nome do helminto está indicado o filo (N: Nematelminto, P: Platelminto) 


\section{R_culicivorax/1-120 \\ S_baturini/1-160 \\ T_brito vi_1/1-160 \\ T_brito vi_2/1-160 \\ T_murrelli_1/1-160 \\ T_murrelli_2/1-160 \\ T_nativa/1-160 \\ T_nelsoni_2/1-160 \\ T_papuae/1-160 \\ T_patagoniensis_1/1-160 \\ T_patagoniensis_2/1-160 \\ T_spiralis/1-160 \\ T_zimbabwensis/1-160 \\ T_muris/1-160 \\ T_suis/1-160 \\ T_trichiura/1-160 \\ M_lignano/1-172 \\ C_sinensis/1-167 \\ O_vivemini/1-167 \\ S_mansoni/1-167 \\ S_mansoni/1-167 \\ S_mattheei/1-167 \\ S_margrebowiei/1-115 \\ T_regenti/1-115 \\ H_nana/1-125 \\ E_canadensis/1-170 \\ E_canadensis/1-170 \\ T_asiatica/1-167 \\ T-solium/1-167 \\ E_multilocularis/1-167 \\ E_granulosus/1-167 \\ H_taeniaeformis/1-167 \\ H_diminuta/1-167 \\ H_microstoma/1-167}

R_culicivorax/1-120

S_baturini/1-160

T_brito wi_1/1-160

T_britovi_2/1-160

T_murrelli_1/1-160

T_murrelli_2/1-160

T_nativa/ $1-160$

T_nelsoni_1/1-160

T_nelsoni_2/1-160

T_papuae/1-160

T_patagoniensis_1/1-160

T_patagoniensis_2/1-160

T_pseudospiralis/1-1

T_spiralis/1-160

T_zimbabwensis/1-160

T_muris/1-160

T_muris/1-160

T_trichiura/1-160

M_lignano/1-172

C_sinensis/1-167

O_vivermini/1-167

Sjaponicum/1-167

S.maponicum/1-167

S_haematobium/1-167

S_mattheei/1-167

S_margrebowiei/1-115

T_regenti/1-115

H_nana/1-125

M_corti/1-167

E_canadensis/1-170

T_saginata/1-167

T_asiatica/1-167

T_solium/1-167

E_granulosus/1-167

H_taeniaeformis/1-167

H_diminuta/1-167

H_microstoma/1-167

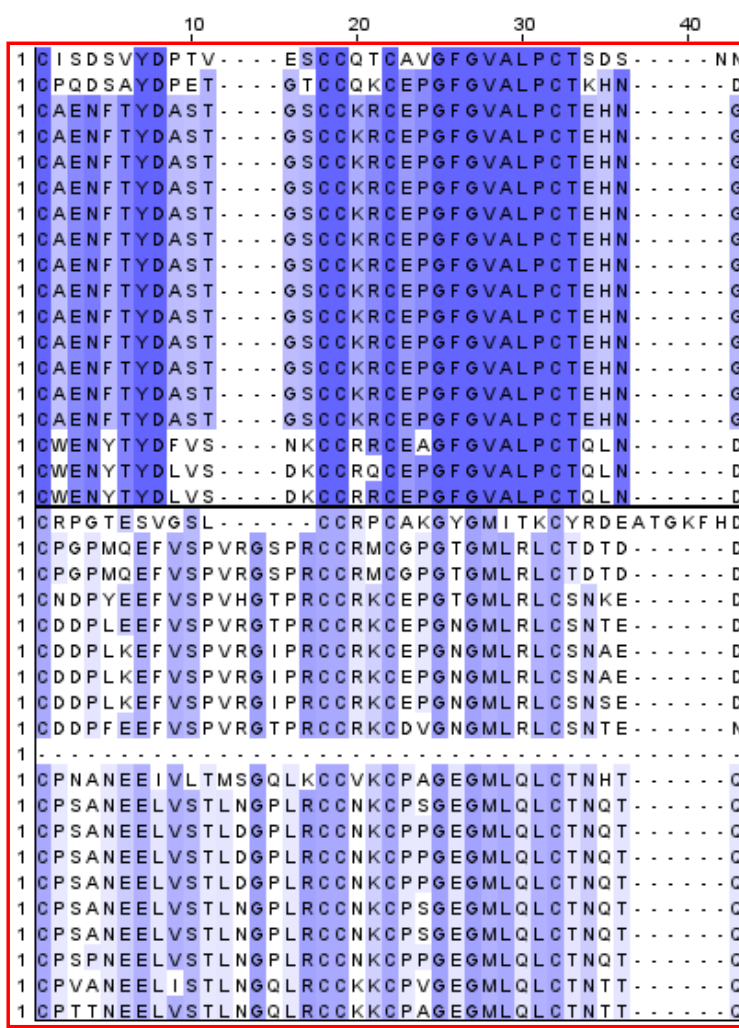

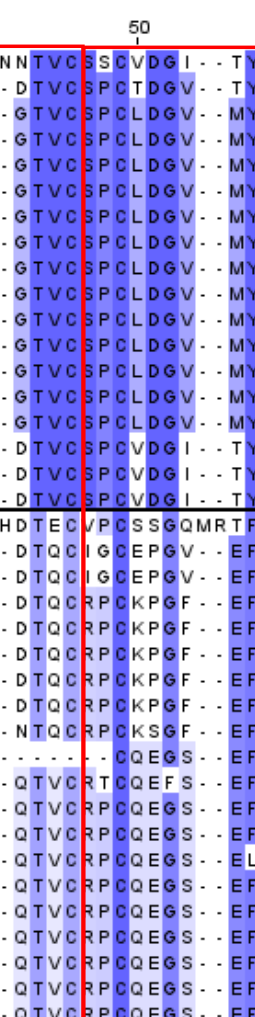

QTVCRPCQEG

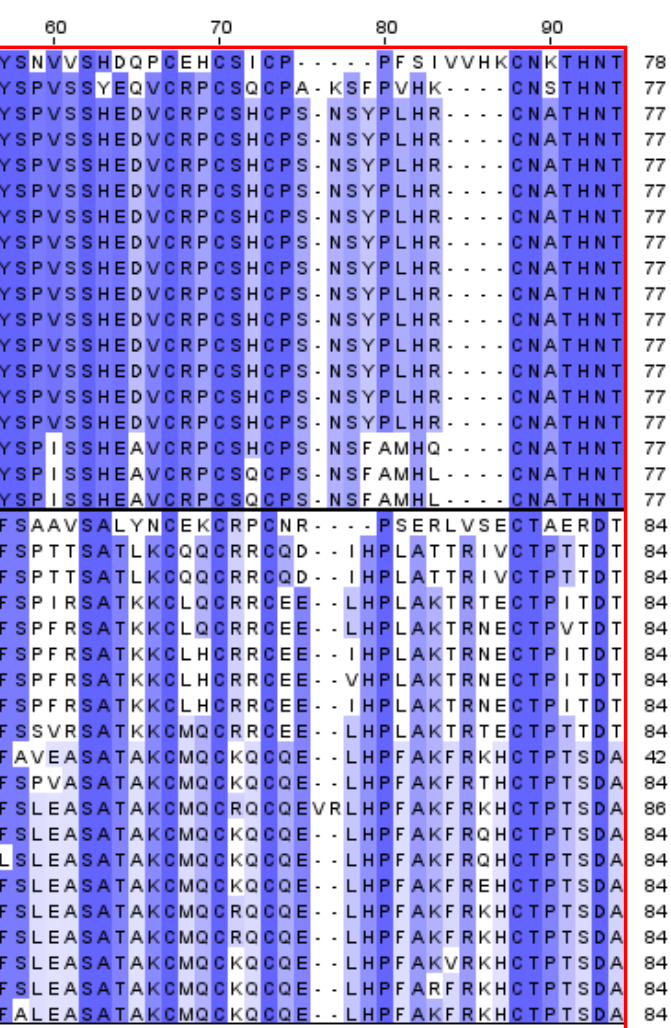

150

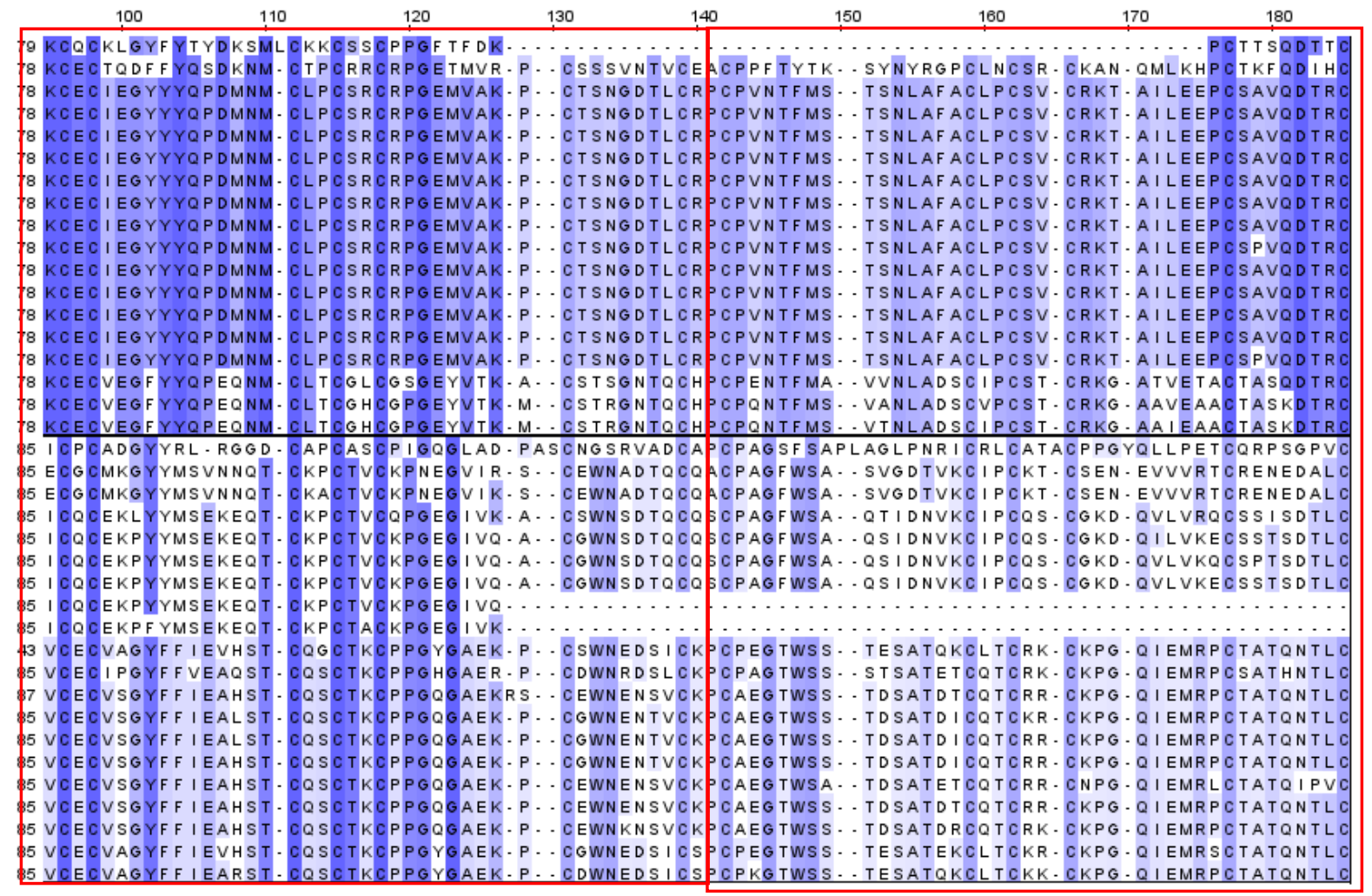

120

160

160
160

160

160

160

160

160

160

160

160

160

160

160

160

Figura 183. Alinhamento dos homólogos de SmTNFR de helmintos que possuem três e quatro domínios de TNFR (CRD) identificados. Alinhamento com 38 sequências somente da região dos domínios conservados (que contém 3 e 4 domínios, cerca de 170 resíduos aminoácidos) usando o algoritmo MUSCLE (programa MEGA 7.0 - JalView). Os resíduos de aminoácidos estão coloridos em tons de roxo conforme o 
nível de identidade. As caixas em vermelho representam os 4 domínios ricos em cisteína. 


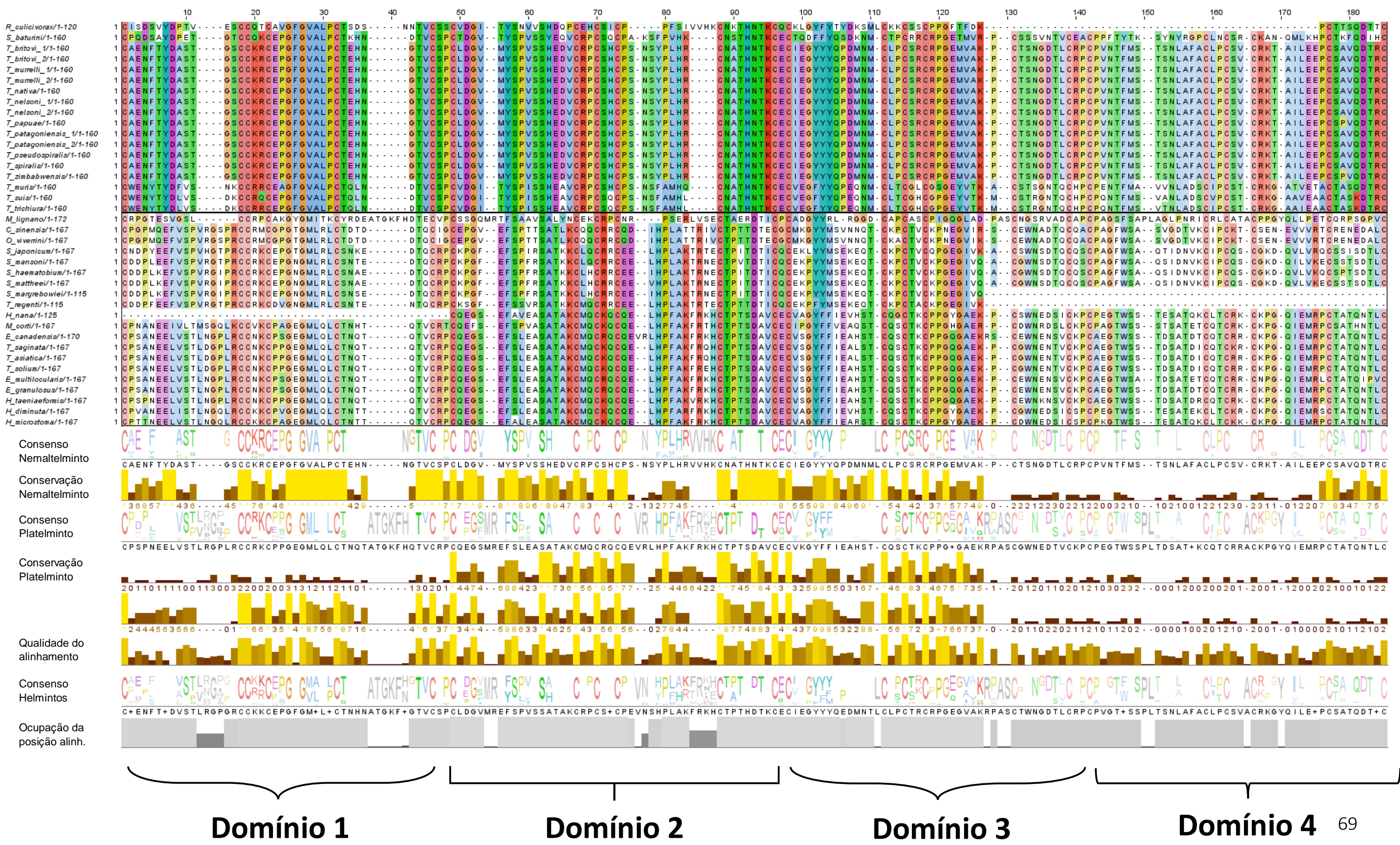


Figura 49. Alinhamento dos homólogos de SmTNFR de helmintos que possuem três e quatro domínios de TNFR (CRD) identificados. Alinhamento com 38 sequências somente da região dos domínios conservados (que contém 3 e 4 domínios, cerca de 170 resíduos aminoácidos) usando o algoritmo MUSCLE (programa MEGA 7.0). Os resíduos de aminoácidos estão coloridos conforme o nível de identidade seguindo o padrão Clustal. Abaixo do alinhamento são mostradas as anotações a respeito da taxa de conservação do alinhamento de platelmintos, nematelmintos e todos os helmintos assim como suas respectivas sequencias consenso. Além disso também é indicado a qualidade do alinhamento e a taxa de ocupação do alinhamento em cada posição. Imagem e anotações do alinhamento gerados pelo programa Jalview.

Primeira observação que é perceptível é o alinhamento e conservação das cisteínas, característica marcante dos domínios de TNFR, ou, Domínios ricos em cisteínas (CRD); é possível notar a grande conservação existente nas cisteínas ao observar a sequência consenso gerada para todo o alinhamento (helmintos). É possível observar inserção de alguns aminoácidos no grupo dos platelmintos (posições 12 a 15; 84 a 87, grupo inferior) em relação aos nematelmintos (grupo superior). Além disso, é possível notar que existe uma maior conservação nos primeiros 130 aminoácidos no grupo dos nematelmintos (grupo superior). Este alinhamento é muito importante pois será a base das análises filogenéticas que serão demonstradas mais adiante.

\subsection{Análise dos módulos dos domínios ricos em cisteínas dos homólogos de SmTNFR}

Um aspecto importante dos receptores da família de TNF é a organização modular (ou de subdomínios) dos CRD (domínios TNFR). Naismith e Sprang [55] propuseram uma classificação dos subdomínios dos CRD baseados no número de pontes dissulfetos e da topologia da estrutura. Essencialmente estes autores propuseram que o receptor de TNF-alfa tipo 1 possui três módulos topológicos: A1, B2 e C2. As letras denotam o tipo de topologia $(A, B$ e $C$ ) e os números descrevem o número de pontes dissulfetos. A maioria dos receptores homólogos ao de TNFR1 consistem uma formação modular composta por módulos A2 e B1, entretanto, os autores também predisseram os módulos A2, C2 e X 0 para outros receptores da família [55].

A fim de prosseguimos com uma análise dos possíveis módulos dos domínios CRD dos homólogos de helmintos utilizamos a ferramenta HMMER. Para a identificação dos módulos dos domínios CRD foi utilizada as sequências dos módulos 
dos CRD dos receptores humanos, já muito bem caracterizados pela literatura [44], para a construção de um HMM para cada módulo (A1, A2, B1, B2, C2, X2, N1). Este HMM foi usado para a busca dos módulos nas sequências de proteínas dos homólogos de SmTNFR dos helmintos. Infelizmente, embora tecnicamente interessante, esta abordagem não resultou na definição clara dos módulos.

Analisando o alinhamento dos domínios TNFR podemos observar que estes são muito semelhantes entre as diferentes espécies (Figuras 18 e 19), assim, realizamos uma busca no Prosite Expasy para a identificação das prováveis pontes dissulfeto que se formam entre as cisteínas presentes em cada domínio. De maneira geral fomos capazes de identificar 3 pontes dissulfetos para cada domínio de TNFR reconhecido. Este resultado está sumarizado na Tabela 4 e indica que, assim como SmTNFR, os módulos que compõem cada domínio são A1, B2.

Com base nestas informações assumimos até o momento que a disposição dos módulos dos receptores dos helmintos seja uma sucessão de módulos A1 e B2 como é o de $S$. mansoni e o receptor de NGF humano (vide Figura 3B na introdução). 
Tabela 4. Número de pontes dissulfetos encontradas em cada domínio TNFR dos homólogos de TNFR

\begin{tabular}{|c|c|c|c|c|c|c|c|c|c|c|c|c|c|c|c|c|c|c|}
\hline Organismo & Gene ID & $\begin{array}{l}\text { \# D. } \\
\text { TNFR }\end{array}$ & $\begin{array}{l}\text { C. } \\
\text { D1 }\end{array}$ & $\begin{array}{l}\text { PD1 } \\
\text { D1 }\end{array}$ & $\begin{array}{l}\text { PD2 } \\
\text { D1 }\end{array}$ & $\begin{array}{l}\text { PD3 } \\
\text { D1 }\end{array}$ & $\begin{array}{l}\text { C. } \\
\text { D2 }\end{array}$ & $\begin{array}{l}\text { PD1 } \\
\text { D2 }\end{array}$ & $\begin{array}{l}\text { PD2 } \\
\text { D2 }\end{array}$ & $\begin{array}{l}\text { PD3 } \\
\text { D2 }\end{array}$ & $\begin{array}{l}\text { C. } \\
\text { D3 }\end{array}$ & $\begin{array}{l}\text { PD1 } \\
\text { D3 }\end{array}$ & $\begin{array}{l}\text { PD2 } \\
\text { D3 }\end{array}$ & $\begin{array}{l}\text { PD3 } \\
\text { D3 }\end{array}$ & $\begin{array}{l}\text { C. } \\
\text { D4 }\end{array}$ & $\begin{array}{l}\text { PD1 } \\
\text { D4 }\end{array}$ & $\begin{array}{l}\text { PD2 } \\
\text { D4 }\end{array}$ & $\begin{array}{l}\text { PD3 } \\
\text { D4 }\end{array}$ \\
\hline A. lumbricoides & ALUE_00004903 & 1 & $\begin{array}{l}41- \\
79\end{array}$ & $41-54$ & $\begin{array}{l}57- \\
70\end{array}$ & $\begin{array}{l}60- \\
78\end{array}$ & & & & & & & & & & & & \\
\hline A. suum & GS_05866 & 1 & $\begin{array}{l}100- \\
137\end{array}$ & $\begin{array}{l}100- \\
113\end{array}$ & $\begin{array}{l}116- \\
129\end{array}$ & $\begin{array}{l}119- \\
137\end{array}$ & & & & & & & & & & & & \\
\hline C. sinensis & $\operatorname{csin} 103507$ & 4 & $\begin{array}{l}68- \\
107\end{array}$ & $68-85$ & $\begin{array}{l}86- \\
99\end{array}$ & $\begin{array}{l}89- \\
107\end{array}$ & $\begin{array}{l}110- \\
153\end{array}$ & $\begin{array}{l}110- \\
126\end{array}$ & $\begin{array}{l}129- \\
145\end{array}$ & $\begin{array}{l}132- \\
153\end{array}$ & $\begin{array}{l}155- \\
192\end{array}$ & $\begin{array}{l}155- \\
168\end{array}$ & $\begin{array}{l}171- \\
184\end{array}$ & $\begin{array}{l}174- \\
192\end{array}$ & $\begin{array}{c}195 \\
- \\
234\end{array}$ & $\begin{array}{l}195- \\
210\end{array}$ & $\begin{array}{l}213- \\
226\end{array}$ & $\begin{array}{l}216- \\
234\end{array}$ \\
\hline E. canadensis & EcG7_03322 & 4 & $\begin{array}{l}63- \\
102\end{array}$ & $63-80$ & $\begin{array}{l}81- \\
94\end{array}$ & $\begin{array}{l}84- \\
102\end{array}$ & $\begin{array}{l}105- \\
150\end{array}$ & $\begin{array}{l}105- \\
121\end{array}$ & $\begin{array}{l}124- \\
142\end{array}$ & $\begin{array}{l}127- \\
150\end{array}$ & $\begin{array}{l}152- \\
190\end{array}$ & $\begin{array}{l}152- \\
165\end{array}$ & $\begin{array}{l}168- \\
182\end{array}$ & $\begin{array}{l}171- \\
190\end{array}$ & $\begin{array}{c}193 \\
- \\
232\end{array}$ & $\begin{array}{l}193- \\
208\end{array}$ & $\begin{array}{l}221- \\
224\end{array}$ & $\begin{array}{l}214- \\
232\end{array}$ \\
\hline E. granulosus & EgrG_000990500 & 4 & $\begin{array}{c}40- \\
79\end{array}$ & $40-57$ & $\begin{array}{l}58- \\
71\end{array}$ & $\begin{array}{l}61- \\
79\end{array}$ & $\begin{array}{l}82- \\
125\end{array}$ & $\begin{array}{l}82- \\
98\end{array}$ & $\begin{array}{l}101- \\
117\end{array}$ & $\begin{array}{l}104- \\
125\end{array}$ & $\begin{array}{l}127- \\
164\end{array}$ & $\begin{array}{l}127- \\
140\end{array}$ & $\begin{array}{l}143- \\
156\end{array}$ & $\begin{array}{l}146- \\
164\end{array}$ & $\begin{array}{c}167 \\
- \\
204\end{array}$ & $\begin{array}{l}167- \\
182\end{array}$ & $\begin{array}{l}185- \\
198\end{array}$ & $\begin{array}{l}188- \\
206\end{array}$ \\
\hline E. multilocularis & $\begin{array}{c}\text { EmuJ_000990500 } \\
.1\end{array}$ & 4 & $\begin{array}{l}40- \\
79\end{array}$ & $40-57$ & $\begin{array}{l}58- \\
71\end{array}$ & $\begin{array}{l}61- \\
79\end{array}$ & $\begin{array}{l}82- \\
125\end{array}$ & $\begin{array}{l}82- \\
98\end{array}$ & $\begin{array}{l}101- \\
117\end{array}$ & $\begin{array}{l}104- \\
125\end{array}$ & $\begin{array}{l}127- \\
164\end{array}$ & $\begin{array}{l}127- \\
140\end{array}$ & $\begin{array}{l}143- \\
156\end{array}$ & $\begin{array}{l}146- \\
164\end{array}$ & $\begin{array}{c}167 \\
- \\
206\end{array}$ & $\begin{array}{l}167- \\
182\end{array}$ & $\begin{array}{l}185- \\
198\end{array}$ & $\begin{array}{l}188- \\
206\end{array}$ \\
\hline G. salaris & $\begin{array}{c}\text { scf718000695089 } \\
9\end{array}$ & 4 & $1-13$ & & & & $\begin{array}{l}16- \\
43\end{array}$ & & & & $\begin{array}{l}88- \\
127\end{array}$ & $\begin{array}{l}88- \\
101\end{array}$ & $\begin{array}{l}104- \\
118\end{array}$ & $\begin{array}{l}107- \\
127\end{array}$ & $\begin{array}{c}130 \\
- \\
171\end{array}$ & $\begin{array}{l}130- \\
147\end{array}$ & $\begin{array}{l}150- \\
163\end{array}$ & $\begin{array}{l}153- \\
171\end{array}$ \\
\hline H. contortus & HCOI_01488400 & 1 & $\begin{array}{l}29- \\
67\end{array}$ & $29-42$ & $\begin{array}{l}45- \\
58\end{array}$ & $\begin{array}{l}48- \\
66\end{array}$ & & & & & & & & & & & & \\
\hline H. polygyrus & $\begin{array}{c}\text { HPOL_00017214 } \\
01\end{array}$ & 1 & $\begin{array}{l}30- \\
68\end{array}$ & $30-43$ & $\begin{array}{c}46- \\
59\end{array}$ & $\begin{array}{l}49- \\
67\end{array}$ & & & & & & & & & & & & \\
\hline H. taeniaeformis & $\begin{array}{c}\text { TTAC_00008498 } \\
01\end{array}$ & 4 & $\begin{array}{l}22- \\
61\end{array}$ & $22-39$ & $\begin{array}{l}40- \\
53\end{array}$ & $\begin{array}{l}43- \\
61\end{array}$ & $\begin{array}{l}64- \\
107\end{array}$ & $\begin{array}{l}64- \\
80\end{array}$ & 83-99 & $\begin{array}{l}86- \\
107\end{array}$ & $\begin{array}{l}109- \\
146\end{array}$ & $\begin{array}{l}109- \\
122\end{array}$ & $\begin{array}{l}125- \\
138\end{array}$ & $\begin{array}{l}128- \\
146\end{array}$ & $\begin{array}{c}149 \\
- \\
188\end{array}$ & $\begin{array}{l}149- \\
164\end{array}$ & $\begin{array}{l}167- \\
180\end{array}$ & $\begin{array}{l}170- \\
188\end{array}$ \\
\hline
\end{tabular}




\begin{tabular}{|c|c|c|c|c|c|c|c|c|c|c|c|c|c|c|c|c|c|c|}
\hline Organismo & Gene ID & $\begin{array}{l}\text { \# D. } \\
\text { TNFR }\end{array}$ & $\begin{array}{l}\text { C. } \\
\text { D1 }\end{array}$ & $\begin{array}{l}\text { PD1 } \\
\text { D1 }\end{array}$ & $\begin{array}{l}\text { PD2 } \\
\text { D1 }\end{array}$ & $\begin{array}{l}\text { PD3 } \\
\text { D1 }\end{array}$ & $\begin{array}{l}\text { C. } \\
\text { D2 }\end{array}$ & $\begin{array}{l}\text { PD1 } \\
\text { D2 }\end{array}$ & $\begin{array}{c}\text { PD2 } \\
\text { D2 }\end{array}$ & $\begin{array}{c}\text { PD3 } \\
\text { D2 }\end{array}$ & $\begin{array}{l}\text { C. } \\
\text { D3 }\end{array}$ & $\begin{array}{l}\text { PD1 } \\
\text { D3 }\end{array}$ & $\begin{array}{l}\text { PD2 } \\
\text { D3 }\end{array}$ & $\begin{array}{l}\text { PD3 } \\
\text { D3 }\end{array}$ & $\begin{array}{l}\text { C. } \\
\text { D4 }\end{array}$ & $\begin{array}{l}\text { PD1 } \\
\text { D4 }\end{array}$ & $\begin{array}{l}\text { PD2 } \\
\text { D4 }\end{array}$ & $\begin{array}{c}\text { PD3 } \\
\text { D4 }\end{array}$ \\
\hline H. diminuta & $\begin{array}{c}\text { HDID_000039570 } \\
1\end{array}$ & 4 & $\begin{array}{l}42- \\
81\end{array}$ & $42-59$ & $\begin{array}{l}60- \\
73\end{array}$ & $\begin{array}{c}63- \\
81\end{array}$ & $\begin{array}{l}84- \\
127\end{array}$ & $\begin{array}{l}84- \\
100\end{array}$ & $\begin{array}{c}103- \\
119\end{array}$ & $\begin{array}{l}106- \\
127\end{array}$ & $\begin{array}{l}129- \\
166\end{array}$ & $\begin{array}{l}129- \\
142\end{array}$ & $\begin{array}{l}145- \\
158\end{array}$ & $\begin{array}{l}148- \\
166\end{array}$ & $\begin{array}{c}169 \\
- \\
208\end{array}$ & $\begin{array}{l}169- \\
184\end{array}$ & $\begin{array}{l}187- \\
200\end{array}$ & $\begin{array}{l}190- \\
208\end{array}$ \\
\hline H. microstoma & $\begin{array}{c}\text { HmN_000322000. } \\
1\end{array}$ & 4 & $\begin{array}{l}42- \\
81\end{array}$ & $42-59$ & $\begin{array}{l}60- \\
73\end{array}$ & $\begin{array}{l}63- \\
81\end{array}$ & $\begin{array}{l}84- \\
127\end{array}$ & $\begin{array}{l}84- \\
100\end{array}$ & $\begin{array}{c}103- \\
119\end{array}$ & $\begin{array}{l}106- \\
127\end{array}$ & $\begin{array}{l}129- \\
166\end{array}$ & $\begin{array}{l}129- \\
142\end{array}$ & $\begin{array}{l}145- \\
158\end{array}$ & $\begin{array}{l}148- \\
166\end{array}$ & $\begin{array}{c}169 \\
- \\
208\end{array}$ & $\begin{array}{l}169- \\
184\end{array}$ & $\begin{array}{l}187- \\
200\end{array}$ & $\begin{array}{l}190- \\
208\end{array}$ \\
\hline H. nana & $\begin{array}{c}\text { HNAJ_00003702 } \\
01\end{array}$ & 3 & $1-41$ & \multicolumn{3}{|c|}{ Não encontradas } & $\begin{array}{l}43- \\
80\end{array}$ & \multicolumn{3}{|c|}{ Não encontradas } & $\begin{array}{l}83- \\
122\end{array}$ & \multicolumn{3}{|c|}{ Não encontradas } & & & & \\
\hline M. lignano & $\begin{array}{c}\text { BOX15_Mlig0180 } \\
38 \mathrm{~g} 1\end{array}$ & 4 & $\begin{array}{l}61- \\
104\end{array}$ & $61-79$ & $\begin{array}{l}82- \\
96\end{array}$ & $\begin{array}{l}85- \\
104\end{array}$ & $\begin{array}{l}106- \\
144\end{array}$ & Nã & encontra & das & $\begin{array}{l}147- \\
190\end{array}$ & $\begin{array}{c}147- \\
164\end{array}$ & $\begin{array}{r}167- \\
182\end{array}$ & $\begin{array}{l}171- \\
190\end{array}$ & & & & \\
\hline M. corti & $\begin{array}{c}\text { MCOS_00002855 } \\
01\end{array}$ & 4 & $\begin{array}{l}196- \\
235\end{array}$ & $\begin{array}{l}196- \\
213\end{array}$ & $\begin{array}{l}214- \\
227\end{array}$ & $\begin{array}{l}217- \\
235\end{array}$ & $\begin{array}{l}238- \\
281\end{array}$ & $\begin{array}{l}238- \\
254\end{array}$ & $\begin{array}{l}257- \\
273\end{array}$ & $\begin{array}{l}260- \\
281\end{array}$ & $\begin{array}{l}283- \\
320\end{array}$ & $\begin{array}{l}283- \\
296\end{array}$ & $\begin{array}{l}299- \\
312\end{array}$ & $\begin{array}{l}302- \\
320\end{array}$ & $\begin{array}{c}323 \\
- \\
362\end{array}$ & $\begin{array}{l}323- \\
338\end{array}$ & $\begin{array}{l}341- \\
354\end{array}$ & $\begin{array}{l}344- \\
362\end{array}$ \\
\hline O. viverrini & T265_08108 & 4 & $\begin{array}{l}63- \\
102\end{array}$ & $63-80$ & $\begin{array}{l}81- \\
94\end{array}$ & $\begin{array}{l}84- \\
102\end{array}$ & $\begin{array}{l}105- \\
148\end{array}$ & $\begin{array}{l}105- \\
121\end{array}$ & $\begin{array}{l}124- \\
140\end{array}$ & $\begin{array}{l}127- \\
148\end{array}$ & $\begin{array}{l}150- \\
187\end{array}$ & $\begin{array}{l}150- \\
163\end{array}$ & $\begin{array}{l}166- \\
179\end{array}$ & $\begin{array}{l}169- \\
187\end{array}$ & $\begin{array}{c}190 \\
- \\
229\end{array}$ & $\begin{array}{l}190- \\
205\end{array}$ & $\begin{array}{l}208- \\
221\end{array}$ & $\begin{array}{l}211- \\
229\end{array}$ \\
\hline P. redivivus & Pan_g18397.t1 & 1 & $\begin{array}{l}68- \\
105\end{array}$ & $68-81$ & $\begin{array}{l}84- \\
97\end{array}$ & $\begin{array}{l}97- \\
105\end{array}$ & & & & & & & & & & & & \\
\hline R. culicivorax & nRc.2.0.1.t36199 & 2 & $\begin{array}{l}102- \\
134\end{array}$ & \multicolumn{3}{|c|}{ Não encontradas } & $\begin{array}{l}137- \\
177\end{array}$ & $\begin{array}{l}137- \\
153\end{array}$ & $\begin{array}{l}156- \\
169\end{array}$ & $\begin{array}{l}159- \\
177\end{array}$ & & & & & & & & \\
\hline R. culicivorax & nRc.2.0.1.t36941 & 3 & $\begin{array}{l}39- \\
75\end{array}$ & $39-52$ & $\begin{array}{l}53- \\
66\end{array}$ & $\begin{array}{l}56- \\
75\end{array}$ & $\begin{array}{l}78- \\
118\end{array}$ & $\begin{array}{c}78- \\
94\end{array}$ & $97-110$ & $\begin{array}{l}100- \\
118\end{array}$ & $\begin{array}{l}120- \\
158\end{array}$ & $\begin{array}{l}120- \\
134\end{array}$ & $\begin{array}{l}137- \\
150\end{array}$ & $\begin{array}{l}140- \\
158\end{array}$ & & & & \\
\hline S. curassoni & $\begin{array}{c}\text { SCUD_00022272 } \\
01\end{array}$ & 1 & $\begin{array}{l}13- \\
52\end{array}$ & $13-28$ & $\begin{array}{l}31- \\
44\end{array}$ & $\begin{array}{c}34- \\
52\end{array}$ & & & & & & & & & & & & \\
\hline S. haematobium & MS3_00310 & 4 & $\begin{array}{l}86- \\
125\end{array}$ & $\begin{array}{l}86- \\
103\end{array}$ & $\begin{array}{l}104- \\
117\end{array}$ & $\begin{array}{l}107- \\
125\end{array}$ & $\begin{array}{r}128- \\
171\end{array}$ & $\begin{array}{l}128- \\
144\end{array}$ & $\begin{array}{c}147- \\
163\end{array}$ & $\begin{array}{c}150-- \\
171\end{array}$ & $\begin{array}{l}173- \\
210\end{array}$ & $\begin{array}{c}173- \\
186\end{array}$ & $\begin{array}{l}189- \\
202\end{array}$ & $\begin{array}{l}192- \\
210\end{array}$ & $\begin{array}{c}213 \\
- \\
252\end{array}$ & $\begin{array}{l}213- \\
228\end{array}$ & $\begin{array}{l}231- \\
244\end{array}$ & $\begin{array}{l}234- \\
252\end{array}$ \\
\hline S. japonicum & Sjp_0098810 & 4 & $7-46$ & $7-24$ & $\begin{array}{c}25- \\
38\end{array}$ & $\begin{array}{c}28- \\
46\end{array}$ & $\begin{array}{l}49- \\
92\end{array}$ & $\begin{array}{l}49- \\
65\end{array}$ & $68-84$ & $\begin{array}{l}71- \\
92\end{array}$ & $\begin{array}{c}94- \\
131\end{array}$ & $\begin{array}{l}94- \\
107\end{array}$ & $\begin{array}{c}110- \\
123\end{array}$ & $\begin{array}{l}113- \\
131\end{array}$ & $\begin{array}{c}134 \\
- \\
173\end{array}$ & $\begin{array}{c}134- \\
149\end{array}$ & $\begin{array}{l}152- \\
165\end{array}$ & $\begin{array}{c}155- \\
173\end{array}$ \\
\hline S. mansoni & ACS92719.1 & 4 & $3-43$ & $4-21$ & $\begin{array}{c}22- \\
35\end{array}$ & $\begin{array}{l}25- \\
43\end{array}$ & $\begin{array}{l}45- \\
89\end{array}$ & $\begin{array}{l}45- \\
62\end{array}$ & $65-81$ & $\begin{array}{l}68- \\
89\end{array}$ & $\begin{array}{c}90- \\
128\end{array}$ & $\begin{array}{l}91- \\
104\end{array}$ & $\begin{array}{c}107- \\
120\end{array}$ & $\begin{array}{l}110- \\
128\end{array}$ & $\begin{array}{c}130 \\
- \\
170\end{array}$ & $\begin{array}{l}131- \\
146\end{array}$ & $\begin{array}{l}149- \\
162\end{array}$ & $\begin{array}{c}152- \\
170\end{array}$ \\
\hline
\end{tabular}




\begin{tabular}{|c|c|c|c|c|c|c|c|c|c|c|c|c|c|c|c|c|c|c|}
\hline Organismo & Gene ID & $\begin{array}{l}\text { \# D. } \\
\text { TNFR }\end{array}$ & $\begin{array}{l}\text { C. } \\
\text { D1 }\end{array}$ & $\begin{array}{c}\text { PD1 } \\
\text { D1 }\end{array}$ & $\begin{array}{l}\text { PD2 } \\
\text { D1 }\end{array}$ & $\begin{array}{l}\text { PD3 } \\
\text { D1 }\end{array}$ & $\begin{array}{l}\text { C. } \\
\text { D2 }\end{array}$ & $\begin{array}{l}\text { PD1 } \\
\text { D2 }\end{array}$ & $\begin{array}{l}\text { PD2 } \\
\text { D2 }\end{array}$ & $\begin{array}{l}\text { PD3 } \\
\text { D2 }\end{array}$ & $\begin{array}{l}\text { C. } \\
\text { D3 }\end{array}$ & $\begin{array}{l}\text { PD1 } \\
\text { D3 }\end{array}$ & $\begin{array}{l}\text { PD2 } \\
\text { D3 }\end{array}$ & $\begin{array}{l}\text { PD3 } \\
\text { D3 }\end{array}$ & $\begin{array}{l}\text { C. } \\
\text { D4 }\end{array}$ & $\begin{array}{l}\text { PD1 } \\
\text { D4 }\end{array}$ & $\begin{array}{l}\text { PD2 } \\
\text { D4 }\end{array}$ & $\begin{array}{l}\text { PD3 } \\
\text { D4 }\end{array}$ \\
\hline S. margrebowiei & $\begin{array}{c}\text { SMRZ_00011457 } \\
01\end{array}$ & 3 & $\begin{array}{l}78- \\
117\end{array}$ & $78-95$ & $\begin{array}{l}96- \\
109\end{array}$ & $\begin{array}{l}99- \\
117\end{array}$ & $\begin{array}{l}120- \\
163\end{array}$ & $\begin{array}{l}120- \\
136\end{array}$ & $\begin{array}{l}139- \\
155\end{array}$ & $\begin{array}{l}142- \\
163\end{array}$ & $\begin{array}{l}165- \\
192\end{array}$ & Não & encont & das & & & & \\
\hline S. mattheei & $\begin{array}{c}\text { SMTD_00000239 } \\
01\end{array}$ & 4 & $\begin{array}{l}66- \\
105\end{array}$ & $66-83$ & $\begin{array}{l}84- \\
97\end{array}$ & $\begin{array}{l}87- \\
105\end{array}$ & $\begin{array}{l}108- \\
151\end{array}$ & $\begin{array}{l}108- \\
124\end{array}$ & $\begin{array}{l}127- \\
143\end{array}$ & $\begin{array}{l}130- \\
151\end{array}$ & $\begin{array}{l}153- \\
190\end{array}$ & $\begin{array}{l}153- \\
166\end{array}$ & $\begin{array}{l}169- \\
182\end{array}$ & $\begin{array}{l}172- \\
190\end{array}$ & $\begin{array}{c}193 \\
- \\
232\end{array}$ & $\begin{array}{l}193- \\
208\end{array}$ & $\begin{array}{l}211- \\
224\end{array}$ & $\begin{array}{l}214 \\
232\end{array}$ \\
\hline S. baturini & $\begin{array}{c}\text { SBAD_00004183 } \\
01\end{array}$ & 2 & $7-52$ & $25-46$ & $\begin{array}{l}28- \\
38\end{array}$ & & $\begin{array}{l}55- \\
94\end{array}$ & $\begin{array}{l}55- \\
70\end{array}$ & $73-86$ & $\begin{array}{l}76- \\
94\end{array}$ & & & & & & & & \\
\hline S. baturini & $\begin{array}{c}\text { SBAD_00008681 } \\
01\end{array}$ & 4 & $9-44$ & $9-22$ & $\begin{array}{l}23- \\
36\end{array}$ & $\begin{array}{l}26- \\
44\end{array}$ & $\begin{array}{l}47- \\
87\end{array}$ & $\begin{array}{l}47- \\
63\end{array}$ & $66-79$ & $\begin{array}{l}69- \\
87\end{array}$ & $\begin{array}{l}89- \\
126\end{array}$ & $\begin{array}{l}89- \\
102\end{array}$ & $\begin{array}{l}105- \\
118\end{array}$ & $\begin{array}{l}108- \\
126\end{array}$ & $\begin{array}{c}129 \\
- \\
168\end{array}$ & $\begin{array}{l}129- \\
144\end{array}$ & $\begin{array}{l}147- \\
160\end{array}$ & $\begin{array}{l}150 \\
168\end{array}$ \\
\hline T. asiatica & $\begin{array}{c}\text { TASs00007g0187 } \\
7\end{array}$ & 4 & $\begin{array}{l}113- \\
152\end{array}$ & $\begin{array}{l}113- \\
130\end{array}$ & $\begin{array}{l}131- \\
144\end{array}$ & $\begin{array}{l}134- \\
152\end{array}$ & $\begin{array}{l}155- \\
198\end{array}$ & $\begin{array}{l}155- \\
171\end{array}$ & $\begin{array}{c}174- \\
190\end{array}$ & $\begin{array}{l}177- \\
198\end{array}$ & $\begin{array}{l}200- \\
237\end{array}$ & $\begin{array}{l}200- \\
213\end{array}$ & $\begin{array}{l}216- \\
229\end{array}$ & $\begin{array}{l}219- \\
237\end{array}$ & $\begin{array}{c}240 \\
- \\
279\end{array}$ & $\begin{array}{l}240- \\
255\end{array}$ & $\begin{array}{l}258- \\
271\end{array}$ & $\begin{array}{l}261 \\
279\end{array}$ \\
\hline T. saginata & $\begin{array}{c}\text { TSAs00042g0584 } \\
7\end{array}$ & 4 & $\begin{array}{c}113- \\
152\end{array}$ & $\begin{array}{l}113- \\
130\end{array}$ & $\begin{array}{l}131- \\
144\end{array}$ & $\begin{array}{l}143- \\
152\end{array}$ & $\begin{array}{l}155- \\
198\end{array}$ & $\begin{array}{l}155- \\
171\end{array}$ & $\begin{array}{l}174- \\
190\end{array}$ & $\begin{array}{l}177- \\
198\end{array}$ & $\begin{array}{l}200- \\
237\end{array}$ & $\begin{array}{l}200- \\
213\end{array}$ & $\begin{array}{l}216- \\
229\end{array}$ & $\begin{array}{l}219- \\
237\end{array}$ & $\begin{array}{c}240 \\
- \\
279\end{array}$ & $\begin{array}{l}240- \\
255\end{array}$ & $\begin{array}{l}258- \\
271\end{array}$ & $\begin{array}{l}261 \\
279\end{array}$ \\
\hline T. solium & TsM_000678000 & 4 & $\begin{array}{l}11- \\
52\end{array}$ & $11-28$ & $\begin{array}{l}29- \\
42\end{array}$ & $\begin{array}{l}32- \\
50\end{array}$ & $\begin{array}{l}53- \\
96\end{array}$ & $\begin{array}{l}53- \\
69\end{array}$ & $72-88$ & $\begin{array}{l}75- \\
96\end{array}$ & $\begin{array}{l}98- \\
135\end{array}$ & $\begin{array}{l}98- \\
111\end{array}$ & $\begin{array}{l}114- \\
127\end{array}$ & $\begin{array}{l}117- \\
135\end{array}$ & $\begin{array}{c}138 \\
- \\
177\end{array}$ & $\begin{array}{c}138- \\
153\end{array}$ & $\begin{array}{l}156- \\
169\end{array}$ & $\begin{array}{l}159 \\
177\end{array}$ \\
\hline T. britovi & T03_11861.1 & 4 & $\begin{array}{l}104- \\
139\end{array}$ & $\begin{array}{l}104- \\
117\end{array}$ & $\begin{array}{l}118- \\
131\end{array}$ & $\begin{array}{l}121- \\
139\end{array}$ & $\begin{array}{c}142- \\
182\end{array}$ & $\begin{array}{l}142- \\
158\end{array}$ & $\begin{array}{l}161- \\
174\end{array}$ & $\begin{array}{l}164- \\
182\end{array}$ & $\begin{array}{l}184- \\
221\end{array}$ & $\begin{array}{l}184- \\
197\end{array}$ & $\begin{array}{l}200- \\
213\end{array}$ & $\begin{array}{l}203- \\
221\end{array}$ & $\begin{array}{c}224 \\
- \\
263\end{array}$ & $\begin{array}{l}224- \\
239\end{array}$ & $\begin{array}{l}242- \\
255\end{array}$ & $\begin{array}{l}245 \\
263\end{array}$ \\
\hline T. britovi & T03_11861.2 & 4 & $\begin{array}{l}104- \\
139\end{array}$ & $\begin{array}{l}104- \\
117\end{array}$ & $\begin{array}{l}118- \\
131\end{array}$ & $\begin{array}{l}121- \\
139\end{array}$ & $\begin{array}{r}142- \\
182\end{array}$ & $\begin{array}{l}142- \\
158\end{array}$ & $\begin{array}{l}161- \\
174\end{array}$ & $\begin{array}{l}164- \\
182\end{array}$ & $\begin{array}{l}184- \\
221\end{array}$ & $\begin{array}{l}184- \\
197\end{array}$ & $\begin{array}{l}200- \\
213\end{array}$ & $\begin{array}{l}203- \\
221\end{array}$ & $\begin{array}{c}224 \\
- \\
263\end{array}$ & $\begin{array}{l}224- \\
239\end{array}$ & $\begin{array}{l}242- \\
255\end{array}$ & $\begin{array}{l}245 \\
263\end{array}$ \\
\hline T. murrelli & T05_14779.1 & 4 & $\begin{array}{l}138- \\
173\end{array}$ & $\begin{array}{l}138- \\
151\end{array}$ & $\begin{array}{c}152- \\
165\end{array}$ & $\begin{array}{l}155- \\
173\end{array}$ & $\begin{array}{l}176- \\
216\end{array}$ & $\begin{array}{l}176- \\
192\end{array}$ & $\begin{array}{l}195- \\
208\end{array}$ & $\begin{array}{l}198- \\
216\end{array}$ & $\begin{array}{l}218- \\
255\end{array}$ & $\begin{array}{l}218- \\
231\end{array}$ & $\begin{array}{l}234- \\
247\end{array}$ & $\begin{array}{l}237- \\
255\end{array}$ & $\begin{array}{c}258 \\
- \\
297\end{array}$ & $\begin{array}{l}258- \\
273\end{array}$ & $\begin{array}{l}276- \\
289\end{array}$ & $\begin{array}{l}279 \\
297\end{array}$ \\
\hline T. murrelli & T05_14779.2 & 4 & $\begin{array}{l}138- \\
173\end{array}$ & $\begin{array}{c}138- \\
151\end{array}$ & $\begin{array}{c}152- \\
165\end{array}$ & $\begin{array}{l}155- \\
173\end{array}$ & $\begin{array}{l}176- \\
216\end{array}$ & $\begin{array}{l}176- \\
192\end{array}$ & $\begin{array}{l}195- \\
208\end{array}$ & $\begin{array}{l}198- \\
216\end{array}$ & $\begin{array}{l}218- \\
255\end{array}$ & $\begin{array}{l}218- \\
231\end{array}$ & $\begin{array}{l}234- \\
247\end{array}$ & $\begin{array}{l}237- \\
255\end{array}$ & $\begin{array}{c}258 \\
- \\
297\end{array}$ & $\begin{array}{l}258- \\
273\end{array}$ & $\begin{array}{l}276- \\
289\end{array}$ & $\begin{array}{l}279 \\
297\end{array}$ \\
\hline T. nativa & T02_15720.1 & 4 & $\begin{array}{c}139- \\
174\end{array}$ & $\begin{array}{l}139- \\
152\end{array}$ & $\begin{array}{c}153- \\
166\end{array}$ & $\begin{array}{c}156- \\
174\end{array}$ & $\begin{array}{l}177- \\
217\end{array}$ & $\begin{array}{l}177- \\
193\end{array}$ & $\begin{array}{l}196- \\
209\end{array}$ & $\begin{array}{l}199- \\
217\end{array}$ & $\begin{array}{l}219- \\
256\end{array}$ & $\begin{array}{l}219- \\
232\end{array}$ & $\begin{array}{l}235- \\
248\end{array}$ & $\begin{array}{l}238- \\
256\end{array}$ & $\begin{array}{c}259 \\
- \\
298\end{array}$ & $\begin{array}{l}259- \\
274\end{array}$ & $\begin{array}{l}277- \\
290\end{array}$ & $\begin{array}{l}280 \\
298\end{array}$ \\
\hline
\end{tabular}




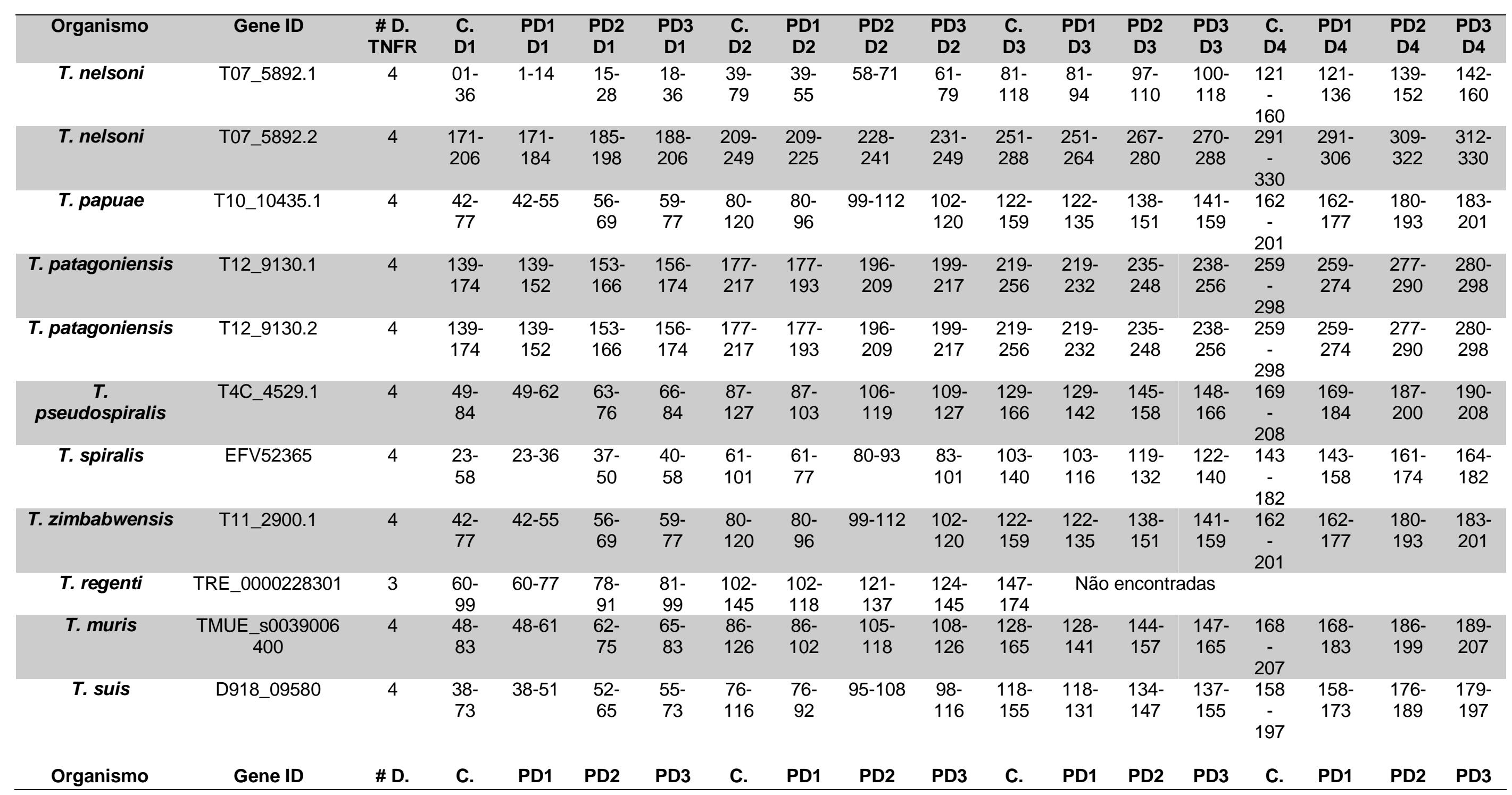




\begin{tabular}{|c|c|c|c|c|c|c|c|c|c|c|c|c|c|c|c|c|c|c|}
\hline & & TNFR & D1 & D1 & D1 & D1 & D2 & D2 & D2 & D2 & D3 & D3 & D3 & D3 & D4 & D4 & D4 & D4 \\
\hline T. trichiura & $\begin{array}{c}\text { TTRE_00000686 } \\
01\end{array}$ & 4 & $\begin{array}{c}11- \\
46\end{array}$ & $11-24$ & $\begin{array}{c}25- \\
38\end{array}$ & $\begin{array}{l}28- \\
46\end{array}$ & $\begin{array}{c}49- \\
89\end{array}$ & $\begin{array}{l}49- \\
65\end{array}$ & 68-81 & $\begin{array}{c}71- \\
89\end{array}$ & $\begin{array}{l}91- \\
128\end{array}$ & $\begin{array}{l}91- \\
104\end{array}$ & $\begin{array}{l}107- \\
120\end{array}$ & $\begin{array}{l}110- \\
128\end{array}$ & $\begin{array}{c}131 \\
- \\
170\end{array}$ & $\begin{array}{c}131- \\
146\end{array}$ & $\begin{array}{l}149- \\
162\end{array}$ & $\begin{array}{l}152- \\
170\end{array}$ \\
\hline
\end{tabular}

\# D. TNFR= Número de domínios de TNFR; C. D1= Coordenadas do Domínio 1; PD1 D1= Coordenadas da Ponte Dissulfeto 1 Domínio 1; PD2 D1= Coordenadas da Ponte Dissulfeto 2 Domínio 1; PD3 D1= Coordenadas da Ponte Dissulfeto 3 Domínio 1; C. D2= Coordenadas Domínio 2; PD1 D2= Coordenadas Ponte Dissulfeto 1 Domínio 2; PD2 D2= Coordenadas Ponte Dissulfeto 2 Domínio 2; PD3 D2= Coordenadas Ponte Dissulfeto 3 Domínio 2; C. D3= Coordenadas Domínio 3; PD1 D3= Coordenadas Ponte Dissulfeto 1 Domínio 3; PD2 D3= Coordenadas Ponte Dissulfeto 2 Domínio 3; PD3 D3= Coordenadas Ponte Dissulfeto 3 Domínio 3; C. D4 = Coordenadas Domínio 4; PD1 D4= Coordenadas Ponte Dissulfeto 1 Domínio 4; PD2 D4= Coordenadas Ponte Dissulfeto 2 Domínio 4; PD3 D4= Coordenadas Ponte Dissulfeto 3 Domínio 4. 


\subsection{Análise filogenética do alinhamento dos homólogos de SmTNFR}

Utilizando o alinhamento das regiões conservadas dos homólogos nos quais foram identificados 3 e 4 domínios (TNFR ou CRD) foram realizadas diversas análises para construção de árvores filogenéticas a fim de compreender o contexto evolutivo dos genes homólogos a SmTNFR nos helmintos. Cabe destacar que Oliveira e colaboradores [3] haviam proposto que SmTNFR era provavelmente um gene ancestral antes da expansão da família dos receptores de TNF nos genomas dos mamífero.

Existem muitos métodos para inferir as relações evolutivas entre os homólogos, neste trabalho testamos métodos baseados em caracteres ou probalisticos (Método de Máxima Parcimônia; Máxima Verossimilhança e Inferência Bayesiana) e Métodos geométricos ou de distância (Evolução Mínima, UPGMA -Unweighted Pair Group Method with Arithmetic Means- e método Neighbor-joining).

\subsubsection{MÉTOdo de MÁxIMA PARCIMÔNIA}

O método de Máxima Parcimônia se baseia num modelo de evolução implícito onde uma mudança é mais provável que duas; ou seja, trata substituições independentes gerando o mesmo resultado como um evento relativamente raro. $\mathrm{O}$ menor número de eventos na alteração do código genético é provavelmente a hipótese mais plausível que ocorreu evolutivamente [56]. A Figura mostra a árvore obtida pelo método de Máxima Parcimônia a partir do alinhamento feito com os 38 homólogos de SmTNFR que possuíam três e quatro domínios CRD. 


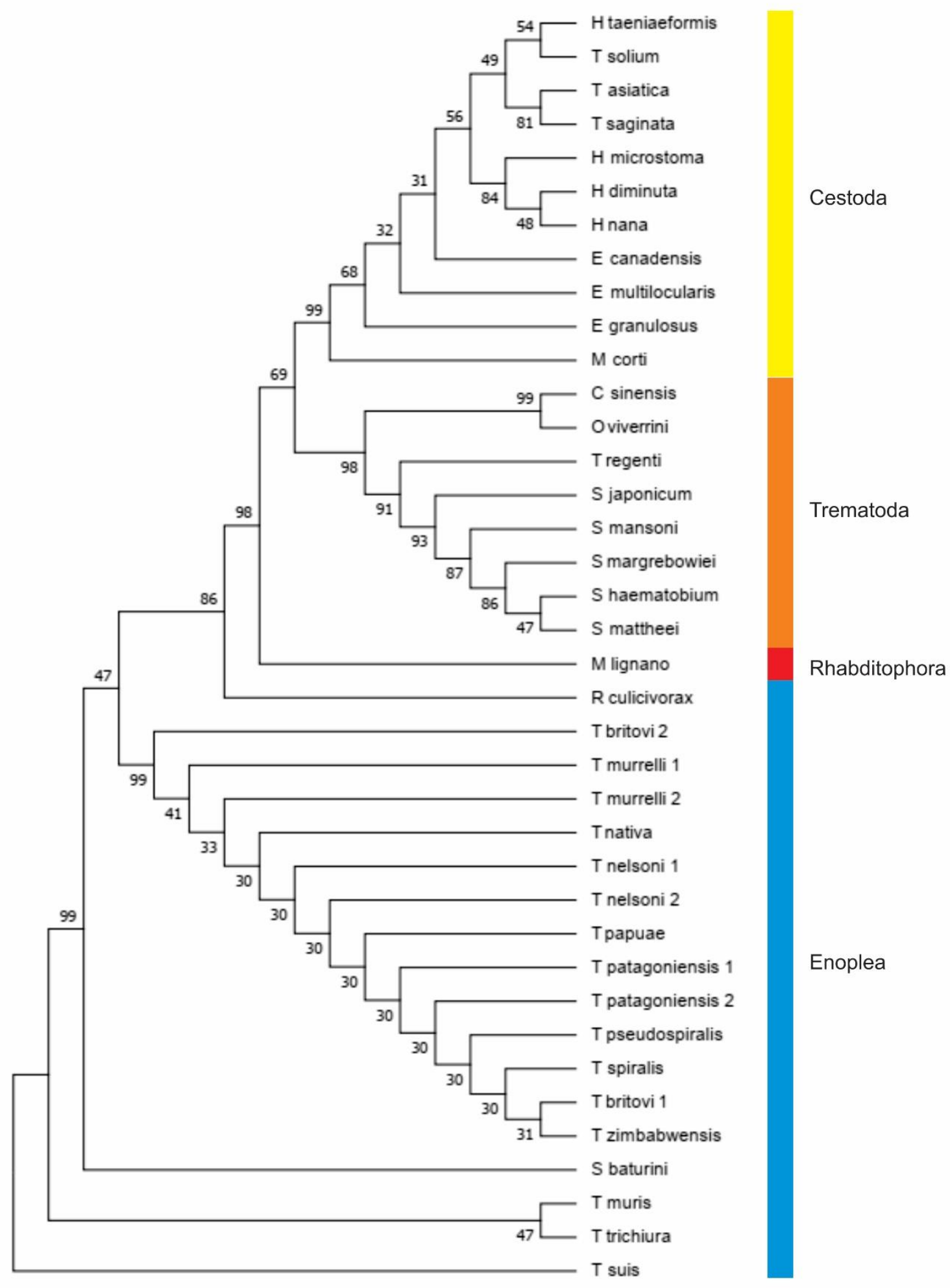

Figura 20. Análise da filogenia molecular dos homólogos de SmTNFR que contêm 3 e 4 domínios TNFR pelo Método de Máxima Parcimônia. A história evolutiva foi inferida usando o método de Máxima Parcimônia. A árvore \# 1 de 10 árvores mais parcimoniosas (comprimento $=215$ ) é mostrada. $O$ índice de consistência é $(0,891509)$, o índice de retenção é $(0,970323)$, e o índice de composição é $0,866521(0,865052)$ para todos os sítios e sítios parcimôniainformativos (em parênteses). A porcentagem de árvores replicadas em que a taxa de grupos associados no teste de bootstrap (1000 réplicas) é mostrada próximo aos 
ramos[57]. A árvore Máxima Parcimônia foi obtida usando o algoritmo SubtreePruning-Regrafting (SPR) (pg. 126 em [58]) com nível 1 de busca no qual as árvores iniciais foram obtidas pela adição randômica de sequências (10 réplicas). A análise foi realizada com 38 sequências de aminoácidos. Todas as posições contendo gaps ou dados faltantes foram eliminadas. Houve um total de 67 posições no conjunto de dados final. As análises evolutivas foram realizadas no MEGA7[50]. As barras coloridas à direita representam as classes taxonômicas dos respectivos organismos.

\subsubsection{MÉtOdO de MÁxIMA VEROSSIMILHANÇA}

A Máxima Verossimilhança ( $\mathrm{ML}$ - Maximum Likelihood) é um método discreto, assim como a Máxima Parcimônia; no entanto, busca dentre as árvores a mais verossímil de acordo com os dados fornecidos (sequências do alinhamento) e com base no modelo evolutivo. Esse método permite calcular estimativas de menor variância, consequentemente, com menos erros de amostragem. A verossimilhança de uma topologia, dado um alinhamento, é a soma das verossimilhanças dessa topologia para cada um dos sítios do alinhamento. A verossimilhança para cada um dos sítios deve ser calculada como o produto da soma das probabilidades de ocorrência de todas as substituições possíveis em um nó. Para todos os nós da árvore serão consideradas todas as possibilidades de comprimento de ramo[56][59].

A vantagem dessa abordagem da probabilidade em filogenia é a existência de uma ferramenta estatística poderosa. Além disso, essa metodologia permite a inferência de árvores filogenéticas usando modelos evolucionários complexos - incluindo a capacidade de estimar os parâmetros do modelo e assim fazer inferências simultaneamente com relação aos padrões e processos da evolução, além de fornecer os meios para a comparação de árvores concorrentes e modelos. As desvantagens consistem no maior esforço computacional e na grande maioria das análises o espaço/tempo necessário para gerar todas as possíveis árvores é imensamente grande e proibitivo para uma busca exaustiva, demandando a adoção de algoritmos heurísticos de otimização de busca.

A Figura mostra o resultado obtido por meio do método de Máxima Verossimilhança. 


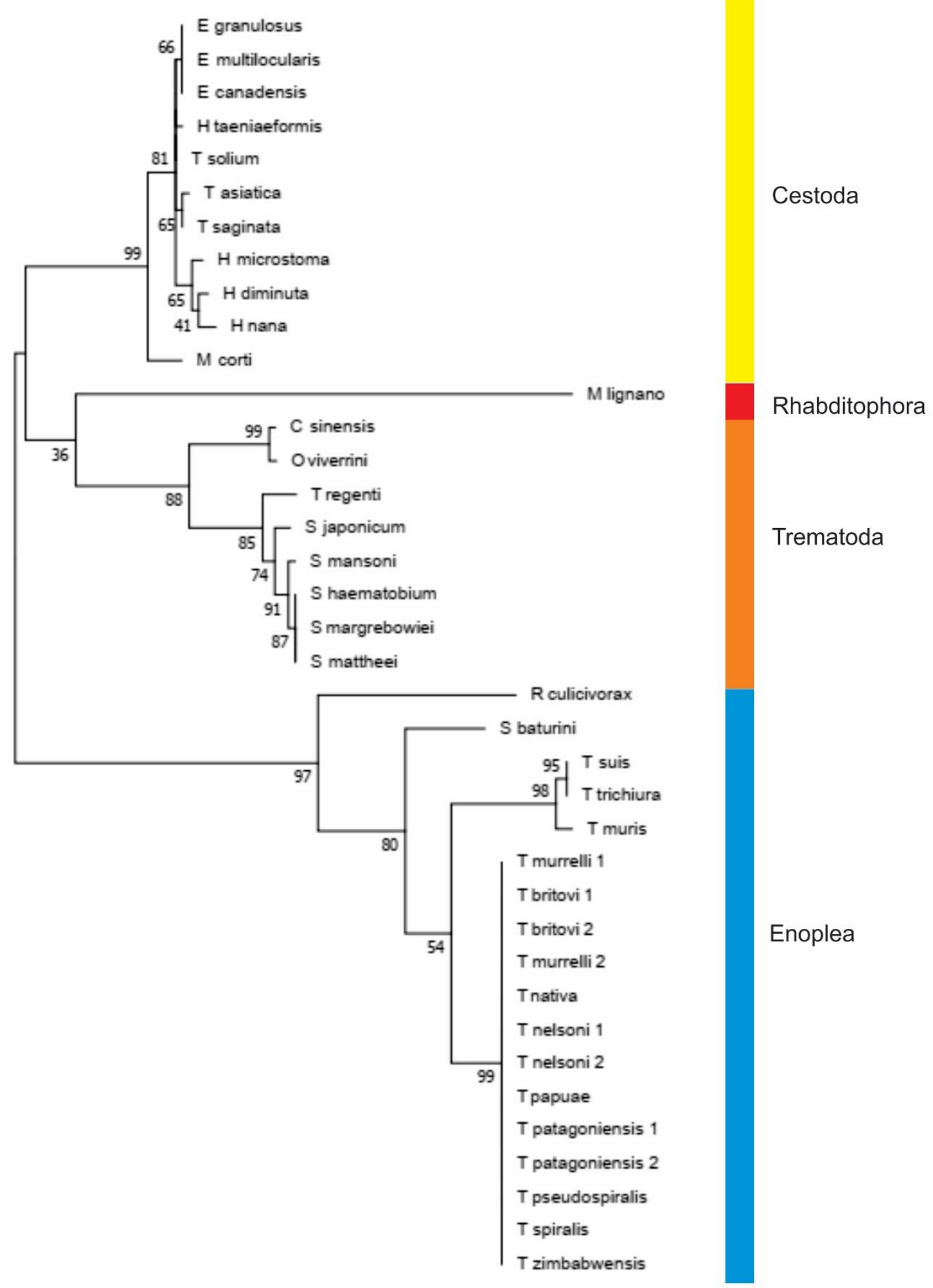

Figura 21 Análise da Filogenia Molecular pelo Método da Máxima Verossimilhança. A história evolutiva foi inferida usando o método de Máxima Verossimilhança no modelo baseado na matriz JTT [60]. A árvore com o maior log de probabilidade $(-1254.80)$ é mostrada. A porcentagem de árvores nas quais a taxa associada ao agrupamento é mostrada ao lado das ramificações. A (s) árvore (s) 
inicial (is) para a busca heurística foram obtidas automaticamente aplicando algoritmos Neighbor-Joining e BioNJ a uma matriz de distâncias pares estimadas usando um modelo JTT, e então selecionando a topologia com valor superior de log verossimilhança. A árvore é desenhada em escala, com comprimentos de ramificações medidas no número de substituições por site. A análise envolveu 38 sequências de aminoácidos. Todas as posições contendo lacunas e dados perdidos foram eliminadas. Houve um total de 67 posições no conjunto de dados final. As análises evolutivas foram realizadas no programa MEGA7 [50]. As barras coloridas à direita representam as classes taxonômicas dos respectivos organismos.

\subsubsection{MÉTODO DE INFERÊNCIA BAYESIANA}

O método de inferência bayesiana parte do mesmo arcabouço matemático da máxima verossimilhança $(\mathrm{ML})$, mas enquanto nos métodos $\mathrm{ML}$ os parâmetros são considerados constantes, no método Bayesiano, os parâmetros do modelo são considerados como variáveis aleatórias com distribuições estatísticas. Antes da análise dos dados, os parâmetros são atribuídos uma distribuição a priori, que é, então, combinada com os dados (ou suas verossimilhanças) para gerar a distribuição a posteriori que serve de a base para as inferências sobre os parâmetros que devem ser estimados. O principal algoritmo empregado para este tipo de abordagem são os baseados em 'Cadeia de Markov', que são uma sequência estocástica (ou cadeia) de estados cuja probabilidade da mudança do estado atual para outro estado ou para permanecer no mesmo estado não dependem dos estados passados, apenas do estado atual [59]. O resultado obtido pelo método de Inferência Bayesiana é mostrado na Figura . 


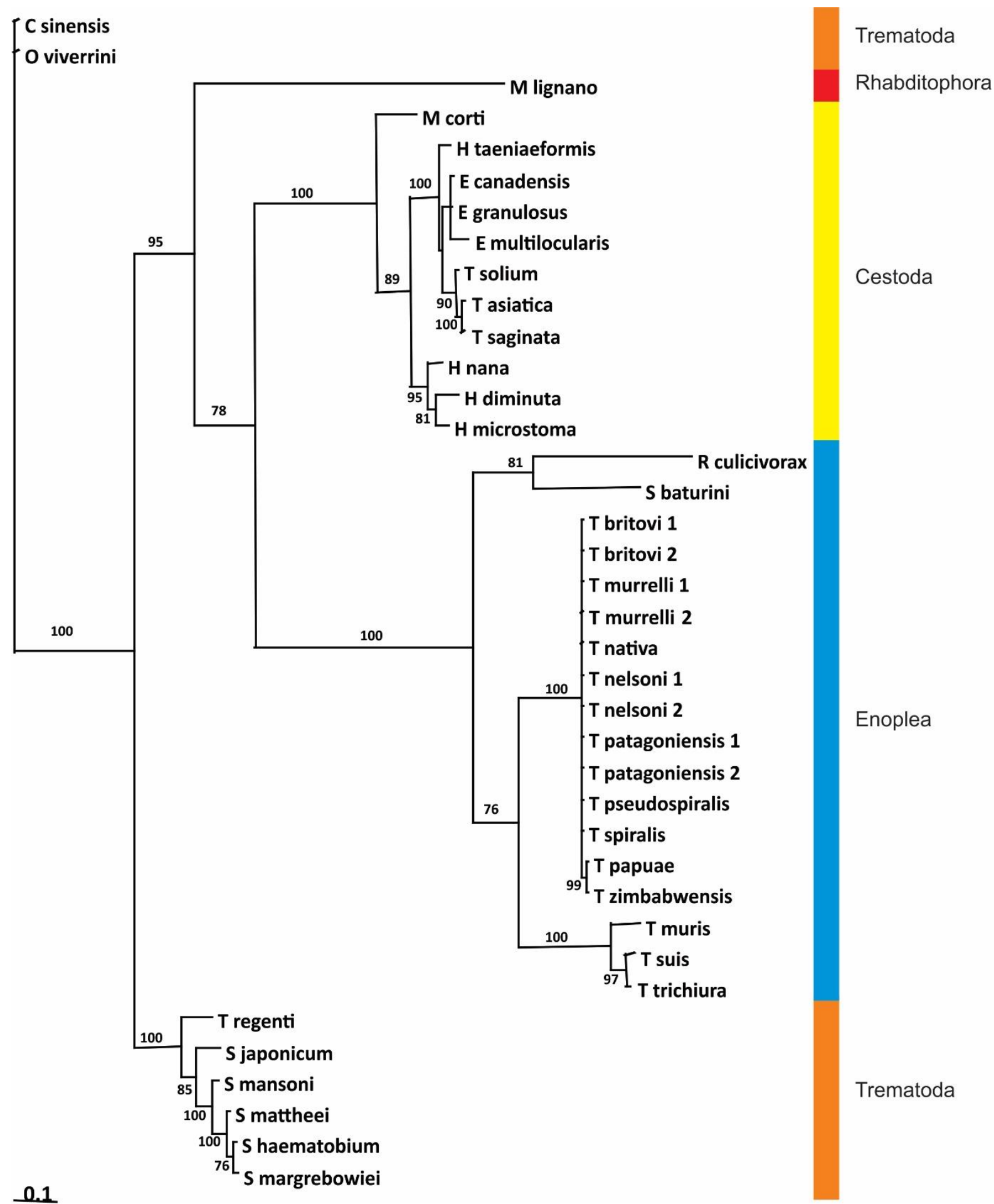

Figura 22. Análise da filogenia molecular de 38 homólogos de SmTNFR realizada por Inferência Bayesiana. A árvore e análise de 3022 árvores foram geradas pelo programa Mr. Bayes [53]. As barras coloridas à direita representam as classes taxonômicas dos respectivos organismos. 


\subsubsection{MÉTODO DA EVOLUÇÃo MÍNIMA}

Nos métodos baseados em distâncias os dados das sequências são primeiramente transformados em uma matriz de distâncias entre pares de sequências, com o comprimento total dos ramos necessários para ajustar esta matriz para cada topologia possível sendo calculado, a topologia escolhida é aquela com o menor comprimento total de ramos. A distância evolutiva entre um par de sequências pode ser estimada de várias maneiras, com a forma mais simples sendo distância-p, isto é, a fração dos sítios em que as duas sequências diferem entre si [56].

O método de 'Evolução Mínima' (ME, Minimum Evolution), leva em conta a possibilidade de que tenham ocorrido múltiplas substituições nas mesmas posições das sequências [56]. O resultado obtido pela abordagem do método da Evolução Mínima é mostrado na Figura 5. 


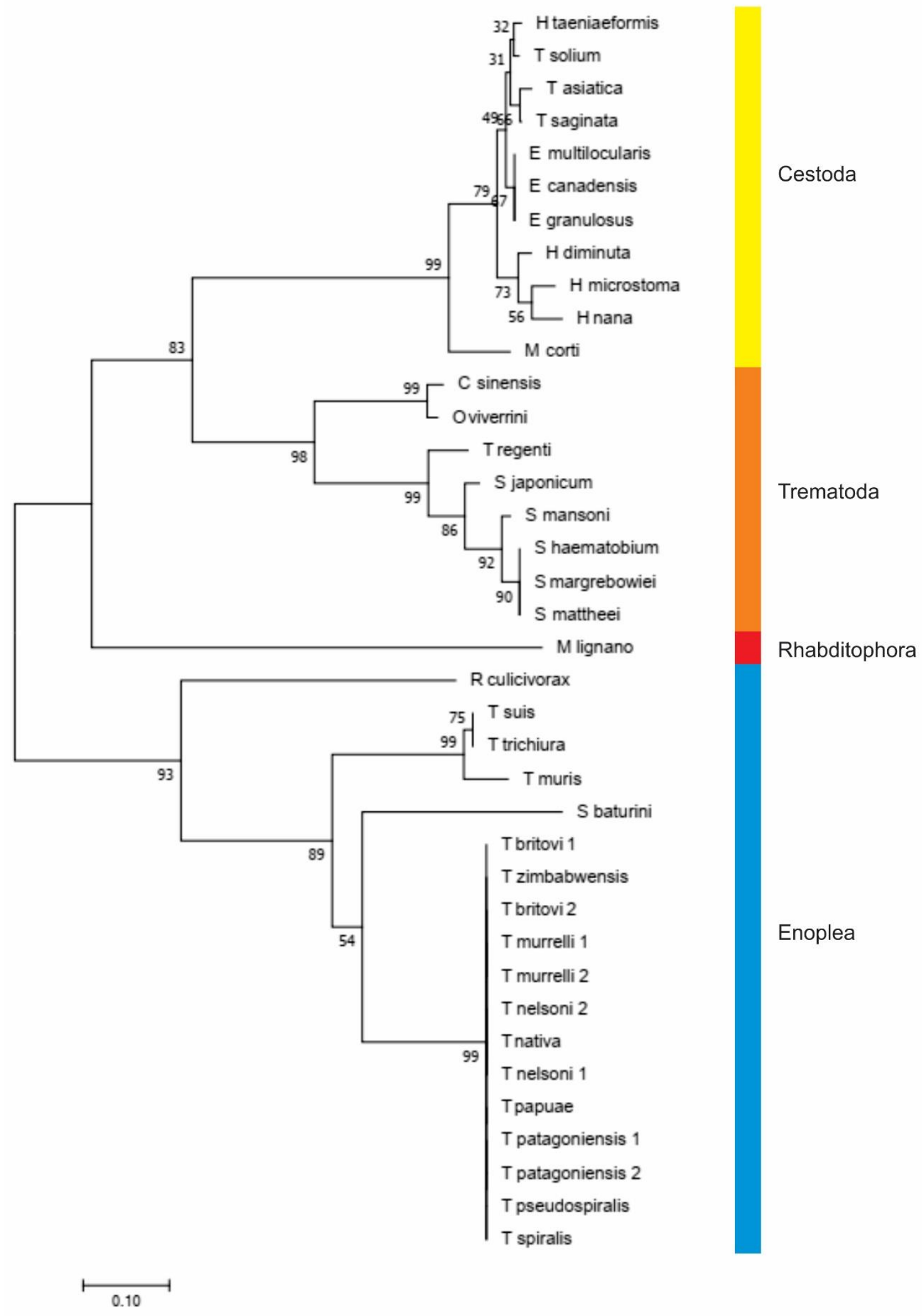

Figura 5. Análise da filogenia molecular dos homólogos de SmTNFR pelo Método de Evolução Mínima [61]. A história evolutiva foi inferida usando o método de Evolução Mínima. Árvore número 1 de 46 árvores de evolução mínima (soma do comprimento dos ramos $=3,26930572$ ) é mostrada. A porcentagem de árvores 
replicadas em que as taxas dos grupos associados no teste de bootstrap (1000 replicas) é mostrada próxima aos ramos [57]. A árvore é representada em escala, com comprimento dos aramos na mesma unidade das distâncias evolutivas usadas para inferir a árvore filogenética. As distâncias evolutivas foram computadas usando o Método de correção de Poisson [62] e estão nas unidades do número de aminoácidos substituídos por local. A árvore ME foi realizada usando o algoritmo Close-NeighborInterchange (CNI) [58] em um nível de busca 1. O algoritmo Neighbor-joining [63] foi usado para gerar a árvore inicial. A análise envolveu 38 sequências de aminoácidos. Todas as posições contendo lacunas e dados ausentes (gaps) perdidos foram eliminadas. Houve um total de 67 posições no conjunto de dados final. Análises evolutivas foram conduzidas no programa MEGA7 [50]. As barras coloridas à direita representam as classes taxonômicas dos respectivos organismos.

\subsubsection{MÉTODO DE NEIGHBOR-JOINING}

Entre os métodos baseados em distâncias, o chamado neighbor-joining, é um dos mais usados, principalmente, por causa da sua eficiência computacional, especialmente quando a quantidade de sequências analisadas é muito grande. Este método funciona em passos, minimizando a soma dos comprimentos dos ramos a cada passo do processo de agrupamento ('clusterização') das sequências [56]. O resultado obtido com esta abordagem de análise é mostrado na Figura 6. 


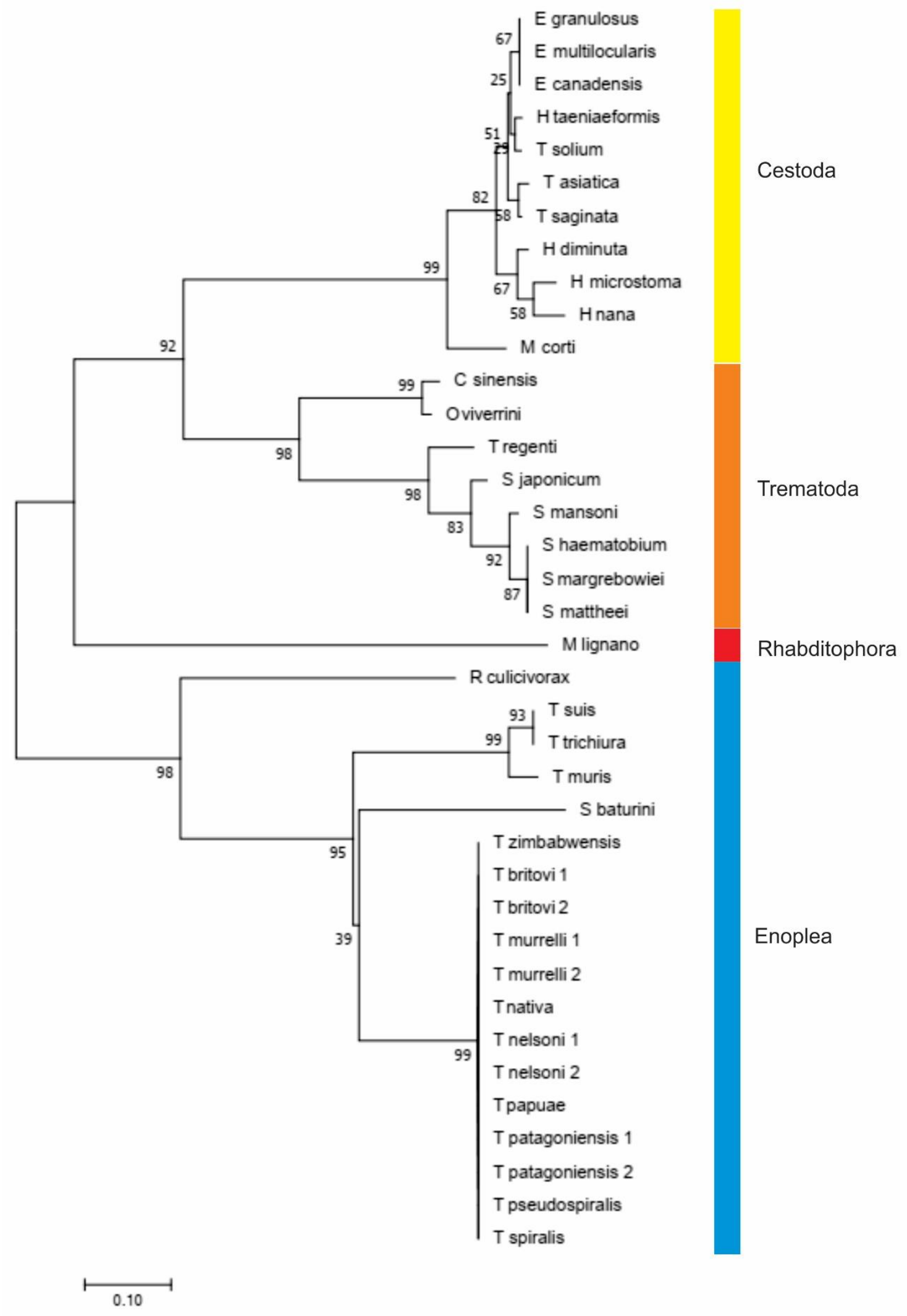

Figura 6. Análise da filogenia molecular dos homólogos de SmTNFR inferida pelo método de Neighbor-Joining [63]. A árvore ideal com a soma do comprimento do ramo $=3.34095585$ é mostrada. As porcentagens de árvores replicadas em que a taxa dos grupos associados no teste de bootstrap (1000 réplicas) são mostradas próximas às ramificações [57]. A árvore é desenhada em escala, com comprimentos 
de ramos nas mesmas unidades das distâncias evolutivas usadas para inferir a árvore filogenética. As distâncias evolutivas foram calculadas usando o método de correção de Poisson [62] e estão nas unidades do número de substituições de aminoácidos por local. A análise foi realizada com 38 sequências de aminoácidos. Todas as posições contendo lacunas e gaps foram eliminadas. Houve um total de 67 posições no conjunto de dados final. As analises evolutivas foram conduzidas no programa MEGA7 [50]. As barras coloridas à direita representam as classes taxonômicas dos respectivos organismos.

\subsubsection{MÉTODO UPGMA}

UPGMA (Unweighted Pair-Group Method using arithmetic Averages) é um método bem utilizado no qual os pares de sequências que mostram a menor distância evolutiva estão agrupados em primeiro lugar. Um dos principais problemas com este método é que seu uso pressupõe que a taxa evolutiva manteve-se constante ao longo da história evolutiva de um dado conjunto de organismos [59]. O resultado obtido com esta abordagem é mostrado na Figura 7. 


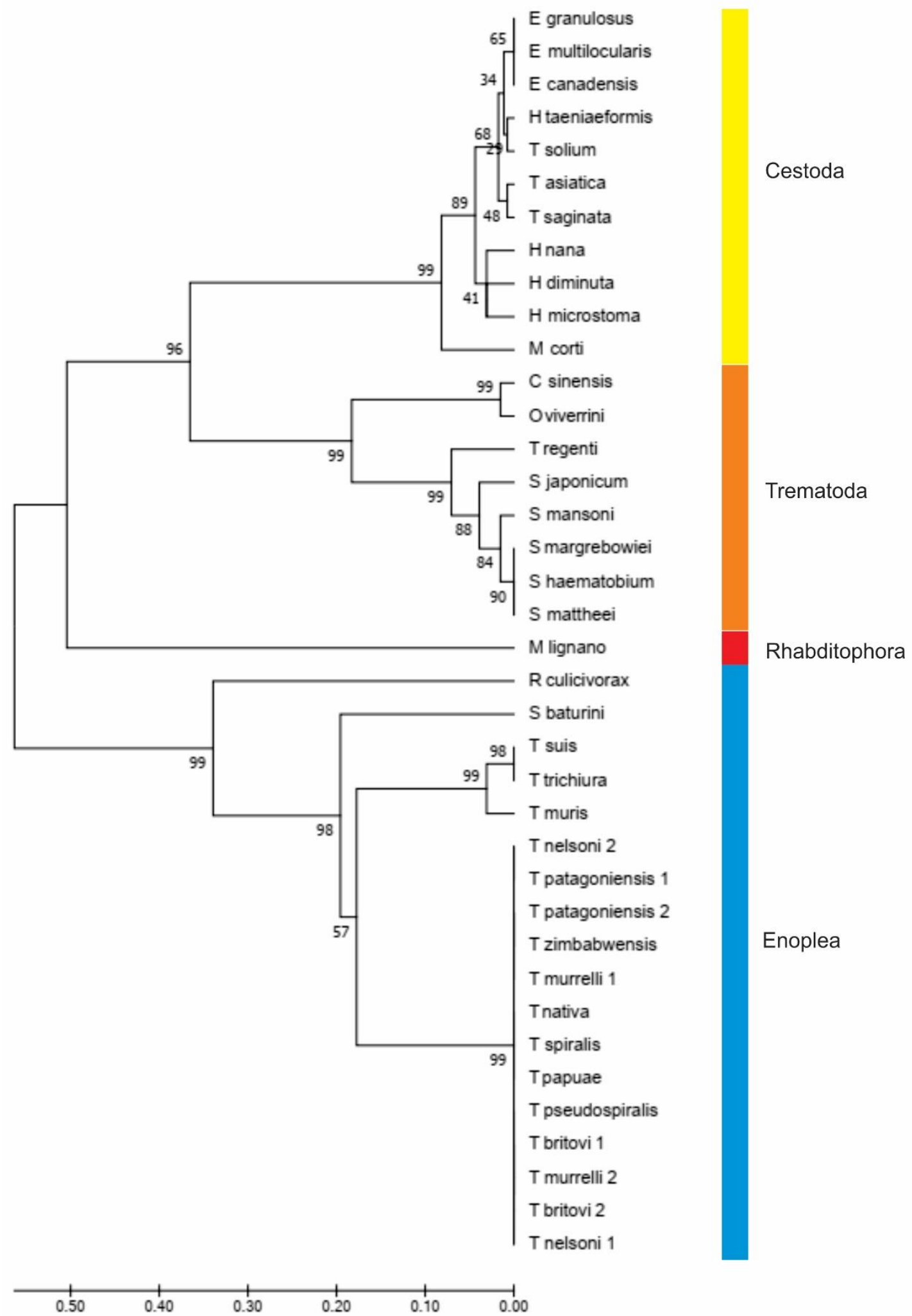

Figura 7. Análise da filogenia molecular dos homólogos de SmTNFR usando o método UPGMA[64]. A árvore ideal com a soma do comprimento do ramo = 2.75802943 é mostrada. A porcentagem de árvores replicadas em que as taxa associados agrupados no teste de bootstrap (1000 réplicas) são mostradas próximas às ramificações [57]. A árvore é desenhada em escala, com comprimentos de ramos nas mesmas unidades das distâncias evolutivas usadas para inferir a árvore 
filogenética. As distâncias evolutivas foram calculadas usando o método de correção de Poisson [62] e estão nas unidades do número de substituições de aminoácidos por local. A análise envolveu 33 sequências de aminoácidos. Todas as posições contendo lacunas e dados perdidos foram eliminadas. Houve um total de 158 posições no conjunto de dados final. Análises evolutivas foram realizadas no programa MEGA7 [50]. As barras coloridas à direita representam as classes taxonômicas dos respectivos organismos.

Mesmo diante desta grande diversidade de métodos para filogenia molecular, os resultados obtidos para os homólogos de SmTNFR são muito semelhantes. Isto sugere um resultado consistente, no qual podemos entender que as árvores indicam que nenhum grande evento de inserção, deleção ou duplicação ocorreu nesta família de genes ao longo da evolução. A separação dos clados está de acordo com o esperado para a evolução dos respectivos filos e classes.

Deve-se destacar que o os receptores em platelmintos são ancestrais aos dos nematoides, e destaca-se o receptor de $M$. lignano (platelminto de vida livre) que em geral está nas posições mais basais das árvores.

\subsection{Modelagem molecular comparativa dos receptores de TNF- alfa de platelmintos e nematelmintos}

A fim de tentar obter um modelo tridimensional da possível estrutura dos receptores, elegemos um homólogo representante de platelmintos (S. mansoni, SmTNFR) e um de nematelmintos ( $T$. spiralis, TsTNFR). A modelagem molecular comparativa foi realizada utilizando o programa Yasaha homology modeling (http://www.yasara.org/homologymodeling.htm) com a colaboração do Dr. José Geraldo de Carvalho Pereira do LNBio (Laboratório Nacional de Biociências) do CNPEM (Centro para Pesquisas em Energia e Materiais), Campinas - SP. A Figura 86 ilustra as duas melhores modelagens para $\operatorname{SmTNFR}(\mathrm{A})$ e TsTNFR (B).

Mesmo com relativas baixas taxas de identidade, ambos os homólogos possuem uma estrutura tridimensional predita parecida e estas são muito semelhante à estrutura do TNFR humano, proteína efetivamente cristalizada que teve sua conformação tridimensional efetivamente desvendada [65]. O receptor forma uma espécie de gancho, que quando associado a outras duas moléculas idênticas forma um trímero que será capaz de interagir com o ligante que também assume conformação trimérica para que possa ser possível a interação com o receptor. 


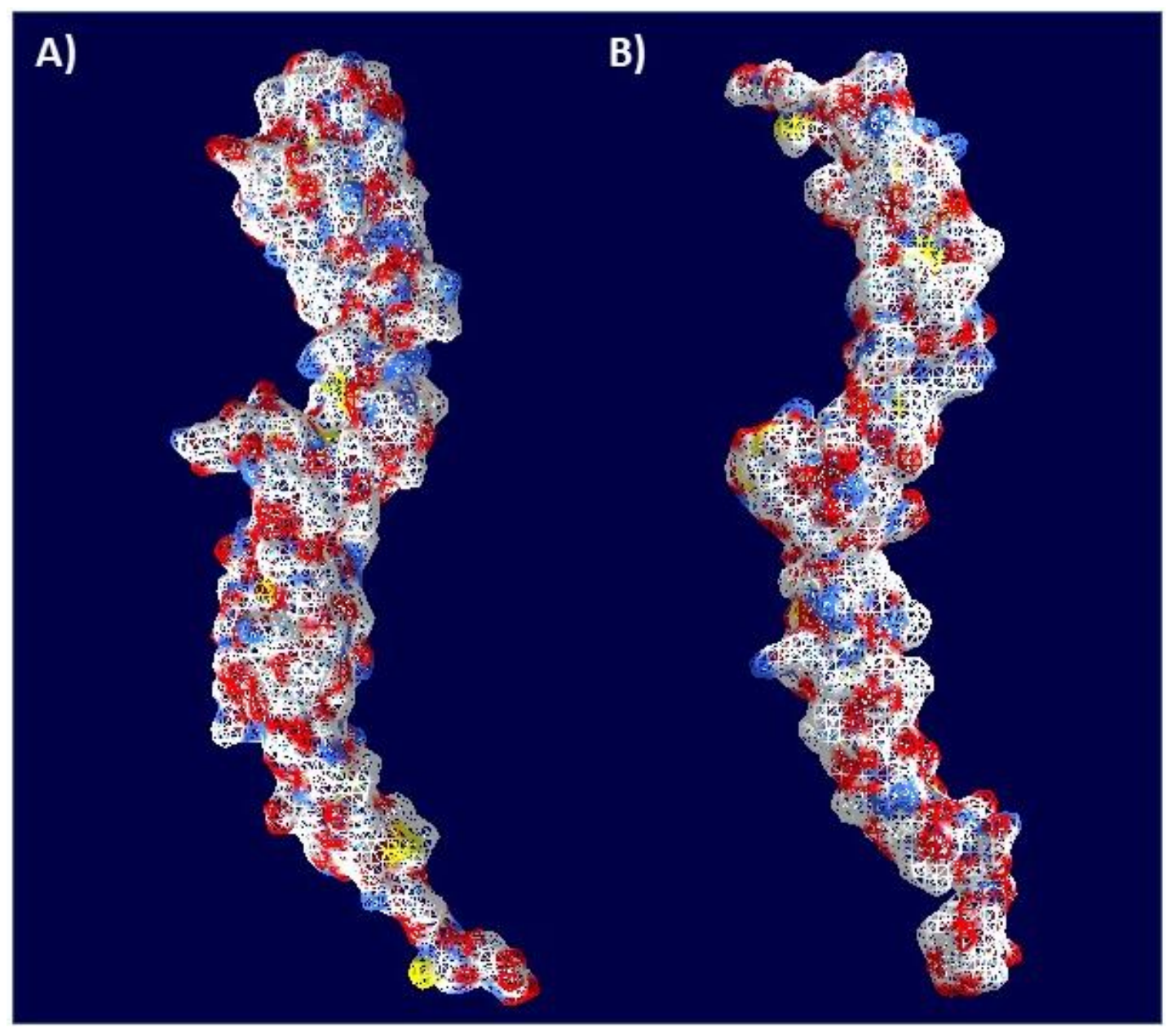

Figura 8. Modelagem molecular (visualização 3D) dos receptores SmTNFR (S. mansoni, Platelminto) (A) e TsTNFR (T. spiralis, Nematelminto) (B). A representação das figuras ilustra a superfície da molécula.

Outra abordagem que foi testada na modelagem comparativa foi a identificação dos receptores SmTNFR e TsTNFR com o TNF-alfa humano. Para esta abordagem também foi utilizada o programa Yasaha homology modeling (http://www.yasara.org/homologymodeling.htm). Os resultados obtidos são mostrados na Figura 97 (SmTNFR) e Figura 1028 (TsTNFR). 


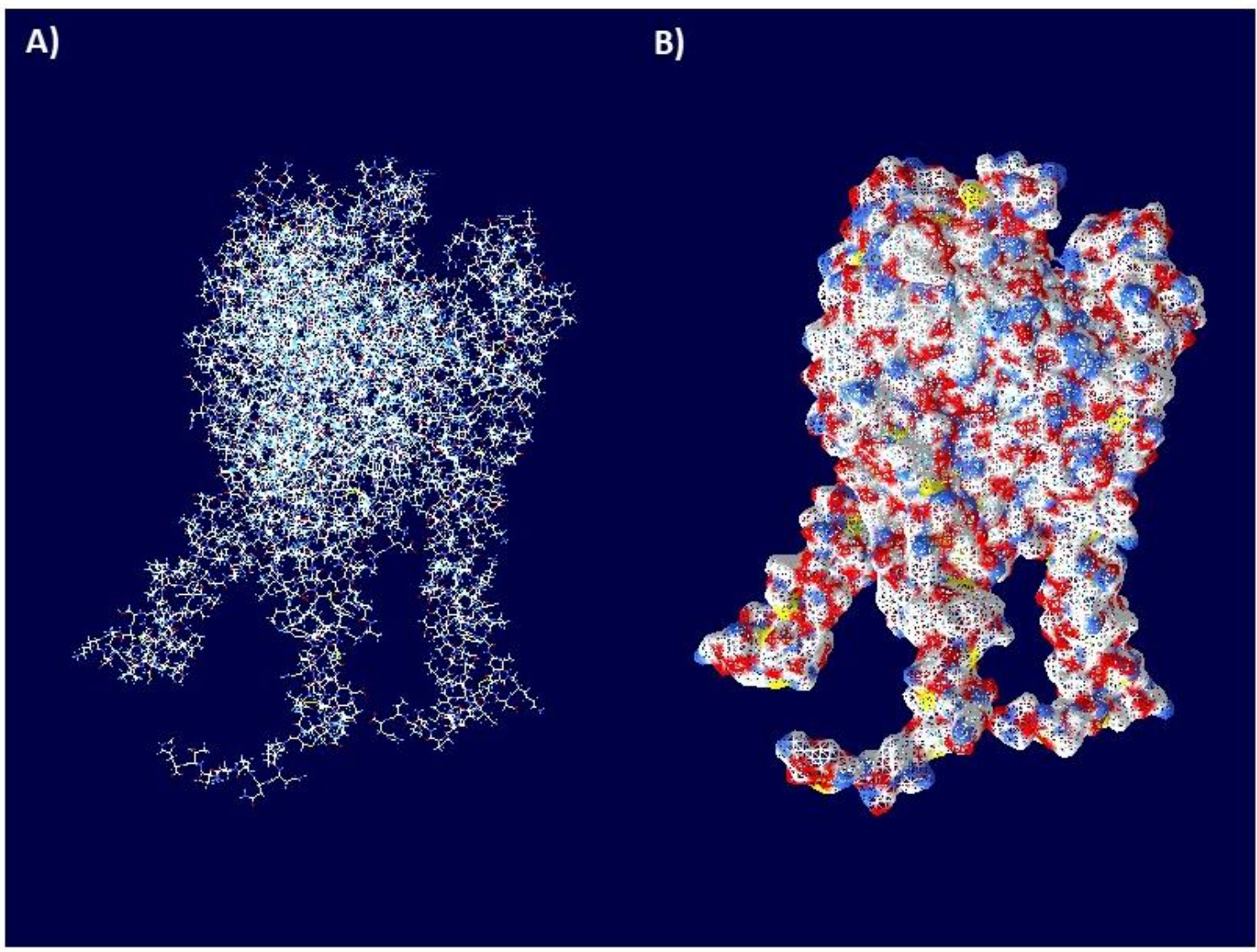

Figura 9. Modelagem molecular com o homólogo do receptor de TNF em platelminto (S. mansoni SmTNFR) acoplado com o TNF-alfa humano. A) Representação dos esqueletos de carbono das moléculas. B) Representação da superfície das moléculas. É possível notar a formação de um trímero dos receptores para interação com a citocina humana que também assume a forma trimérica (conforme a descrição da literatura) para a interação. 


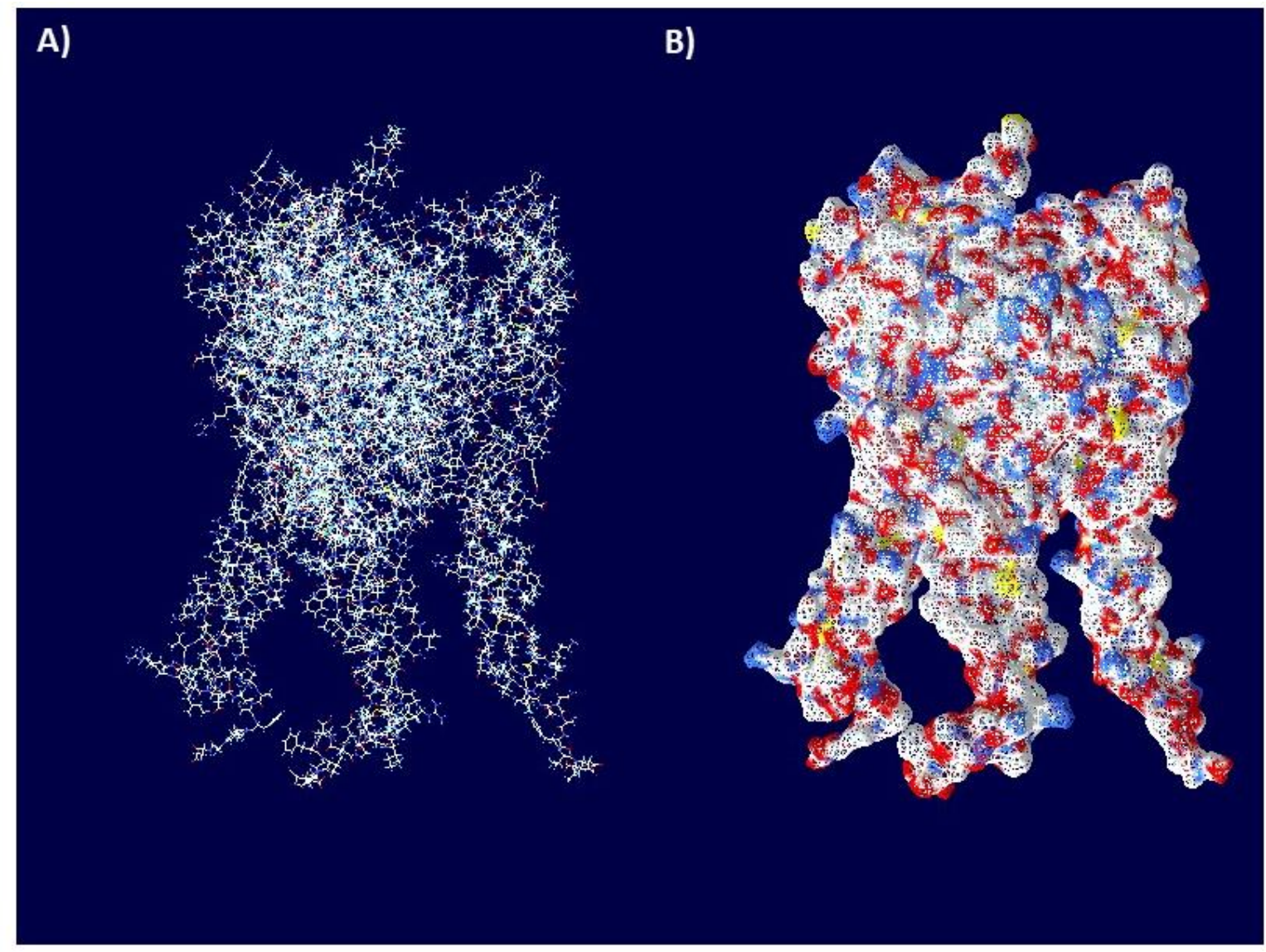

Figura 10. Modelagem molecular com o homólogo do receptor de TNF em nematelminto ( $T$. spiralis, TsTNFR) acoplado com o TNF-alfa humano. A) Representação dos esqueletos de carbono das moléculas. B) Representação da superfície das moléculas. É possível notar a formação de um trímero dos receptores para interação com a citocina humana que também assume a forma trimérica (conforme a descrição da literatura) para a interação.

É notável poder observar a possível interação que pode ocorrer entre a citocina humana e os receptores os parasitas. Além disso, conforme o esperado é interessante observar a conformação trimérica que os receptores dos helmintos provavelmente assumem caso interajam com o TNF-alfa humano, de maneira similar à que ocorre com os receptores de mamíferos [65].

Os arquivos ".pdb" com os resultados das modelagens mostradas nas Figuras 26, 27 e 28 estão disponíveis no CD-ROM de arquivos anexos à esta dissertação. 


\subsection{Identificação dos homólogos de ligantes da família de TNF- alfa humanos em helmintos}

Até o momento não havia sido identificado alguma sequência com similaridade com o próprio TNF-alfa humano no parasita S. mansoni. Logo, a descrição do efeito da citocina que fora observado e relatado pela literatura, juntamente com o fato da ausência do ligante endógeno, nos faz supor que o parasita utiliza o ligante hospedeiro para acionar a via de sinalização mediada por SmTNFR.

Entretanto, a fim de verificar se esta hipótese pode ser verdadeira para os demais parasitas, promovemos uma busca de ligantes utilizando um HMM do ligante TNF-alfa que está disponível nos bancos de dados de proteína. Utilizamos este HMM para realizar uma busca por ligantes nos genomas dos parasitas que estavam depositado no Wormbase Parasite (https://parasite.wormbase.org/index.html) [12].

O resultado surpreendente é que foram encontrados cinco homólogos de TNF-alfa no genoma do platelminto $M$. lignano, somente nesta única espécie cujo habitat é a vida livre. Impulsionados por este achado, procuramos no SRA Sequence Read Archive (https://www.ncbi.nlm.nih.gov/sra) por sequências (reads) em experimentos de RNA-seq de organismos evolutivamente próximos e que não tinham o genoma sequenciado. Encontramos alguns reads em poucas espécies e o alinhamento permitiu-nos remontar genes homólogos para as espécies: Macrostomum tuba (4 homólogos), Microdalyellia ruebushi (2 homólogos), Microdalyellia fusca (1 homólogo). Estes resultados estão sumarizados na Tabela 5. Cabe destacar que estas espécies de platelmintos são da classe Rhabidtophora, platelmintos de vida livre.

Diante destes resultados interessantes, fizemos uma busca no SRA por sequências homólogas ao receptor de TNF nas espécies $M$. tuba, $M$. ruebushi, $M$. fusca (todos platelmintos de vida livre) e nenhuma sequência homóloga foi encontrada. Assim, M. lignano é, até o momento, o único helminto que possui homólogos ao receptor de TNF (1 homólogo) e ao ligante da família de TNF (5 homólogos).

As sequências dos homólogos de helmintos dos ligantes da família de TNF-alfa estão disponíveis no Arquivo Suplementar 2, no CD-ROM anexo a esta dissertação. 
Tabela 5. Homólogos dos ligantes de TNF humanos em helmintos identificados pelas abordagens de HMMer e BLAST.

\begin{tabular}{|c|c|c|c|c|c|c|c|}
\hline Filo & Classe & Organismo & Gene ID & $\begin{array}{l}\text { HMMer } \\
\text { e-value }\end{array}$ & Hospedeiro & scaffold genomico & Coordenadas \\
\hline Platelminto & Rhabditophora & M. lignano & 7543-snap-gene-0.3-mRNA-1 & $9.2 e-155$ & Vida Livre & Scaffold unitig_7543 & $651-9914$ \\
\hline Platelminto & Rhabditophora & M. lignano & 0002434-snap-gene-0.8-mRNA-1 & $7.9 e-126$ & Vida Livre & $\begin{array}{l}\text { Scaffold } \\
\text { uti_cns_0002434 }\end{array}$ & $93866-95263$ \\
\hline Platelminto & Rhabditophora & M. lignano & 0003791-snap-gene-0.3-mRNA-1 & $1.4 \mathrm{e}-123$ & Vida Livre & $\begin{array}{l}\text { Scaffold } \\
\text { uti cns } 0003791\end{array}$ & $10940-12109$ \\
\hline Platelminto & Rhabditophora & M. lignano & 0005014-snap-gene-0.4-mRNA-1 & $2.5 e-122$ & Vida Livre & $\begin{array}{l}\text { Scaffold } \\
\text { uti_cns_0005014 }\end{array}$ & $28762-29933$ \\
\hline Platelminto & Rhabditophora & M. tuba & Mtuba_comp32280_c0_seq1 & & Vida Livre & & \\
\hline Platelminto & Rhabditophora & M. tuba & Mtuba_comp49742_c0_seq1 & & Vida Livre & & \\
\hline Platelminto & Rhabditophora & M. tuba & Mtuba_comp10275_c0_seq1 & & Vida Livre & & \\
\hline Platelminto & Rhabditophora & M. tuba & Mtuba_comp64136_c0_seq1 & & Vida Livre & & \\
\hline Platelminto & Rhabditophora & M. ruebushi & M_ruebushi_seq1 & & Vida Livre & & \\
\hline Platelminto & Rhabditophora & M. ruebushi & M_ruebushi_seq2 & & Vida Livre & & \\
\hline Platelminto & Rhabditophora & M. fusca & gnl|SRA|SRR1797774.18034832.2 & & Vida Livre & & \\
\hline
\end{tabular}




\subsection{Comparação dos homólogos de ligantes dos helmintos os ligantes da família de TNF-alfa humanos}

De maneira semelhante à realizada com os homólogos dos receptores de TNF, foi realizado um BLASTp dos 12 homólogos dos helmintos contra 19 ligantes da família de TNF de humanos. Os resultados obtidos estão organizados na Tabela suplementar 2 junto aos arquivos anexos (CD-ROM) desta dissertação.

Matrizes com os dados dos alinhamentos feitos com o programa BLASTp foram construídas e são mostradas nas próximas figuras. $\mathrm{Na}$

Figura 119 são mostrados os E-values, na Figura os scores, na

Figura as porcentagens de identidade dos alinhamentos, na

Figura as taxas de similaridade e por fim, na Figura as taxas de cobertura dos homólogos aos ligantes de TNF de helmintos em relação aos ligantes da família de TNF humano.

É interessante notar que nove dos doze homólogos identificados possuem similaridade com o TNF-alfa humano propriamente dito, e o homólogo de M. tuba (49742) possui menor E-value e score com esta molécula.

Os homólogos desta e das outras espécies também possuem similaridades com outros ligantes da família de TNF-alfa, como EDA-A2, EDA-A1, BAFF_TN13B_HUMAN, APRIL_TNF13_HUMAN, TWEAK_TNF12_HUMAN, e LT-alfa (linfotoxina, conhecida também como TNF-beta). 


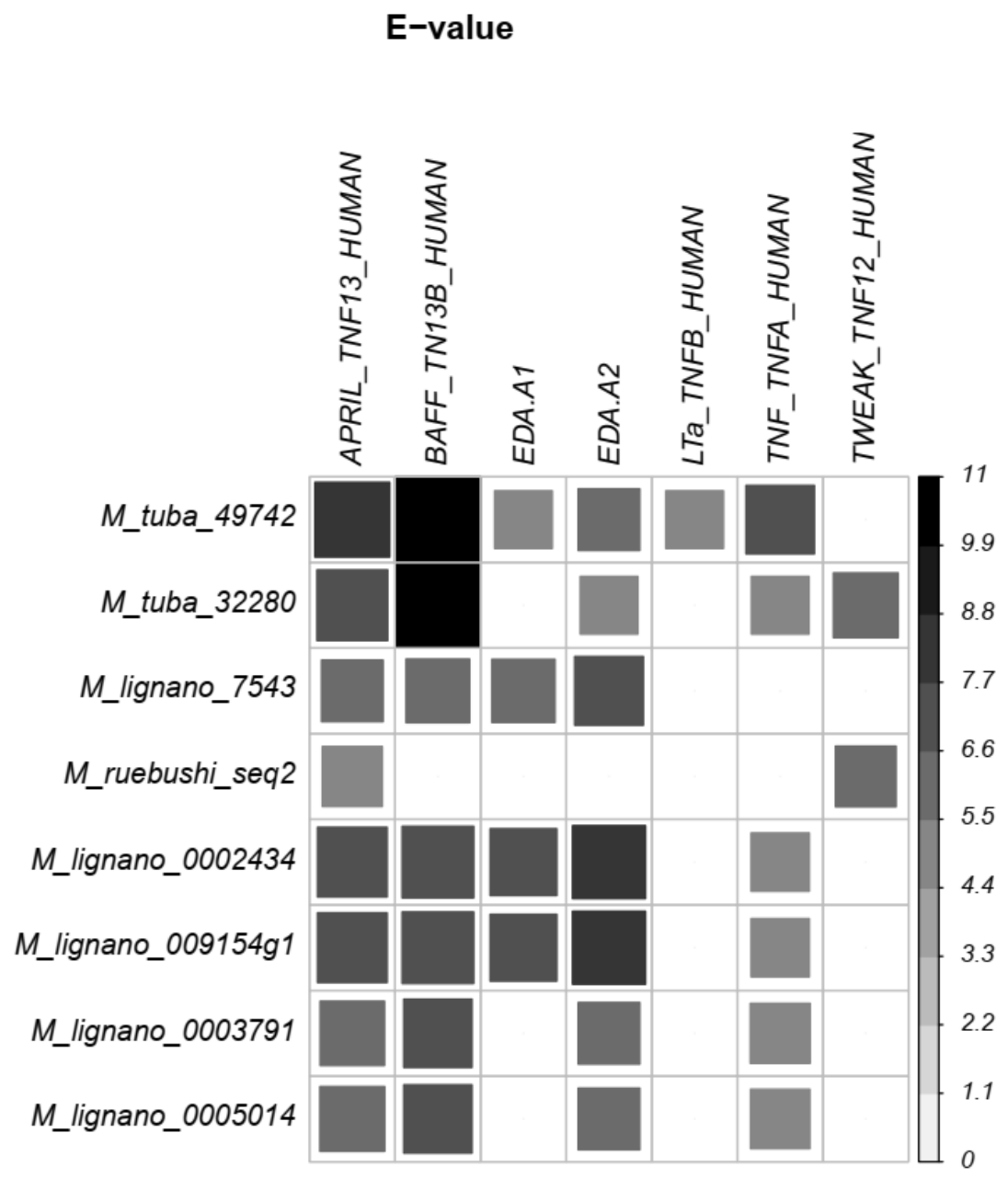

Figura 11. Matrix dos $E$-values (- $\log _{10} E$-value) dos alinhamentos dos homólogos de ligantes de TNF-alfa de helmintos com os ligantes da família de TNF humano por BLASTp. Nas linhas estão identificados os homólogos de ligantes de TNF dos helmintos e nas colunas estão identificados os membros da família dos ligantes de TNF-alfa humanos. Quanto maior a intensidade e a área preenchida com preto menor o valor de E-value, à direita encontra-se uma escala de cor aplicada aos valores -log10 E-value. 


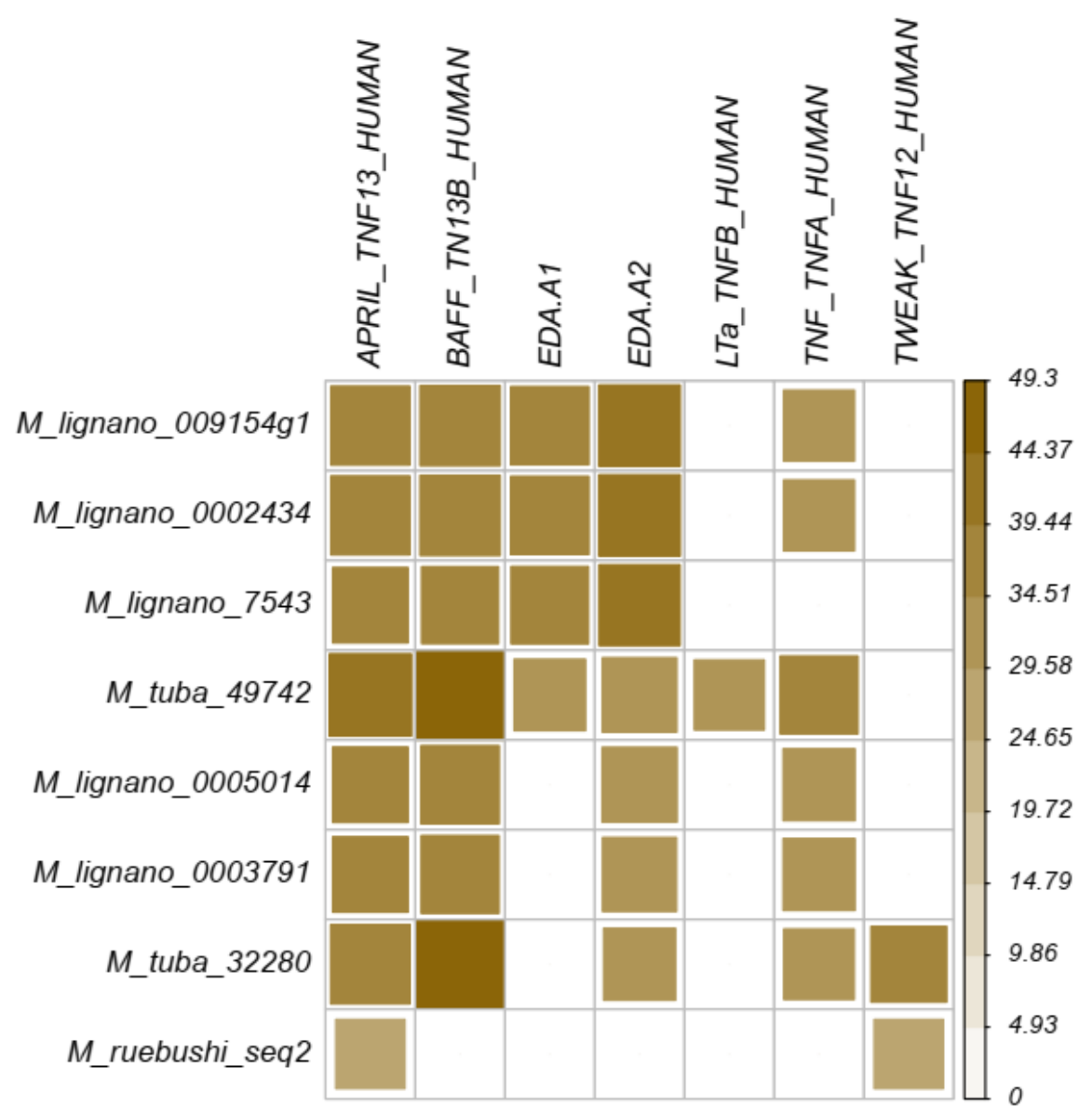

Figura 30. Matrix dos scores dos alinhamentos dos homólogos de ligantes de TNF-alfa de helmintos com os ligantes da família de TNF humanos por BLASTp. Nas linhas estão identificados os homólogos dos ligantes de TNF dos helmintos e nas colunas estão identificados os membros da família dos ligantes de TNF humanos. Quanto maior a intensidade e a área preenchida com marrom maior o valor do Score, à direita encontra-se uma escala de cor aplicada aos valores de Score dos alinhamentos. 


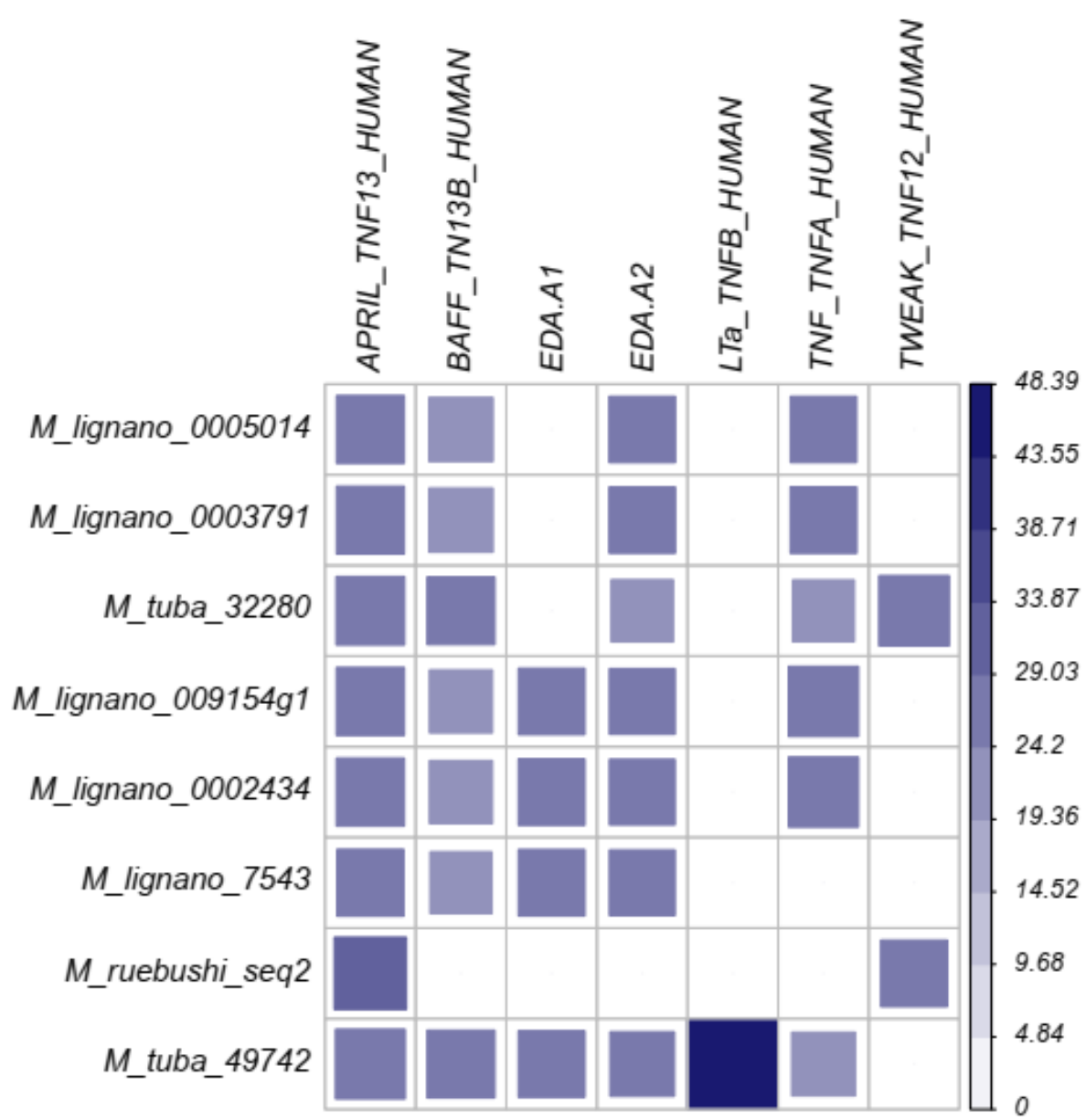

Figura 31. Matrix das porcentagens de identidades dos alinhamentos dos homólogos dos ligantes de TNF-alfa de helmintos com os ligantes da família de TNF humano. Nas linhas estão identificados os homólogos dos ligantes de TNF dos helmintos e nas colunas estão identificados os membros da família dos ligantes de TNF humanos. Quanto maior a intensidade e a área preenchida com azul maior o valor da \% de identidade, à direita encontra-se uma escala de cor aplicada aos valores de identidade dos alinhamentos. 


\section{Porcentagem de similaridade}

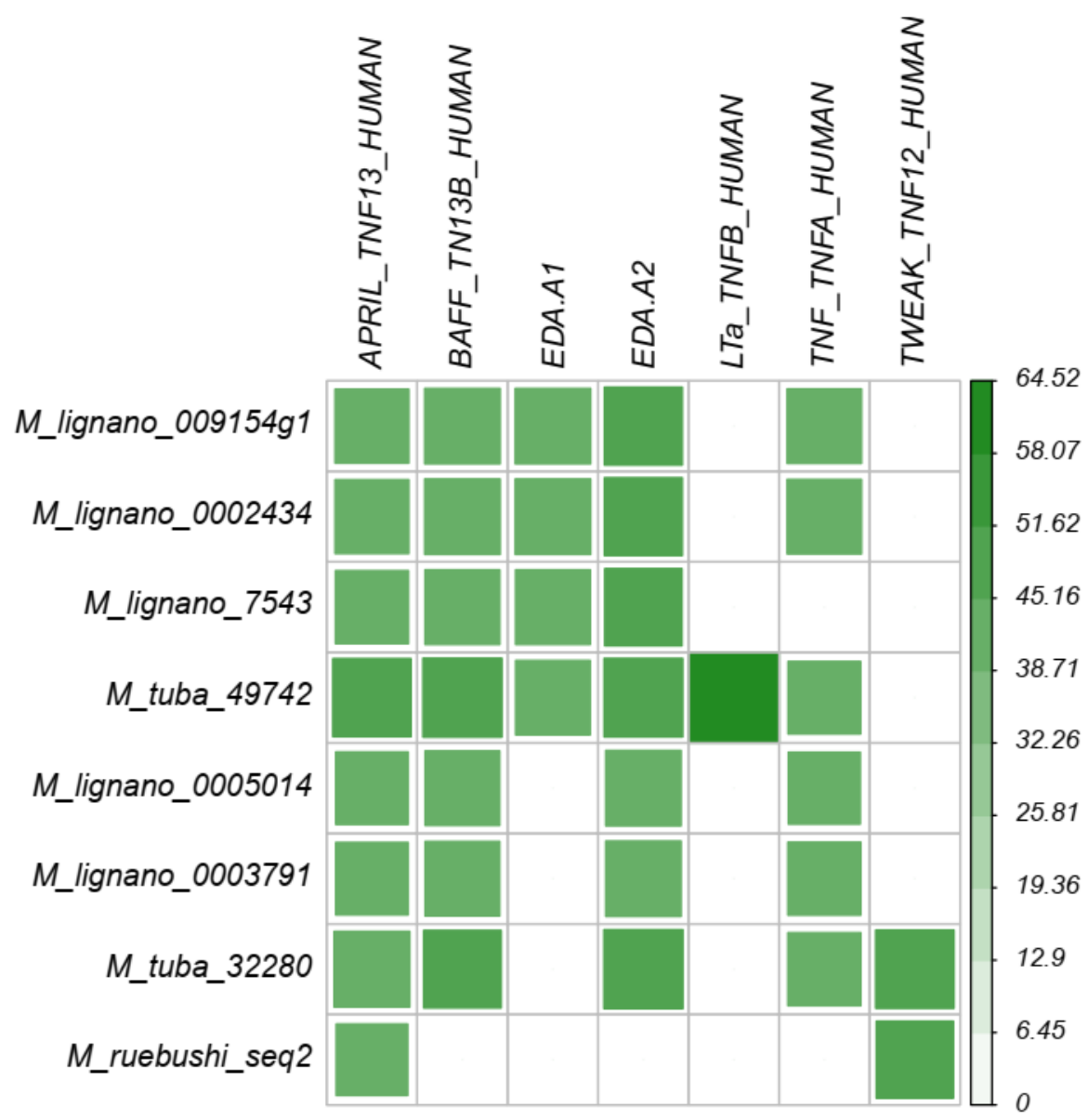

Figura 32. Matrix das porcentagens de similaridade dos alinhamentos dos homólogos dos ligantes de TNF-alfa de helmintos com os ligantes da família de TNF humanos por BLASTp. Nas linhas estão identificados os homólogos dos ligantes de TNF dos helmintos e nas colunas estão identificados os membros da família dos ligantes de TNF humanos. Quanto maior a intensidade e a área preenchida com verde maior o valor da \% de similaridade, à direita encontra-se uma escala de cor aplicada aos valores de similaridade dos alinhamentos. 


\section{Cobertura do humano pelo homólogo do parasita}

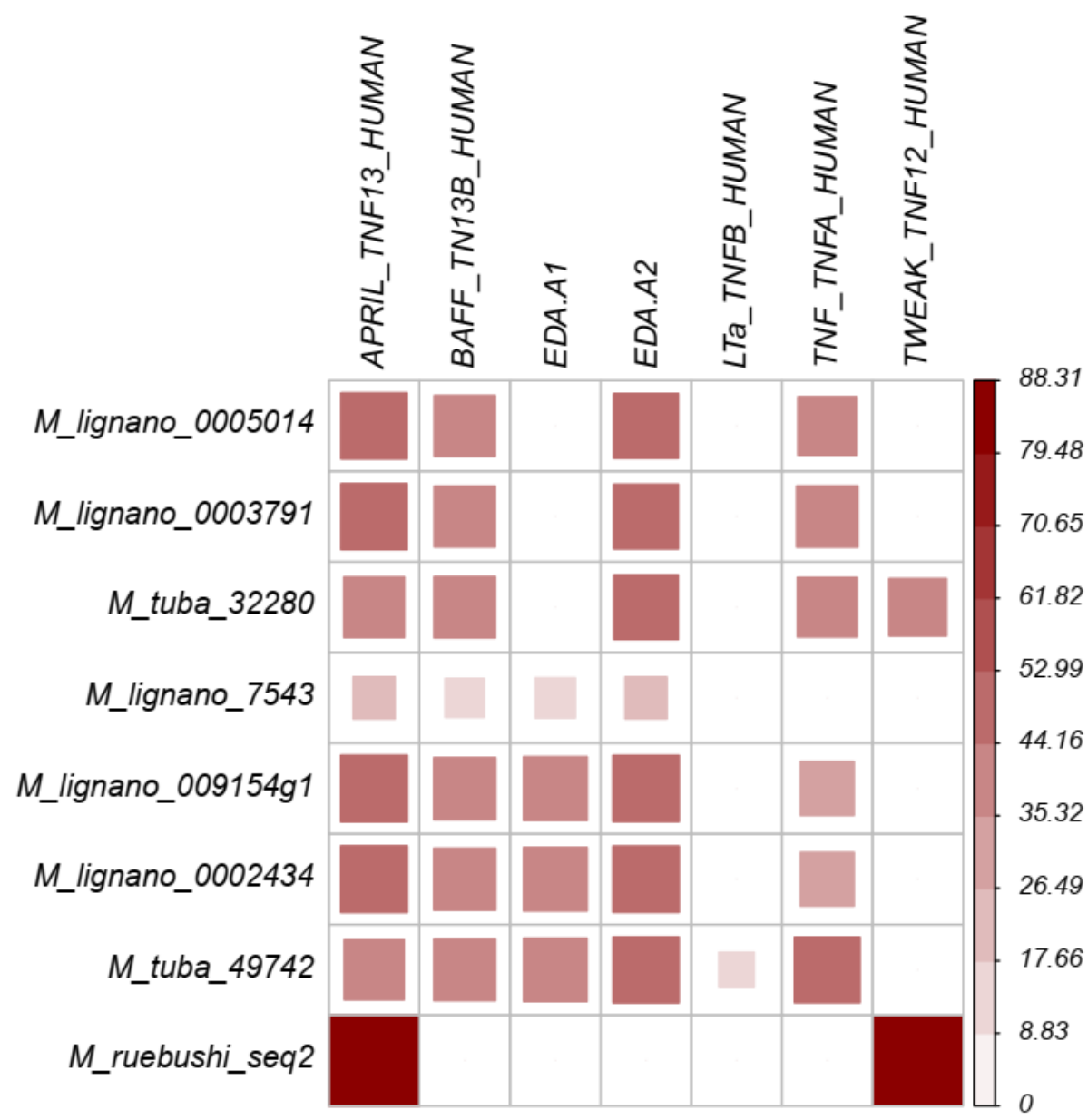

Figura 33. Matrix das porcentagens de cobertura das sequências dos ligantes humanos pelos homólogos de ligantes dos helmintos por BLASTp. Nas linhas estão identificados os homólogos dos ligantes de TNF dos helmintos e nas colunas estão identificados os membros da família dos ligantes de TNF humanos. Quanto maior a intensidade e a área preenchida com vermelho maior o valor da porcentagem de cobertura, à direita encontra-se uma escala de cor aplicada aos valores de cobertura dos alinhamentos. 


\subsection{Identificação e alinhamento dos domínios conservados dos homólogos de ligantes da família de TNF-alfa humanos}

De forma semelhante à que foi feita com os receptores foi realizada a busca por domínios conservados nos ligantes homólogos ao TNF. Os domínios proteicos conservados encontrados estão documentados na Tabela 6 e esquematicamente representados na Figura 12. Em seguida foi realizado um alinhamento no MUSCLE e o resultado obtido é mostrado na Figura 13.

\subsection{Análise filogenética dos ligantes de helmintos homólogos aos ligantes de TNF humano}

Numa abordagem similar à que foi feita com os receptores de TNF de helmintos realizamos uma análise filogenética com os 12 homólogos dos ligantes de TNF dos helmintos de vida livre.

Baseado nos princípios do método, na experiência obtida com as análises dos receptores e no que está sendo utilizado na literatura atual decidimos utilizar o método de Inferência Bayesiana. O resultado obtido por esta abordagem está mostrado na Figura 14. 
Tabela 6. Domínios conservados encontrados nos homólogos de TNF (ligante) em helmintos

\begin{tabular}{|c|c|c|c|c|c|c|c|c|c|}
\hline Organismo & Gene ID & \# AA & $\begin{array}{l}\text { Pept. } \\
\text { Sinal }\end{array}$ & $\begin{array}{l}\text { \# Dom. } \\
\text { TM }\end{array}$ & $\begin{array}{c}\text { Coord. } \\
\text { TM } 1\end{array}$ & $\begin{array}{l}\text { Coord. } \\
\text { TM2 }\end{array}$ & $\begin{array}{l}\text { \# Dom. } \\
\text { TNF }\end{array}$ & $\begin{array}{l}\text { \# AA } \\
\text { Dom. } \\
\text { TNF }\end{array}$ & Coord.Dom. TNF \\
\hline M. lignano & 7543-snap-gene-0.3-mRNA-1 & 543 & Não & 2 & $274-296$ & $355-357$ & 1 & 117 & $424-541$ \\
\hline M. lignano & 0002434-snap-gene-0.8-mRNA-1 & 216 & Não & 1 & $07-29$ & & 1 & 117 & $97-214$ \\
\hline M. lignano & 0003791-snap-gene-0.3-mRNA-1 & 213 & Não & 1 & $07-29$ & & 1 & 117 & $97-213$ \\
\hline M. lignano & 0005014-snap-gene-0.4-mRNA-1 & 213 & Não & 1 & $07-29$ & & 1 & 117 & $97-213$ \\
\hline M. lignano & Mlig009154g1 & 216 & Não & 1 & $07-29$ & & 1 & 117 & $97-214$ \\
\hline M. tuba & Mtuba_comp32280_c0_seq1 & 220 & Não & 1 & $10-34$ & & 1 & 120 & $77-218$ \\
\hline M. tuba & Mtuba_comp49742_c0_seq1 & 218 & Não & 1 & $10-32$ & & 1 & 112 & $105-216$ \\
\hline M. tuba & Mtuba_comp10275_c0_seq1 & 283 & Não & 1 & $43-65$ & & 1 & 105 & $160-265$ \\
\hline M. tuba & Mtuba_comp64136_c0_seq1 & 316 & Não & 1 & $74-96$ & & 1 & 119 & $196-314$ \\
\hline M. ruebushi & M_ruebushi_seq1 & 117 & Não & 0 & & & 1 & 75 & $36-110$ \\
\hline M. ruebushi & M_ruebushi_seq2 & 77 & Não & 0 & & & 1 & 76 & $01-71$ \\
\hline M. fusca & gnl|SRA|SRR1797774.18034832.2 & 33 & Não & 0 & & & 1 & 28 & $05-33$ \\
\hline
\end{tabular}

\#AA= Número de aminoácidos codificados; Pept. Sinal= Presença de Peptídeo sinal; \# Dom. TM= Numero de Domínios Transmembrana; Coord. TM1= Coordenada do Domínio Transmembrana 1; Coord. TM2= Coordenada do domínio transmembrana 2; \# Dom. TNF= Número de domínios TNF; \# AADom TNF= número de aminoácidos no domínio conservado de TNF; Coord TNF= Coordenada do domínio de TNF; 
M. ligano 7543

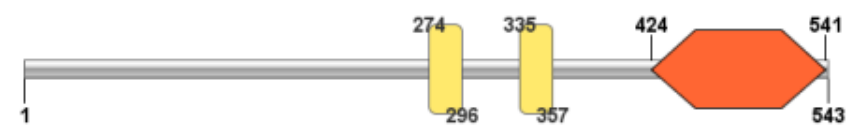

M. ligano 2434

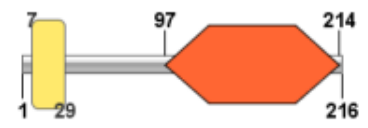

M. ligano 3791

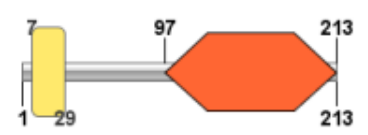

M. ligano 5014

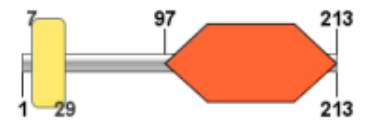

M. ligano $9154 g 1$

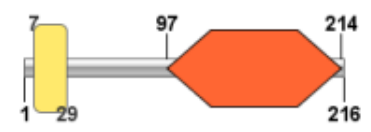

M. tuba 32280

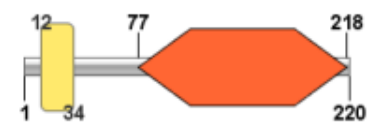

M. tuba 49742

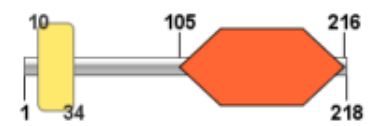

M. tuba 10275

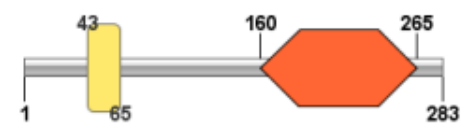

M. tuba 10275

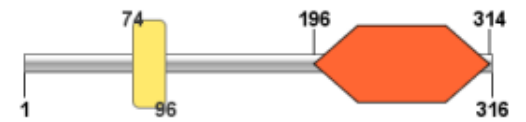

M. ruebushi-seq1

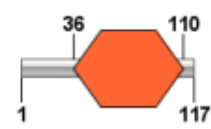

M. ruebushi seq2

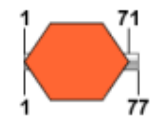

M. fusca

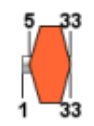

Transmembrana

Figura 124. Representação esquemática dos domínios conservados reconhecidos nos homólogos dos ligantes da família de TNF-alfa em helmintos. Os hexágonos laranjas representam o domínio de TNF-alfa e os retângulos amarelos representam regiões transmembrana. O comprimento das linhas e a distância dos elementos representados não são fidedignos às distâncias reais de cada homólogo. 
Conservation

Quality

Consensus

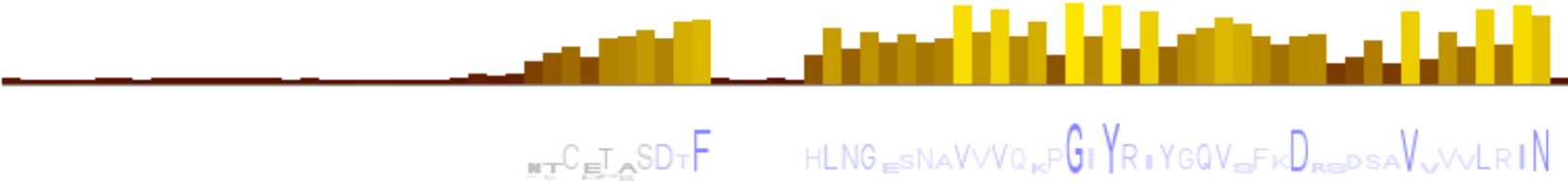

TNEYF TRDGSLGPLKCRDDFFEEEG+++NTCETASDTFPEWRCHLNGESNAVVVQKPG IYR IYGQVSFKDRSDSAVVVVLRINP

Occupancy

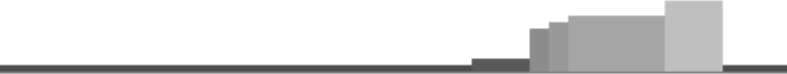

M_lignano_7543 M_lignano_2434 M_lignano_3791 M_lignano_5014 M-lignano_915 M-tuba-32280 M-tuba 49742 M-tuba_10275 M_tuba_64136 M_ruebushi_seq 1 Mruebushi_seq 2 M_fused

Conservation $51 \ldots . . . . . N Y N F V Q C H Q Q N R Q P A S R N G R$. QANAPYTTCTVSGERRLREGDRVGLF ISESLRTVNCYHKTTFWGMVRM $51 \ldots \ldots \ldots$ NYNF VQCHQQNRQPASRNGR - QANAPYT TC TVSGERRLREGDRVGLF I PESLRT VNCYRKTTF WGMVRI $51 \ldots \ldots \ldots$ NYNF VQCHQQNRQPASRDGR - QANAPYT TC TVSGERRLREGDRVGLF I PESLRTVNCYHKTTFWGM. KL $51 \ldots \ldots \ldots N Y \ldots N F Q C H Q Q N R Q P A S R D G R$ - QANAPYTTC TVSGERRLREGDRVGLF IPESLRTVNCYHKT TFWGM - KL $50 \ldots \ldots \ldots$ NYNF VQCHQQNRQPASRNGR. QANAPYTTCTVSGERRLREGDRVGLF IPESLRTVNCYRKTTFWGMVRM

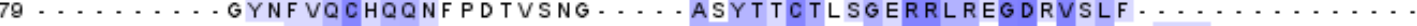
$49 \ldots \ldots . . . .$. EHSFVQCHQQNLPLGA.... MQSAPYTTCTLNGERRLRQGDKVSLYVPESRRT I NAYFKTTFWG IVRM 45 EN CGPECWAPSRTWL SCF SHSRRPQQSNSSTRASGQF SVCTI DGVRRF KRGDVVSLQTSQP

$54 \ldots \ldots . . .6$. . . . . $19 \ldots \ldots \ldots$ DVTWATCAL ............. NVTGSQLPCSVTTARRLSAGDRVAVQLPQAYRLI DPHYSITYVDLVQL

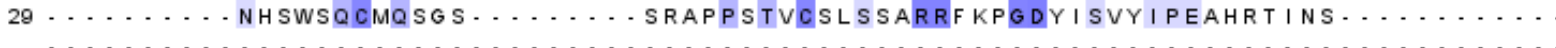


Figura 135. Alinhamento dos domínios conservados de TNF dos homólogos dos ligantes da família de TNF em helmintos. Alinhamento com 11 sequências de homólogos de TNF-alfa com os domínios de TNF conservados (158 resíduos aminoácidos) usando o programa MUSCLE. Os resíduos de aminoácidos estão coloridos em tons de roxo conforme o nível de conservação conforme o método de AMAS [51].

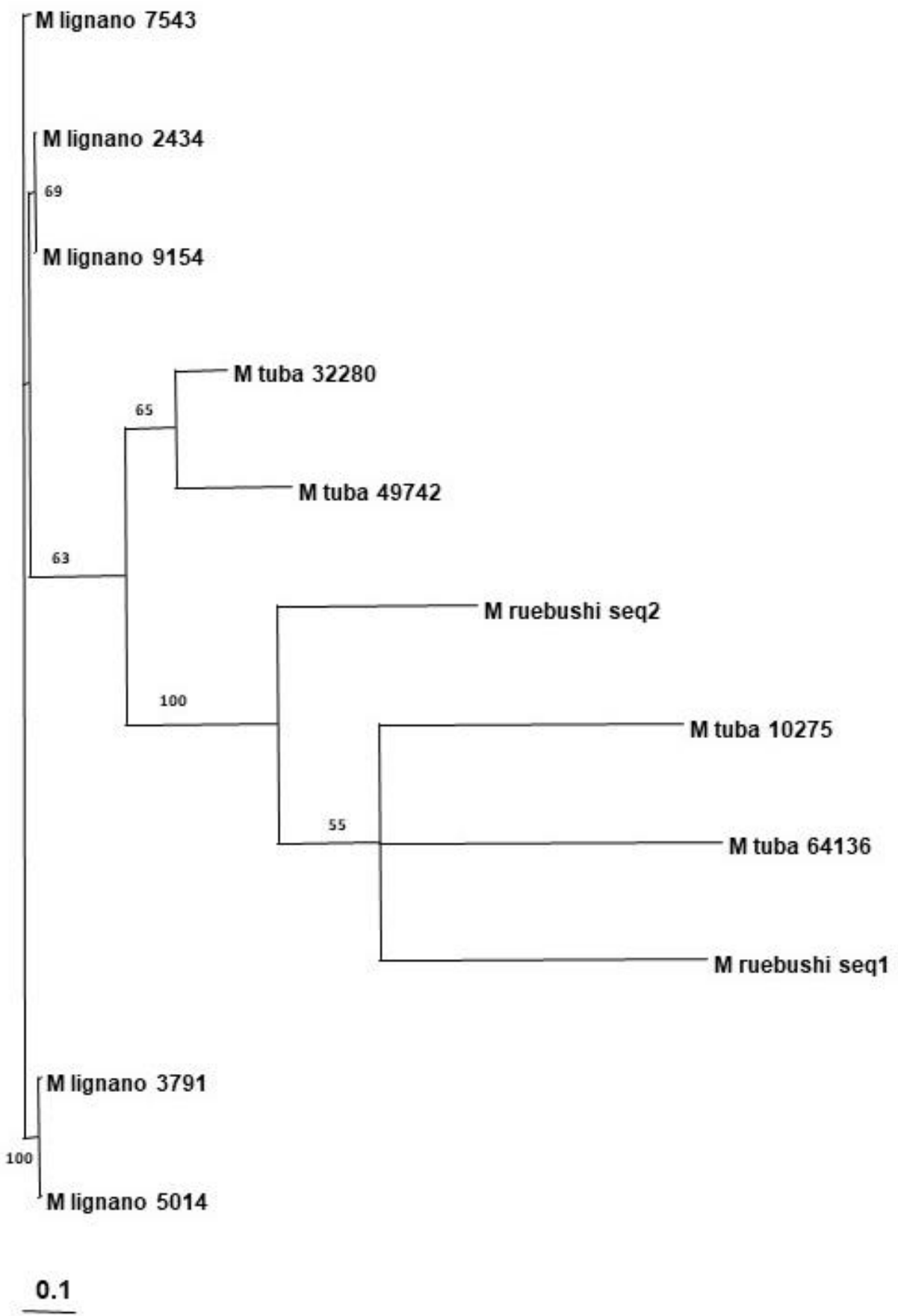

Figura 146. Análise da filogenia molecular de 11 homólogos de TNF realizada por Inferência Bayesiana. A árvore e análise de credibilidade de 158 árvores foram geradas pelo programa Mr. Bayes [53]. 


\section{Discussão}

Existem poucos trabalhos na literatura que descrevam a caracterização da via de sinalização de TNF-alfa em invertebrados. Esta é uma das razões que destacam a importância dos resultados obtidos neste trabalho para a comunidade científica.

Um dos primeiros resultados interessantes a se destacar é a presença de homólogos de receptores de TNF-alfa somente em helmintos. Os protozoários, organismos unicelulares que, em geral, vivem no interior de outras células, não possuem nenhuma evidência nas sequências do genoma e transcriptoma de homólogos de SmTNFR. O aparecimento do receptor de TNF-alfa provavelmente ocorreu ao longo da evolução com a expansão dos genomas e surgimento dos metazoários.

O estudo do contexto genômico e a busca por ESTs para melhorar e expandir as predições gênicas para as pontas UTRs, embora interessante, não resultou em uma melhora significativa, especialmente devido à relativa pouca quantidade de ESTs de helmintos disponíveis nos bancos de dados públicos. Sem dúvida um novo assembly com os reads de sequenciamento de nova geração disponíveis no banco SRA - Sequence Read Archive (https://www.ncbi.nlm.nih.gov/sra) poderia dar um melhor resultado na correção de eventuais erros nas predições gênicas. Entretanto este processo dispenderia uma grande capacidade computacional para 0 armazenamento e processamento de dados, o que não é logisticamente fácil de obter.

A busca de homólogos utilizando a ferramenta HMMER (http://hmmer.org/) se mostrou muito mais eficiente, especialmente devido ao fato de o programa construir um HMM de busca com a sequências de helmintos. Isso faz com que ele seja um modelo mais adequado, pois nos permite computar e fazer um modelo de probabilidades com sequências de organismos evolutivamente próximos gerando um padrão de busca eficaz, ajustado e flexível para a pesquisa nos bancos de dados. Diferentemente do BLAST que exige um alinhamento preciso, resultando numa abordagem menos flexível, porém não menos útil. De fato, são algoritmos com princípios diferentes, porém as abordagens se complementam para a busca de homólogos [30].

Foram identificados 47 homólogos em 42 espécies, em quatro espécies (do gênero Trichinella) existem duas isoformas para o mesmo transcrito e em duas espécies ( $R$. culicivorax e $S$. baturini) existe a localização de dois homólogos em locais distintos do 
genoma, sugerindo duplicação gênica. No entanto é importante ter presente que estes dois organismos têm as piores montagens dos genomas (conforme será abordado a seguir, Figura 37) a duplicação pode ser um artefato técnico, entretanto se isto não é artefato técnico, este fato sugere que o início da expansão dos receptores ocorreu nos nematelmintos. Isto é muito interessante pois os mamíferos possuem mais de 20 membros da família de receptores de TNF-alfa [67].

É interessante descrever que foram reconhecidos domínios característicos dos receptores de TNF, em 33 homólogos 4 domínios (como esperado) e os outros 12 homólogos com um número menor, além disso, é possível detectar a presença de domínios transmembrana na região amino e mais a carboxi-terminal de alguns dos homólogos. Isto provavelmente é devido não a fatores biológicos, mas a fatores técnicos derivados do sequenciamento e das montagens dos genomas dos helmintos (como mostraremos a seguir).

Ao avaliar as montagens (assemblies) do genoma dois principais critérios devem ser levados em consideração: o número dos contigs e o N50. O número de contigs é importante pois revela em quantos "pedaços" o genoma do organismo está montado. Um contig é o produto de alinhamento de diversos reads e um conjunto de contig forma um super contig ou scaffold genômico. Assim, quanto menor o número de contigs melhor é a montagem do genoma. O N50 é definido como o comprimento (em pares de bases) do contigs que alberga $50 \%$ das bases totais do genoma, uma vez que estes contigs estejam ordenados do menor para o maior; é razoável assumir que é como se fosse uma mediana da montagem do genoma. Assim, quanto maior o N50, melhor a montagem de um genoma [67].

Um levantamento realizado sobre o N50 e o número de contigs das versões atuais do assemblies dos genomas que foram interrogados neste projeto revelaram dados interessantes. A Figura 15 mostra a relação do N50 (A) e do número de contigs (B) dos genomas interrogados com o número dos domínios conservados de TNFR. Podemos observar que a maior parte dos organismos que possuem menos de 4 domínios de TNFR possuem os menores N50 (Figura 37 A) e os maiores números de contigs (Figura $37 \mathrm{~B}$ ). Isto sugere fortemente que os genes estão incompletos em virtude das montagens dos genomas. Os preditores gênicos erram substancialmente quando os genomas são mal montados, geram transcritos incompletos e com a identificação errada de exons, como pudemos perceber nos genes/proteínas que foram estudados neste trabalho [67]. 
A)

log N50 vs. \# domínios TNFR

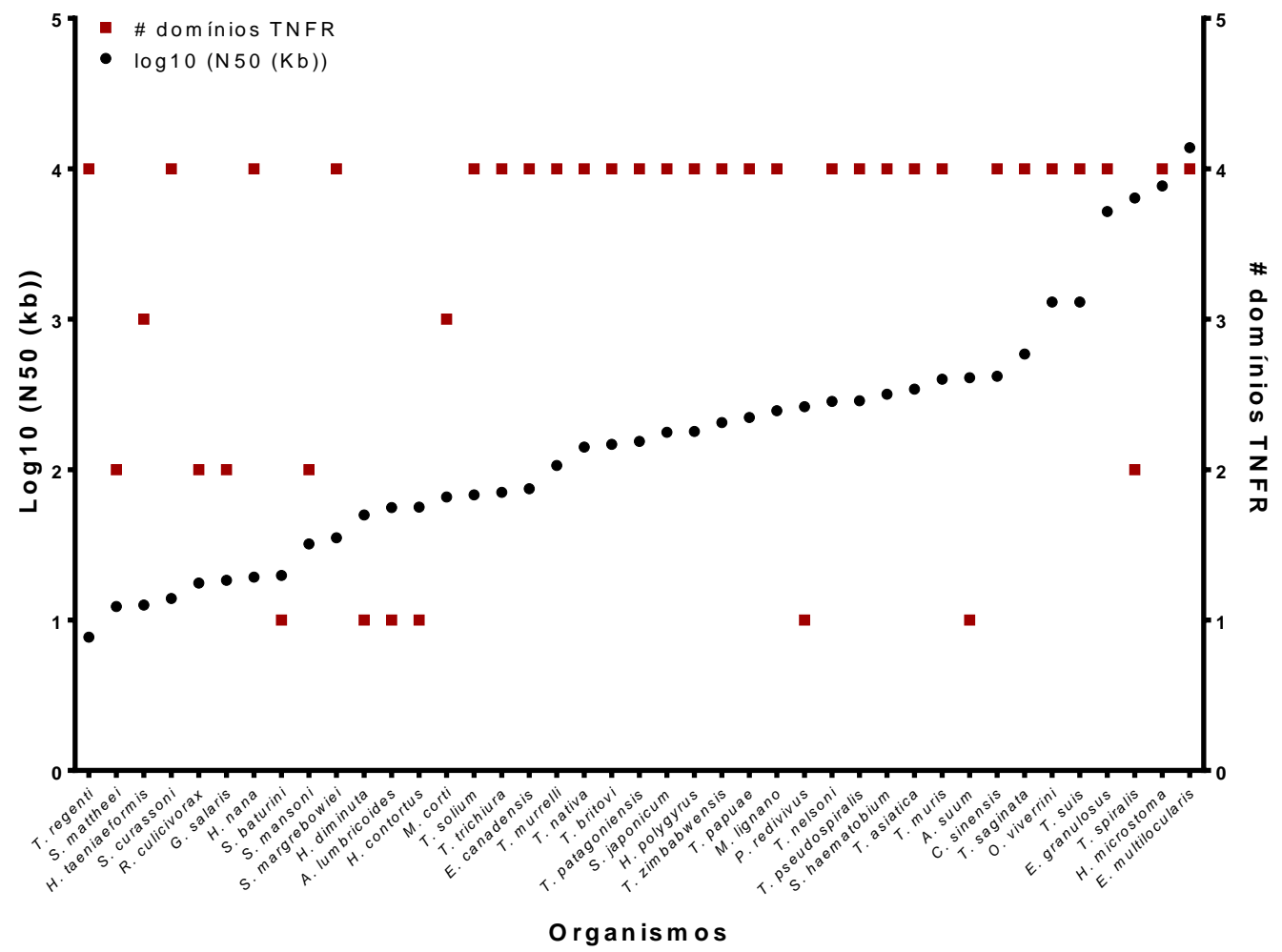

B)

\# contigs vs. \# domínios TNFR

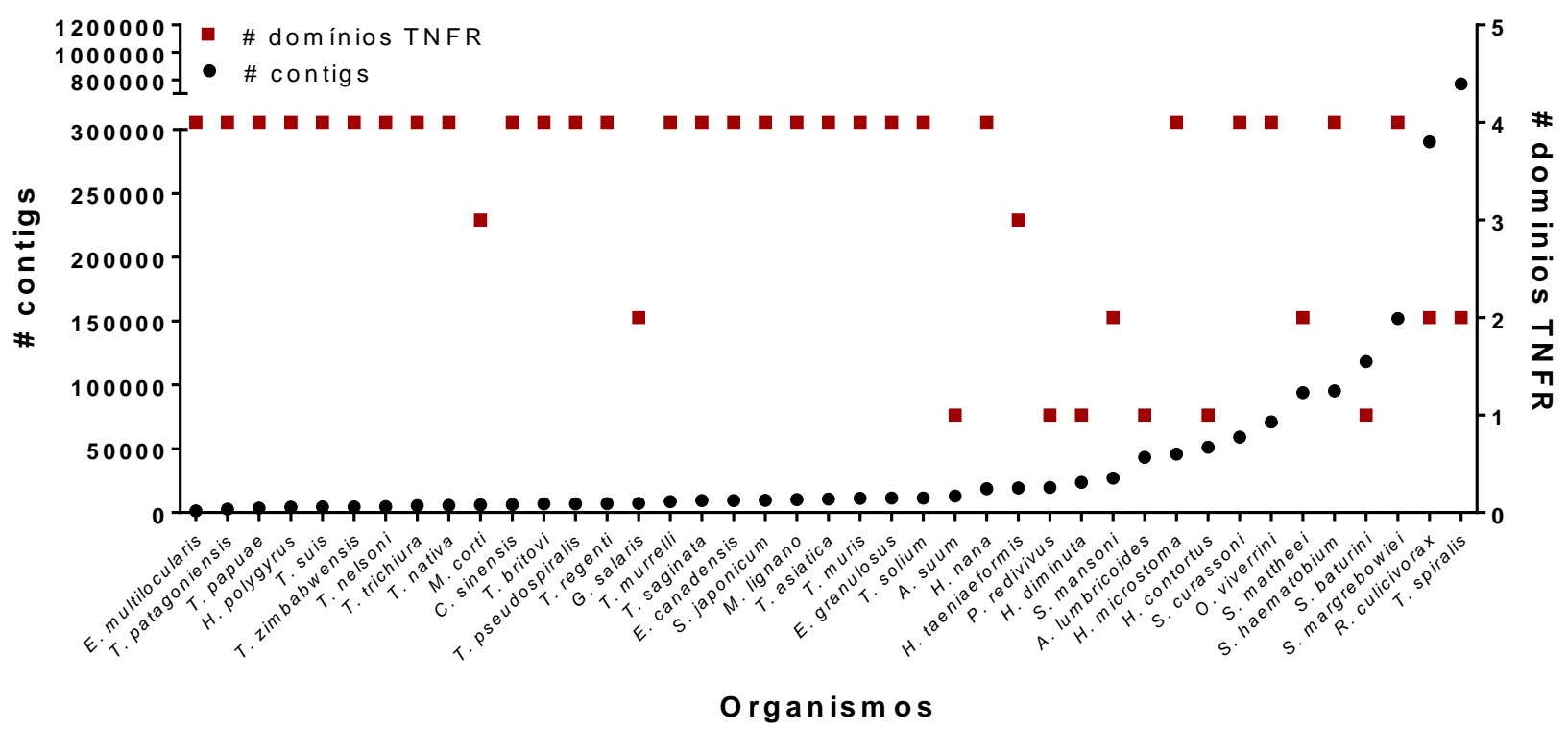

Figura 157. Relação do N50 e do número de contigs dos genomas dos organismos que possuem homólogos de SmTNFR e o número de domínios TNFR codificados pelo respectivo gene homólogos. A) Comparação do log10 N50 (kb) dos genomas dos organismos com o número de domínios do respectivo 
homólogo. B) Comparação do número de contigs do genoma dos organismos com o número de domínios do respectivo homólogo.

Os domínios característicos de TNF, os domínios ricos em cisteínas, são a marca que classifica um receptor como membro da família de TNF, estes domínios são classificados em módulos. Propomos que a maior parte dos homólogos dos receptores possuem provavelmente módulo A1, B2, assim como a porção extracelular dos receptores NGF, no entanto a maior parte deles não possui Death Domain [44]. Entretanto é interessante observar que existem três exceções; O receptor de $M$. lignano (platelminto de vida livre), $R$. culicivorax (nematelminto que parasita insetos) e H. nana que possuem Death Domain.

As análises filogenéticas com os diferentes métodos apresentaram como resultados árvores muito semelhantes o que revela que nenhum grande evento de inserção, deleção ou duplicação importante ocorreu nestes homólogos de modo a interferir na distribuição dos organismos nos clados conforme o esperado.

O processo de utilizar tantos métodos nos permitiu compreender um pouco mais sobre os princípios aplicados à filogenia. Os métodos de Máxima Verossimilhança e Inferência Bayesiana são atualmente os mais frequentemente usados o que nos faz elencar, a árvore obtida por Inferência Bayesiana como a representativa deste estudo.

Outro resultado digno de ser destacado é a modelagem molecular comparativa. Este recurso é muito útil para inferir a estrutura tridimensional de homólogos evolutivamente próximos, com altas taxas de identidade. É de senso comum entre os pesquisadores da área que taxas de identidade entre 30 e $40 \%$ são o limiar da razoabilidade para a modelagem, infelizmente a maior parte dos homólogos deste estudo está no limite da razoabilidade. Assim esta ferramenta deve ser utilizada com cautela, dependendo do que se quer analisar.

Para avaliar pontos mais gerais, como ver a conservação dos aminoácidos em uma região específica (uma região que faz a interface de interação com outra proteína ou a região de um sítio ativo) pode-se utilizar a modelagem comparativa porque é quase como olhar um alinhamento das sequências, mas facilita quando está espacialmente representado pois sabemos que resíduo de aminoácido está perto do que. Essa é uma análise que não exige um modelo com muita precisão, mas o modelo precisa ser correto. Por outro lado, as vezes deseja-se analisar coisas mais 
detalhadas, simular a ligação de uma molécula por exemplo. Nesse caso o ideal seria um modelo com grande precisão, que neste caso não temos.

A modelagem comparativa surgiu da observação que, em proteínas homólogas, a estrutura proteica é mais conservada que a sequência. Logo, tem-se a certeza que as proteínas são homólogas e a chance é muita alta de que suas estruturas sejam semelhantes. Parte do problema é, portanto, determinar se há homologia. Outra parte é fazer um bom alinhamento entre as sequências. $O$ alinhamento dirá qual resíduo (aminoácido) em uma sequência corresponde a qual na outra sequência. Isso é o que determinará a posição deles na estrutura modelada. Fica claro que quanto maior a identidade, maior a certeza de homologia e menor a chance de cometer erros no alinhamento.

Apesar da identidade ter a função tanto de inferir que há homologia quanto de servir como guia para o alinhamento, ela não pode ser considerada de forma absoluta. Os receptores de TNFR possuem várias cisteínas, e SmTNFR e TsTNFR tem 22, todas muito bem conservadas e distribuídas nos quatro domínios; ligações dissulfeto (11 ligações); isto é uma evidência bem clara de homologia, pois o alinhamento apresentado na Figura 183 quase não tem gaps e ao considerarmos as cisteínas como âncoras para fazer esse alinhamento, deixando claro como essas sequências devem ser alinhadas. Portanto, nesse caso, a identidade não é um fator limitante para a construção do modelo uma vez que conseguimos inferir a homologia e o alinhamento com base nas cisteínas e nas suas respectivas ligações dissulfeto, ambas muito bem conservadas. Porém, como a identidade e a similaridade não são altas a precisão do modelo fica comprometida. Isso indica que as cadeias laterais dos resíduos podem não estar corretamente posicionadas e que algumas regiões da cadeia principal (backbone), sobretudo nas regiões de loops (alças) podem não estar na conformação correta.

Logo queremos utilizar este modelo para visualizar as regiões mais conservadas em relação a outros TNFR (humanos e parasitas). Entretanto, devido a todas as questões levantadas não podemos confiar na modelagem da interação dos receptores de helmintos com o TNF-alfa humano (embora a modelagem seja muito interessante e conforme o esperado) que, para ser fidedigna, precisaria de um modelo mais preciso a fim de poder calcular a energia desta interação. É necessário olhar com zelo para estes belos modelos tridimensionais de interação. 
Vale ressaltar que um dos aspectos mais importantes deste trabalho foi a identificação de 12 homólogos do ligante TNF somente nos platelmintos de vida livre (classe Rhabditophora) que possuem domínio de TNF conservado. Somente no platelminto de vida livre $M$. lignano foi encontrado um ligante e o receptor, nas espécies próximas $M$. tuba, $M$. ruebushi, M. fusca não foram encontrados receptores, provavelmente pela escassez de dados uma vez que seus genomas não foram sequenciados e não existem dados de sequências de RNA-seq suficientes para encontra-los. Entretanto a presença de mais de um homólogo do ligante por espécie já indica que a expansão da família dos ligantes já ocorreu nos helmintos.

Estes dados nos levam a supor que as espécies que pertencem a classe Rhabditophora, que são organismos de vida livre, possuem o ligante próprio para acionar a via de sinalização e este ligante foi por alguma razão perdido ao longo da evolução nos Trematodos e Cestodos (platelmintos parasitas). Desta forma poderíamos criar a hipótese que a perda do ligante foi uma consequência do parasitismo. Entretanto para poder fazer esta inferência com segurança é necessário obter mais sequências de receptores de platelmintos da via livre que possuam ligantes homólogos e, no momento não dispomos destas informações. Isto seria muito interessante pois as análises filogenéticas realizadas neste trabalho mostram que, em sua grande maioria, o homólogo de M. lignano se localiza numa posição mais basal da árvore sugerindo a ancestralidade deste receptor em relação aos dos demais helmintos.

Diante de todos os resultados apresentados, entendemos que este estudo trouxe à luz da comunidade científica um conjunto e dados muito interessante e importante sobre os invertebrados e parasitas. Estes dados levantam outras questões acerca do papel da sinalização da via de TNFR que merecem ser exploradas para ampliar o entendimento da complexa relação entre parasita-hospedeiro. Isto permitirá o eventual desenvolvimento de novas abordagens terapêuticas e vacinais uma vez que esta via de sinalização, em $S$. mansoni, está envolvida na regulação de importantes eventos fisiológicos e metabólicos.

Este estudo também demonstra como é importante explorar as informações que estão depositadas nos bancos de dados públicos, pois esta abordagem permite responder inúmeras perguntas sobre a biologia básica dos organismos sem ser necessário possuir um grande aporte financeiro. Esta estratégia é uma alternativa que deve ser valorizada nos períodos de grande crise econômica que comprometem o fomento da pesquisa científica. 


\section{ConClusões}

- Existem 47 homólogos de receptores de TNF-alfa em 42 espécies de helmintos: 22 platelmintos e 20 nematelmintos. A proporção de homólogos encontrada entre os filos, baseado no número de genomas disponíveis é significativamente superior em platelmintos. Não foram encontrados homólogos dos receptores em protozoários.

- Para quatro espécies de nematelmintos existem duas isoformas de homólogos de receptor e em duas espécies ocorre duplicação gênica.

- Dois homólogos são em helmintos são de vida livre: o nematelminto $P$. redivivus e o platelminto $M$. lignano.

- Os 47 homólogos possuem domínios característicos de receptores de TNFR, os CRDs (domínios TNFR), que apresentam a organização modular característica de NGFR, sem, entretanto, a presença de Death domain na região intracelular (com exceção de três espécies).

- As análises filogenéticas sugerem que a evolução destes homólogos ocorreu conforme o esperado em helmintos, não ocorreu nenhum evento importante de inserção e deleção. O homólogo de $M$. lignano apresenta uma posição ancestral na maioria das análises.

- A modelagem molecular comparativa foi uma ótima abordagem para entender o contexto tridimensional dos domínios extracelulares e suas pontes dissulfetos, entretanto deve ser considerada com cautela em homólogos com baixa taxa de identidade/similaridade, como é este caso. Logo a modelagem com o ligante, embora interessante não pode ser considerada como fidedigna nesta situação.

-Foram encontrados 12 homólogos de ligante em quatro espécies de platelmintos de vida livre (Classe Rhabditophora); entretanto até o momento somente $M$. lignano apresenta um homólogo ao receptor e cinco homólogos a ligantes.

- O fato de se encontrar homólogos ao TNF somente em espécies de vida livre é importante pois nos faz pensar que a perda do ligante pode ter ocorrido ao longo da evolução com o surgimento do parasitismo (causa ou consequência); entretanto o conjunto de dados atual não nos permite explorar esta hipótese. Seria necessário encontrar mais homólogos de receptor de TNF nesta classe de platelmintos para 
sustentar esta ideia, entretanto a ausência de dados de sequenciamento dos genomas das espécies da classe impede a realização de análises para confirmar esta hipótese.

- Este conjunto de dados mostra como é importante para a comunidade cientifica investigar o papel da via de sinalização mediada pelos receptores de TNF nos helmintos a fim de obter uma melhor compreensão sobre: a biologia básica do parasita (metabolismo, maturação sexual, etc.), a relação molecular estabelecida entre parasita e seu hospedeiro (troca de sinais - ligantes entre as espécies), o papel da via no contexto evolutivo do parasitismo, ou seja entender a relação da perda do ligante como evento relevante para a adaptação no parasitismo.

- Os resultados parciais deste trabalho foram apresentados (na forma de pôster) no Encontro Anual da Sociedade Americana de Medicina Tropical e Higiene (ASTMH) em 2014, em Nova Orleans, EUA (vide certificado nos CD de arquivos anexos).

- Este trabalho está sendo submetido à avaliação para possível publicação no periódico International Journal of Parasitology.

\section{REFERÊNCIAS BIBLIOGRÁFICAS}

[1] WHO, "Schistosomiasis," 2014. .

[2] M. da Saúde, "Casos confirmados de esquistossomose no Brasil," 2008. .

[3] K. C. Oliveira et al., "Identification of the Schistosoma mansoni TNF-alpha receptor gene and the effect of human TNF-alpha on the parasite gene expression profile," PLoS Negl. Trop. Dis., vol. 3, no. 12, 2009.

[4] D. Molyneux, "Neglected tropical diseases," Community Eye Health Journal, 2013.

[5] "Human genome at ten: The sequence explosion," Nature, vol. 464, no. 7289, pp. 670-671, 2010.

[6] M. Berriman et al., "The genome of the blood fluke Schistosoma mansoni," Nature, vol. 460, no. 7253, pp. 352-358, 2009.

[7] I. J. Tsai et al., "The genomes of four tapeworm species reveal adaptations to parasitism," Nature, vol. 496, no. 7443, pp. 57-63, 2013.

[8] J. A. Cotton et al., "The genome of Onchocerca volvulus, agent of river blindness," Nat Microbiol, vol. 2, p. 16216, 2016.

[9] M. J. Gardner et al., "Genome sequence of the human malaria parasite Plasmodium falciparum," Nature, vol. 419, no. 6906, pp. 498-511, 2002.

[10] Y. L. Lau et al., "Deciphering the Draft Genome of Toxoplasma gondii RH Strain," PLoS One, vol. 11, no. 6, p. e0157901, 2016.

[11] N. M. El-Sayed et al., "Comparative genomics of trypanosomatid parasitic protozoa," Science (80-. )., vol. 309, no. 5733, pp. 404-409, 2005.

[12] C. International Helminth Genomes, "Comparative genomics of the major parasitic worms," Nat Genet, 2018.

[13] S. Verjovski-Almeida et al., "Transcriptome analysis of the acoelomate human parasite Schistosoma mansoni," Nat Genet, vol. 35, no. 2, pp. 148-157, 2003. 
[14] M. Chai et al., "Transcriptome profiling of lung schistosomula,in vitro cultured schistosomula and adult Schistosoma japonicum," Cell. Mol. Life Sci., vol. 63, no. 7-8, pp. 919-929, 2006.

[15] S. Mangiola et al., "Getting the most out of parasitic helminth transcriptomes using HelmDB: implications for biology and biotechnology," Biotechnol Adv, vol. 31, no. 8, pp. 1109-1119, 2013.

[16] A. R. Jex et al., "Genome and transcriptome of the porcine whipworm Trichuris suis," Nat Genet, vol. 46, no. 7, pp. 701-706, 2014.

[17] L. G. Avelar, L. A. Nahum, L. F. Andrade, and G. Oliveira, "Functional Diversity of the Schistosoma mansoni Tyrosine Kinases," J Signal Transduct, vol. 2011, p. 603290, 2011.

[18] C. Yang and G. Arrizabalaga, "The serine/threonine phosphatases of apicomplexan parasites," Mol Microbiol, vol. 106, no. 1, pp. 1-21, 2017.

[19] WHO, "Soil-transmitted helminth infections," Fact Sheets, 2018.

[20] WHO, "Schistosomiasis, Countries or areas at risk.," 2008. [Online]. Available: http://gamapserver.who.int/mapLibrary/Files/Maps/Global_ShistoPrevalence_IT HRiskMap.png.

[21] WHO-Geneve, WHO Technical Report Series 912: prevention and control of schistosomiasis and soil-transmitted helminthiasis. Geneva: World Health Organization, 2002.

[22] WHO, "Echinococcosis," Fact Sheets. WHO, 2018.

[23] W. H. O. World Health Organization, "Accelerating work to oercome the global impact of negleted tropical diseases. A RoadMap for Implementation." WHO, http://www.who.int/neglected_diseases/diseases/en/, 2012.

[24] E. V Koonin, "Orthologs, paralogs, and evolutionary genomics," Annu Rev Genet, vol. 39, pp. 309-338, 2005.

[25] S. F. Altschul, W. Gish, W. Miller, E. W. Myers, and D. J. Lipman, "Basic local alignment search tool," J Mol Biol, vol. 215, no. 3, pp. 403-410, 1990.

[26] S. R. Eddy, "Multiple alignment using hidden Markov models," Proc Int Conf Intell Syst Mol Biol, vol. 3, pp. 114-120, 1995.

[27] S. R. Eddy, "Hidden Markov models," Curr Opin Struct Biol, vol. 6, no. 3, pp. 361-365, 1996.

[28] S. R. Eddy, "Accelerated Profile HMM Searches," PLoS Comput Biol, vol. 7, no. 10, p. e1002195, 2011.

[29] "The Schistosoma japonicum genome reveals features of host-parasite interplay," Nature, vol. 460, no. 7253, pp. 345-351, 2009.

[30] W. Hu et al., "Evolutionary and biomedical implications of a Schistosoma japonicum complementary DNA resource," Nat. Genet., vol. 35, no. 2, pp. 139147, 2003.

[31] L. P. Farias et al., "Screening the Schistosoma mansoni transcriptome for genes differentially expressed in the schistosomulum stage in search for vaccine candidates," Parasitol. Res., vol. 108, no. 1, 2011.

[32] H. You, G. N. Gobert, M. K. Jones, W. Zhang, and D. P. McManus, "Signalling pathways and the host-parasite relationship: putative targets for control interventions against schistosomiasis: signalling pathways and future antischistosome therapies," Bioessays, vol. 33, no. 3, pp. 203-214, 2011.

[33] J. M. Fitzpatrick et al., "Anti-schistosomal intervention targets identified by lifecycle transcriptomic analyses," PLoS Negl Trop Dis, vol. 3, no. 11, p. e543, 2009.

[34] J. Knobloch, S. Beckmann, C. Burmeister, T. Quack, and C. G. Grevelding, "Tyrosine kinase and cooperative TGFbeta signaling in the reproductive organs of Schistosoma mansoni," Exp Parasitol, vol. 117, no. 3, pp. 318-336, 2007.

[35] S. Beckmann, C. Buro, C. Dissous, J. Hirzmann, and C. G. Grevelding, "The Syk kinase SmTK4 of Schistosoma mansoni is involved in the regulation of spermatogenesis and oogenesis," PLoS Pathog, vol. 6, no. 2, p. e1000769, 
2010.

[36] W. Wu, E. G. Niles, N. El-Sayed, M. Berriman, and P. T. LoVerde, "Schistosoma mansoni (Platyhelminthes, Trematoda) nuclear receptors: sixteen new members and a novel subfamily," Gene, vol. 366, no. 2, pp. 303-315, 2006.

[37] M. Zamanian, M. J. Kimber, P. McVeigh, S. A. Carlson, A. G. Maule, and T. A. Day, "The repertoire of $G$ protein-coupled receptors in the human parasite Schistosoma mansoni and the model organism Schmidtea mediterranea," BMC Genomics, vol. 12, no. 1, p. 596, 2011.

[38] P. T. Loverde, A. Osman, and A. Hinck, "Schistosoma mansoni: TGF-beta signaling pathways," Exp Parasitol, vol. 117, no. 3, pp. 304-317, 2007.

[39] P. Amiri et al., "Tumour necrosis factor alpha restores granulomas and induces parasite egg-laying in schistosome-infected SCID mice," Nature, vol. 356, no. 6370, pp. 604-607, 1992.

[40] A. W. Cheever, R. W. Poindexter, and T. A. Wynn, "Egg laying is delayed but worm fecundity is normal in SCID mice infected with Schistosoma japonicum and S. mansoni with or without recombinant tumor necrosis factor alpha treatment," Infect Immun, vol. 67, no. 5, pp. 2201-2208, 1999.

[41] M. A. Haseeb, W. B. Solomon, and J. F. Palma, "Schistosoma mansoni: effect of recombinant tumor necrosis factor alpha on fecundity and [14C]-tyrosine uptake in females maintained in vitro," Comp Biochem Physiol C Pharmacol Toxicol Endocrinol, vol. 115, no. 3, pp. 265-269, 1996.

[42] M. A. Haseeb, "Schistosoma mansoni: females enhance [14C]-tyrosine incorporation in males maintained in vitro," J Helminthol, vol. 72, no. 2, pp. 123126, 1998.

[43] S. J. Davies et al., "Involvement of TNF in limiting liver pathology and promoting parasite survival during schistosome infection," Int. J. Parasitol., 2004.

[44] J. L. Bodmer, P. Schneider, and J. Tschopp, "The molecular architecture of the TNF superfamily," Trends Biochem Sci, vol. 27, no. 1, pp. 19-26, 2002.

[45] K. C. Oliveira, M. L. P. Carvalho, J. M. C. Bonatto, D. Schechtman, and S. Verjovski-Almeida, "Human TNF- $\alpha$ induces differential protein phosphorylation in Schistosoma mansoni adult male worms," Parasitol. Res., 2016.

[46] D. A. Benson et al., "GenBank," Nucleic Acids Res., 2013.

[47] K. L. Howe, B. J. Bolt, M. Shafie, P. Kersey, and M. Berriman, "WormBase ParaSite - a comprehensive resource for helminth genomics," Mol. Biochem. Parasitol., 2017.

[48] J. Ludbrook, "Analysis of $2 \times 2$ tables of frequencies: Matching test to experimental design," Int. J. Epidemiol., 2008.

[49] R. C. Edgar, "MUSCLE: Multiple sequence alignment with high accuracy and high throughput," Nucleic Acids Res., 2004.

[50] S. G. and T. K. Kumar S, "MEGA7: Molecular Evolutionary Genetics Analysis version 7.0 for bigger datasets.," Mol. Biol. Evol., vol. 33, p. 5, 2016.

[51] C. D. Livingstone and G. J. Barton, "Protein sequence alignments: a strategy for the hierarchical analysis of residue conservation," Comput Appl Biosci, vol. 9, no. 6, pp. 745-756, 1993.

[52] A. Drozdetskiy, C. Cole, J. Procter, and G. J. Barton, "JPred4: a protein secondary structure prediction server," Nucleic Acids Res, vol. 43, no. W1, pp. W389-94, 2015.

[53] F. Ronquist and J. P. Huelsenbeck, "MrBayes 3: Bayesian phylogenetic inference under mixed models," Bioinformatics, 2003.

[54] I. Korf, "Gene finding in novel genomes," BMC Bioinformatics, 2004.

[55] J. H. Naismith and S. R. Sprang, "Modularity in the TNF-receptor family," Trends in Biochemical Sciences. 1998.

[56] F. M. C. Fernandes-Matioli, "Noções De Filogenética Molecular," Biológico, 2001.

[57] J. Felsenstein, "Confidence Limits on Phylogenies: An Approach Using the 
Bootstrap," Evolution (N. Y)., vol. 39, no. 4, pp. 783-791, 1985.

[58] K. S. Nei M., Molecular Evolution and Phylogenetics. . New York: Oxford University Press, 2000.

[59] S. Whelan, P. Liò, and N. Goldman, "Molecular phylogenetics: State-of-the-art methods for looking into the past," Trends in Genetics. 2001.

[60] D. T. Jones, W. R. Taylor, and J. M. Thornton, "The rapid generation of mutation data matrices from protein sequences," Comput Appl Biosci, vol. 8, no. 3, pp. 275-282, 1992.

[61] N. M. Rzhetsky A., " A simple method for estimating and testing minimum evolution trees.," Mol. Biol. Evol. , vol. 9, pp. 945-967, 1992.

[62] P. L. Zuckerkandl E., "Evolutionary divergence and convergence in proteins," in Evolving Genes and Proteins , V. B. and H. J. Vogel, Ed. New York: Academic Press, 1965, pp. 97-166.

[63] N. Saitou and M. Nei, "The neighbor-joining method: a new method for reconstructing phylogenetic trees," Mol Biol Evol, vol. 4, no. 4, pp. 406-425, 1987.

[64] S. R. R. Sneath P.H.A., Numerical Taxonomy. San Francisco: Freeman, 1973.

[65] J. Li, Q. Yin, and H. Wu, "Structural basis of signal transduction in the TNF receptor superfamily," Adv. Immunol., 2013. 


\section{LISTA DE ANEXOS}

Esta dissertação é acompanhada de um CD-ROM que contém os arquivos listados abaixo com os dados suplementares:

- Aprovação_CEP - Aprovação do comitê de ética em pesquisa da UNIFESP

- Arquivo suplementar 1 - Sequencias dos homólogos de SmTNFR identificados nos helmintos.

- Arquivo suplementar 2 - Sequencias dos homólogos de TNF identificados nos helmintos.

- Certificado_ASTMH - Certificado de apresentação de trabalho (pôster) no Congresso Anual da Sociedade Americana de Medicina Tropical e Higiene (ASTMH) em novembro de 2014.

- $\quad$ hTNFa_SmTNFR - Modelagem molecular comparativa do receptor de TNF em $S$. mansoni acoplado com o ligante (TNF) humano.

- hTNFa_TsTNFR - Modelagem molecular comparativa do receptor de TNF em T. spiralis acoplado com o ligante (TNF) humano.

- SmTNFR - Modelagem molecular comparativa do receptor de TNF em $S$. mansoni.

- Tabela Suplementar 1 - Dados dos alinhamentos obtidos por BLAST entre todos os homólogos dos helmintos de SmTNFR e os receptores humanos pertencentes à família de TNFR.

- Tabela Suplementar 2 - Dados dos alinhamentos obtidos por BLAST entre todos os homólogos dos helmintos de TNF e os ligantes humanos pertencentes à família de TNF.

- TsTNFR - Modelagem molecular comparativa do receptor de TNF em T. spiralis. 